San Jose State University

SJSU ScholarWorks

Master's Projects

Master's Theses and Graduate Research

Spring 2012

\title{
Utilizing Online Tools in a Public Outreach and Participation Strategy for a Multi-Hazard Mitigation Plan (MHMP) Planning Project
}

Jennifer Lehane

San Jose State University

Follow this and additional works at: https://scholarworks.sjsu.edu/etd_projects

Part of the Urban Studies and Planning Commons

\section{Recommended Citation}

Lehane, Jennifer, "Utilizing Online Tools in a Public Outreach and Participation Strategy for a Multi-Hazard Mitigation Plan (MHMP) Planning Project" (2012). Master's Projects. 226.

DOI: https://doi.org/10.31979/etd.9b94-5wpd

https://scholarworks.sjsu.edu/etd_projects/226

This Master's Project is brought to you for free and open access by the Master's Theses and Graduate Research at SJSU ScholarWorks. It has been accepted for inclusion in Master's Projects by an authorized administrator of SJSU ScholarWorks. For more information, please contact scholarworks@sjsu.edu. 


\section{Utilizing Online Tools in a Public Outreach and Participation Strategy for a Multi-Hazard Mitigation Plan (MHMP) Planning Project}

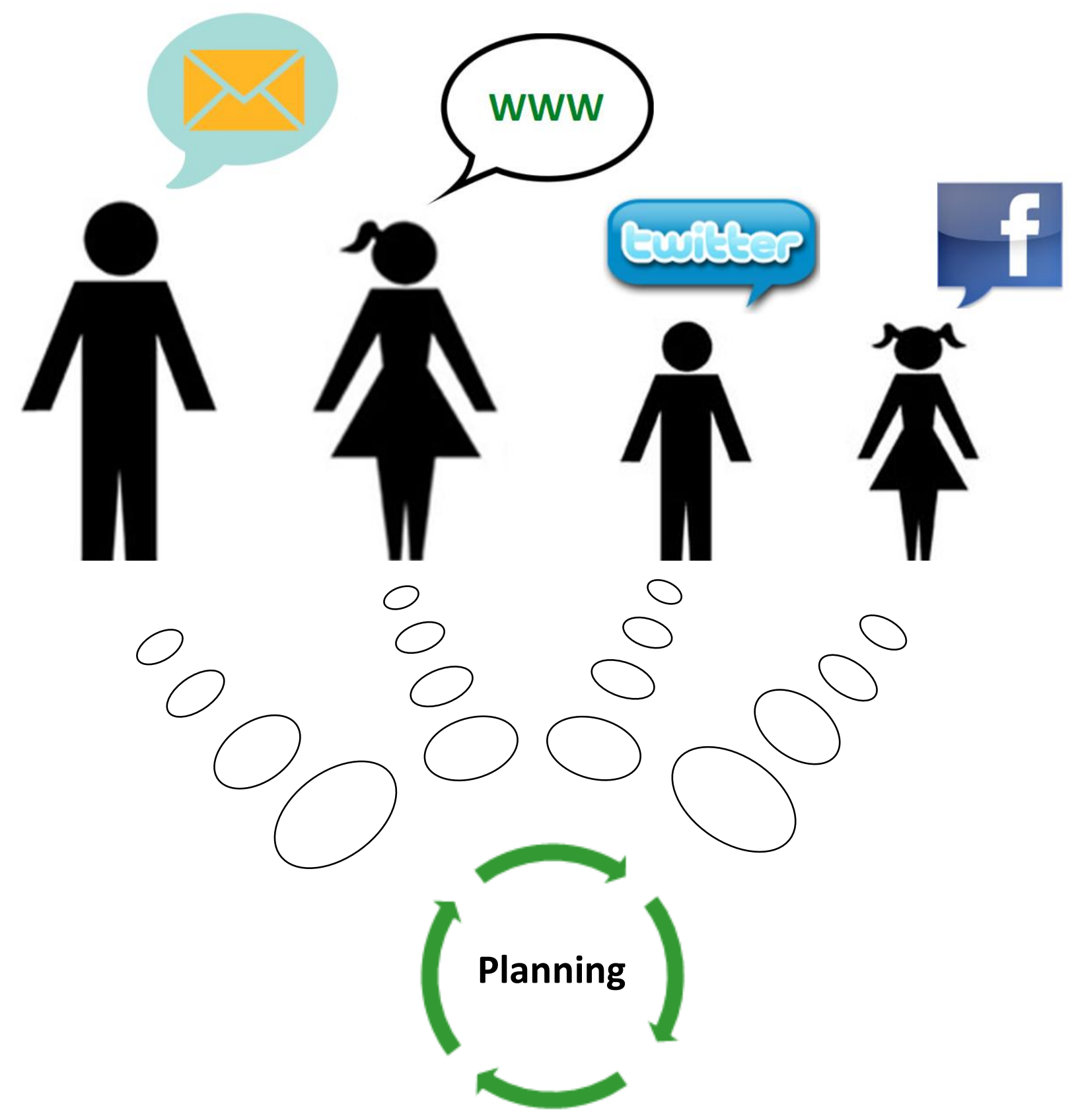





\title{
Utilizing Online Tools in a Public Outreach and Participation Strategy for a Multi-Hazard Mitigation Plan (MHMP) Planning Project
}

\author{
A Planning Report \\ Presented to \\ The Faculty of the Department of \\ Urban and Regional Planning
}

San Jose State University

In Partial Fulfillment

Of the Requirements for the Master's

Degree of Urban and Regional Planning

By

Jennifer Lehane

May 2012 
Intentional Blank Page 



\section{Table of Contents}

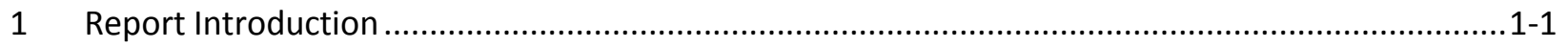

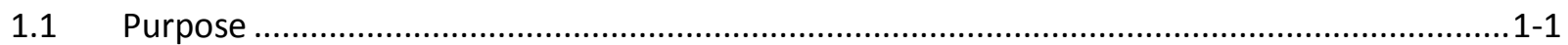

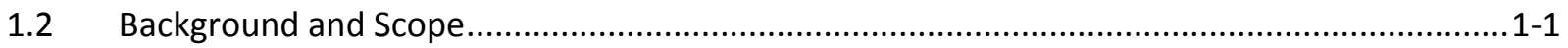

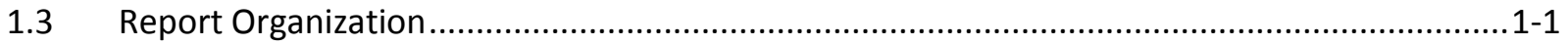

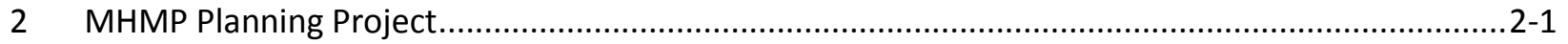

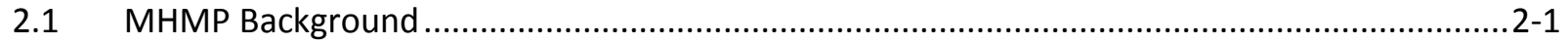

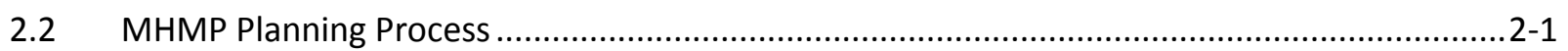

3 MHMP Public Outreach and Participation Strategy .................................................................

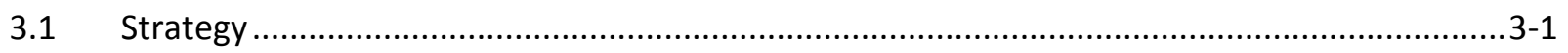

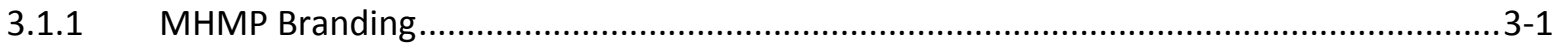

3.1.2 MHMP Traditional Methods of Communication .......................................................... 3-2

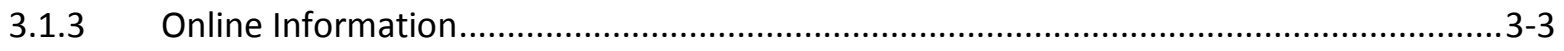

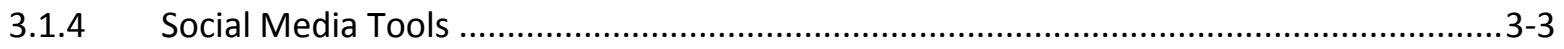

3.1.5 2012 Solano County MHMP ….................................................................................

4 MHMP Online and Social Media Tool Methodology ...................................................................

4.1 MHMP Project Website ..................................................................................................

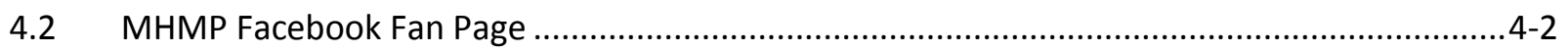

4.2.1 MHMP Facebook Fan Page Development ................................................................... $4-2$

4.2.2 MHMP Facebook Fan Page Promotion ......................................................................4-4

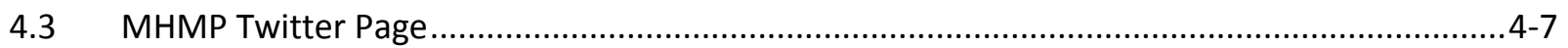

4.3.1 MHMP Twitter Page Development ........................................................................... 4

4.3.2 MHMP Twitter Page Promotion...................................................................................

$4.4 \quad$ Hazard Fortnights.......................................................................................................... 4-10

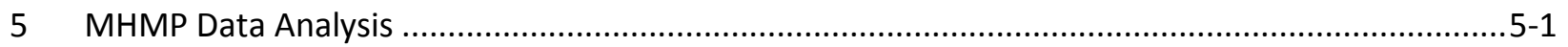

5.1 MHMP Public Outreach and Participation Survey .............................................................. $5-1$

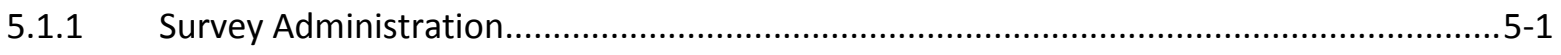

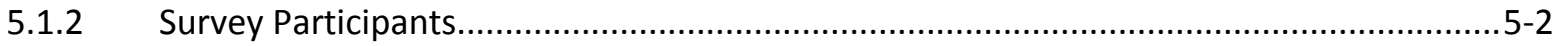

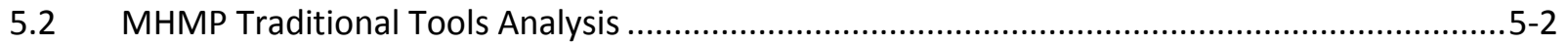

5.2.1 MHMP Public Workshop Knowledge ....................................................................... $5-3$

5.2.2 MHMP Public Workshop Attendance ....................................................................... 5-3 
5.2.3 MHMP Public Workshop Information Helpfulness .................................................... $5-4$

5.2.4 MHMP Planning Project Comments ..............................................................................

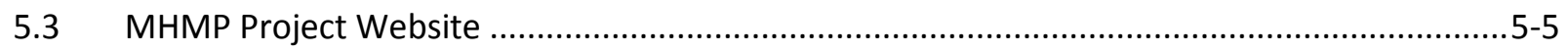

5.3.1 MHMP Project Website GA Reports and Metrics ....................................................... 5-6

5.3.2 MHMP Project Website Knowledge............................................................................ 5-6

5.3.3 MHMP Project Website Visits ................................................................................. $5-8$

5.3.4 MHMP Project Website Visit Duration .....................................................................

5.3.5 MHMP Project Website Tab Views ......................................................................... 5

5.4 MHMP Social Media Tools Data Analysis..................................................................... 5-16

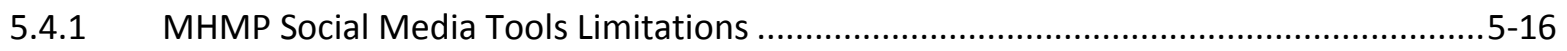

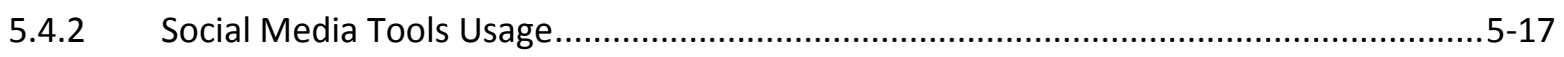

5.4.3 MHMP Facebook Fan Page Likes and Shares............................................................ 5-19

5.4.4 MHMP Twitter Page Follows and Retweets............................................................... 5-19

5.4.5 MHMP Social Media Tools Data Analysis Summary ...................................................5-19

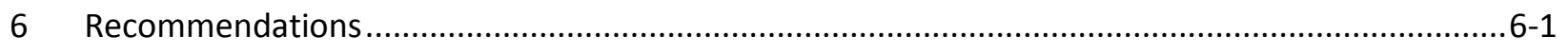

6.1 MHMP Public Outreach and Participation Future Strategy ................................................. 6-1

6.1.1 Nearby MHMP Planning Projects............................................................................. 6-1

6.1.2 MHMP Steering/Planning Committee Members Role ...................................................6-1

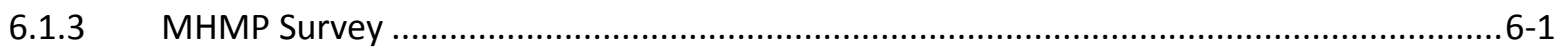

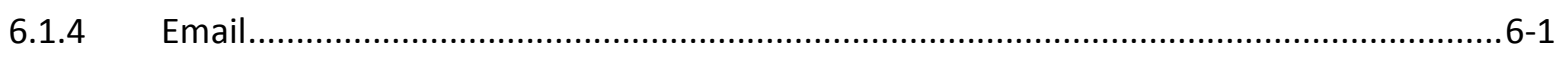

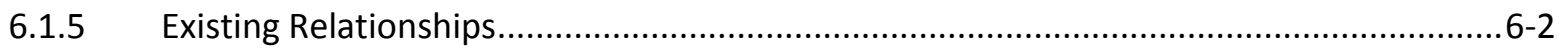

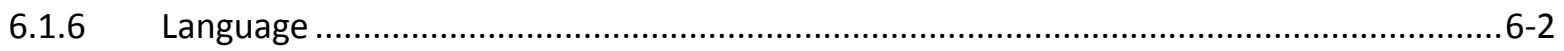

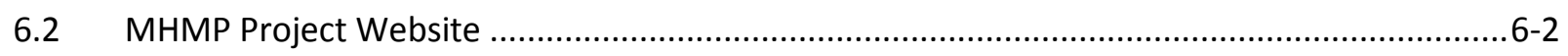

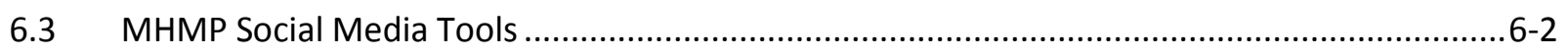

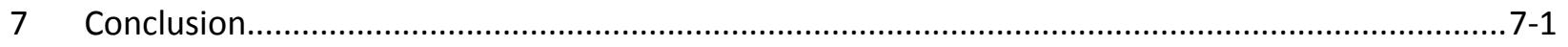

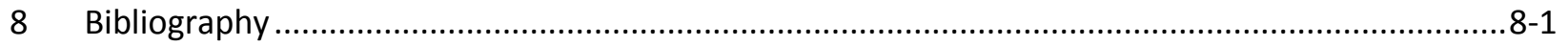


Table 4-1: MHMP Facebook Fan Pages Public Message Recipients .............................................. 4-6

Table 4-2: MHMP Facebook Fan Pages Private Message(s) Recipients.................................................4-7

Table 5-1: MHMP Steering/Planning Committee Members ................................................................ $5-2$

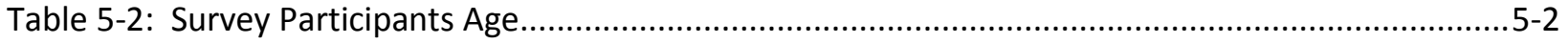

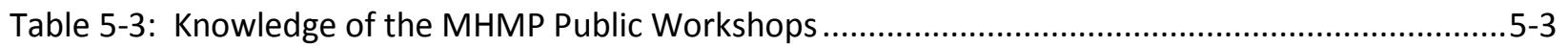

Table 5-4: How Survey Participants learned about the MHMP Public Workshops ................................5-3

Table 5-5: MHMP Public Workshop Attendance ..........................................................................5-4

Table 5-6: Reasons for not attending the MHMP Public Workshops ...................................................5-4

Table 5-7: MHMP Public Workshop Information Helpfulness .............................................................5-4

Table 5-8: MHMP Planning Project Comments ............................................................................. 5-5

Table 5-9: Methods Used to Comment on the MHMP Planning project.............................................5-5

Table 5-10: MHMP Project Website Knowledge................................................................................ 5-6

Table 5-11: Source of Information for Solano County General Planning Projects..................................5-7

Table 5-12: How Survey Participants Learned about the MHMP Project Website ................................5-7

Table 5-13: MHMP Project Website Top 10 Webpages.......................................................................5-10

Table 5-14: MHMP Project Website Reviewed Documents ............................................................5-12

Table 5-15: MHMP Project Website Methods of Access ….............................................................. $5-13$

Table 5-16: MHMP Project Website Traffic Source .............................................................................

Table 5-17: Top 20 Cities MHMP Project Website Visits .....................................................................15

Table 5-18: MHMP Survey Participants Residence ........................................................................ 5-16

Table 5-19: MHMP Project Website Information Usefulness ...........................................................5-16

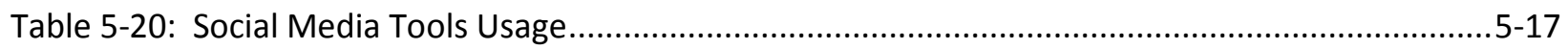

Table 5-21: Social Media Tools Frequently Used ..................................................................................

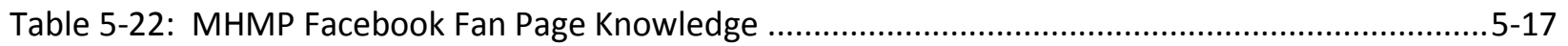

Table 5-23: How Survey Participants Learned about the MHMP Facebook Fan Page ..........................5-18

Table 5-24: MHMP Facebook Fan Page Visits .............................................................................. $5-18$

Table 5-25: MHMP Twitter Page Knowledge ...............................................................................5-18 
Intentional Blank Page 


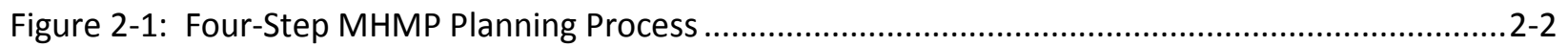

Figure 3-1: Solano County MHMP Project Logo................................................................................

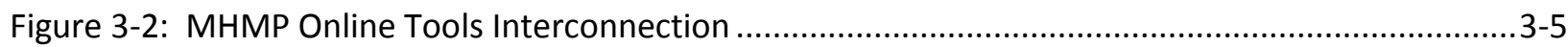

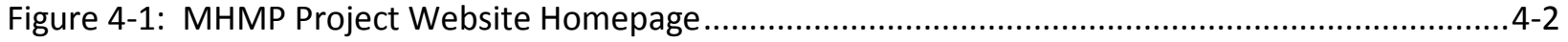

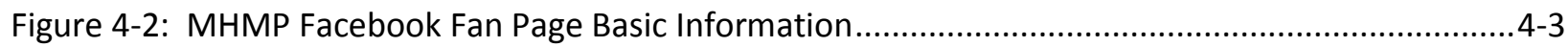

Figure 4-3: Example MHMP Facebook Fan Page Photos .......................................................................4

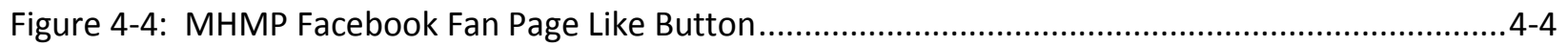

Figure 4-5: CAL FIRE's www.ReadyForWildfire.org Photos................................................................. $4-5$

Figure 4-6: MHMP Twitter Page Profile Information ......................................................................... $4-8$

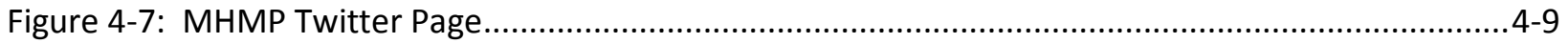

Figure 5-1: MHMP Project Website Visits per Month ........................................................................

Figure 5-2: MHMP Project Website Average Visit Duration ............................................................... $5-9$

Figure 5-3: MHMP Project Website Page Views ................................................................................ 5-10 
Intentional Blank Page 


\section{Acronyms}

$\begin{array}{ll}\text { Cal EMA } & \text { California Emergency Management Agency } \\ \text { CFR } & \text { Code of Federal Regulations } \\ \text { DMA 2000 } & \text { Disaster Mitigation Act of } 2000 \\ \text { EIR } & \text { Environmental Impact Report } \\ \text { FEMA } & \text { Federal Emergency Management Agency } \\ \text { GA } & \text { Google Analytics } \\ \text { GP } & \text { General Plan } \\ \text { MHMP } & \text { Multi-Hazard Mitigation Plan } \\ \text { SEO } & \text { Search Engine Optimization } \\ \text { SP } & \text { Specific Plan }\end{array}$

Stafford Act Robert T. Stafford Disaster Relief and Emergency Assistance Act

USACE U.S. Army Corps of Engineers 
Intentional Blank Page 


\section{Acknowledgements}

I would like to thank my family who has always been there for me through the years. I am blessed to have such a family! To my amazing friends, thank you for all your support.

To Ms. Hilary Nixon, I am grateful for all your guidance and support throughout my Master's Degree Program.

In addition, I would like to thank Mr. Travis Clark for taking a chance on me. You provided me an amazing opportunity to work as a Planner at Michael Baker Jr., while I complete my Master's Degree. I hope one day to be in the position to do the same for somebody else. 
Intentional Blank Page 


\section{Report Introduction}

This report analyses the federal public outreach and participation requirements of a Multi-Hazard Mitigation Plan (MHMP) planning project. Since the public outreach and participation requirements for the development of a MHMP are similar to other planning projects, the ideas discussed in this report can be applied to any other planning project. The intended audience of this report is any person and/or agency at a federal, state, and/or local level that develops planning projects and facilitates public outreach and participation strategies.

\subsection{Purpose}

Public outreach and participation strategies currently utilize traditional forms of communication to engage the public in planning projects. A challenge facing many public agencies and private consultants is effectively engaging the public during the planning project. ${ }^{1}$ With the public's growing use of technology, public agencies and private consultants recognize the need for utilizing online and social media tools in public outreach and participation strategies. ${ }^{2}$ The purpose of this report is to analyze the effectiveness of utilizing online and social media tools in a public outreach and participation strategy for a MHMP planning project.

\subsection{Background and Scope}

This report focuses on unincorporated areas of Solano County, California as a case study, as it is updating its MHMP in 2012. The Solano County MHMP is an effort undertaken by the County to mitigation the effects of natural hazards and plan for resiliency in the future. The MHMP planning project commenced on August 1, 2011 and concluded on March 31, 2012. Similar to any other planning project, public outreach and participation is a major and federally required component of the 2012 Solano County MHMP. Traditional tools utilized during the MHMP planning project include press releases, public notices, and public workshops. Online and social media tools include the MHMP project website, MHMP Facebook fan page, and MHMP Twitter page. In addition to these tools, Flickr was utilized during the MHMP planning project, but it is not analyzed as part of this report.

\subsection{Report Organization}

This report is organized into seven sections, including a background to the report, detailing the MHMP planning project, outlining the methodology designed for the report, analyzing data gathered on the public's usage of traditional tools, MHMP project website, MHMP Facebook fan page, and MHMP Twitter page, and the MHMP public outreach and participation survey responses, and providing recommendations and conclusions. Each section is briefly described as follows:

\footnotetext{
${ }^{1}$ Linda P Wagenet, and Max J. Pfeffer, "Organizing Citizen Engagement for Democratic Environmental Planning," Society \& Natural Resources 20, no. 9 (2007): 801. Academic Search Premier, EBSCOhost (accessed July 8, 2011); Richard D Waters, Emily Burnett, Anna Lamm, and Jessica Lucas, "Engaging Stakeholders through Social Networking: How Nonprofit Organizations are Using Facebook," Public Relations Review 35, no. 2 (June 2009): 102. Academic Search Premier, EBSCOhost (accessed August 7 , 2011).

${ }^{2}$ Stuart G. Walesh, "DAD Is Out, POP Is In," Journal of Management in Engineering 15, no. 1 (January 1999): 3. Academic Search Premier, EBSCOhost (accessed August 7, 2011). ; National Archives and Records Administration. "A Report on Federal Web 2.0 Use and Record Value 2010." http://www.egov.vic.gov.au/website-practice/web-2-0-a/social-networks-and-social-media-ingovernment/a-report-on-federal-web-2-0-use-and-record-value-2010.html (accessed July 31, 2011).
} 
- Section 2, MHMP Planning Project describes the four-step MHMP planning process adapted from federal guidelines and outlines the public outreach and participation federal requirements a MHMP must comply with for FEMA approval.

- Section 3, MHMP Public Outreach and Participation Strategy describes the strategy for traditional, online, and social media tools utilized in the MHMP planning project and outlines the 2012 Solano County MHMP.

- Section 4, MHMP Online Tools Methodology identifies how the public is engaged in the MHMP planning project through traditional, online, and social media tools.

- Section 5, MHMP Online Tools Data Analysis provides information on the data analysis of the MHMP traditional, online, and social media tools. In addition, information is provided on the MHMP public outreach and participation survey responses.

- Section 6, Recommendations outlines the recommendations for future use of online and social tools for a MHMP planning project and other planning projects.

- Section 7, Conclusions details the conclusions of this report based on the data analysis of the MHMP traditional, online, and social media tools, survey responses, observations, and lessons learned during the development of this report. 


\section{MHMP Planning Project}

This section explains the basis for the development of MHMPs and the four-step MHMP planning process taken from the Federal Emergency Management Agency's (FEMA's) MHMP guidance documents.

\subsection{MHMP Background}

Hazard mitigation planning in the United States is guided by the statutory regulations described in the Disaster Mitigation Act of 2000 (DMA 2000) and is implemented through 44 Code of Federal Regulations (CFR) Part 201 and 206. DMA 2000 amended the Robert T. Stafford Disaster Relief and Emergency Assistance Act (Stafford Act) by creating new federal requirements for State, local, special districts, and Tribal agencies to implement effective hazard mitigation planning in their communities through the creation of a MHMP. ${ }^{3}$ The goal of a MHMP is to develop and maintain a community's long-term strategy to reduce the impacts of natural disasters on residents and infrastructure, and decrease a community's risk to reoccurrences. ${ }^{4}$

\subsection{MHMP Planning Process}

MHMPs are guided by FEMA documents, which are the official sources for defining federal requirements for original and updated MHMPs. FEMA documents include:

- Getting Started: Building Support For Mitigation Planning (FEMA 386-1).

- Understanding Your Risks: Identifying Hazards And Estimating Losses (FEMA 386-2).

- Developing the Mitigation Plan: Identifying Mitigation Actions and Implementing Strategies (FEMA 386-3).

- Bringing the Plan to Life: Implementing the Hazard Mitigation Plan (FEMA 386-4).

The four-step MHMP planning process adapted from federal guidance documents as shown in Figure 2-1, provides a framework for the development of MHMPs that meet all the necessary criteria the California Emergency Management Agency (Cal EMA) and FEMA approval. ${ }^{5}$ The MHMP planning process includes organizing resources, assessing risk, developing mitigation actions and setting goals, adopting the MHMP, implementing, evaluating, and revising the MHMP.

The MHMP public outreach and participation strategy is part of organizing resources and occurs throughout the course of the MHMP planning project. As part of the strategy, the MHMP Planning Team forms the MHMP Steering/Planning Committees. The MHMP Steering Committee serves as the backbone of the MHMP planning project and includes Solano County Department/Office staff. The MHMP Planning Committee includes members of the MHMP Steering Committee as well as interested stakeholders in the County. Interested stakeholders consist of residents, property owners, businesses, civic groups, academia, non-profit organizations/groups, and major employers in Solano County. The MHMP Planning Team is the consultant on the MHMP planning project and is responsible of the

\footnotetext{
${ }^{3}$ Federal Emergency Management Agency. “Resource Record Details Disaster Mitigation Act of 2000." Federal Emergency Management Agency. http://www.fema.gov/library/viewRecord.do?id=1935 (accessed September 10, 2011).

4 Federal Emergency Management Agency. “Multi-Hazard Mitigation Planning." Federal Emergency Management Agency. http://www.fema.gov/plan/mitplanning/ (accessed September 10, 2011).

${ }^{5}$ Ibid.
} 
development of all aspects of the project. The results of each element of the MHMP planning process make up the MHMP document when fully complied.

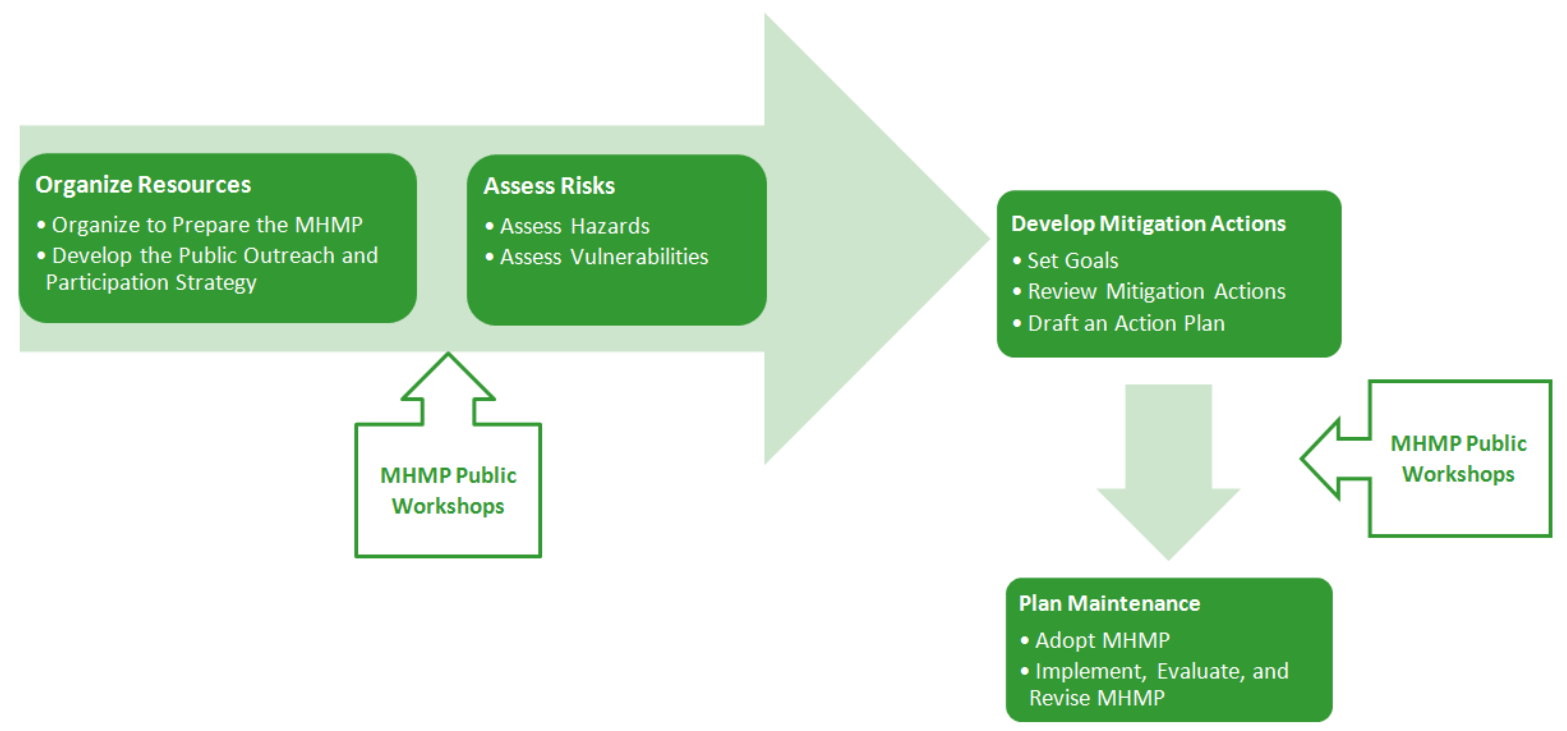

Figure 2-1: Four-Step MHMP Planning Process 


\section{MHMP Public Outreach and Participation Strategy}

This section describes the MHMP public outreach and participation strategy, MHMP branding, traditional tools and their limitations, online tools and their accessibility, social media tools, and existing usage of social tools in planning projects. In addition, this section outlines the 2012 Solano County MHMP.

\subsection{Strategy}

FEMA's 386-1 guidance document provides the MHMP Planning Team information on creating an effective MHMP public outreach and participation strategy. ${ }^{6}$ Creating an effective MHMP public outreach and participation strategy before the commencement of a MHMP planning project is vital as otherwise the engagement will be limited. ${ }^{7}$ Public outreach and participation throughout the MHMP planning project encourages the public to own the MHMP. ${ }^{8}$ Providing opportunities for the public to submit feedback and comments on a MHMP planning project makes interested stakeholders and the public feel more engaged with the MHMP Planning Team. ${ }^{9}$ The public's connection to a MHMP planning project is advantageous as they are more likely to become supporters of the MHMP, help interpret it for others, and facilitate its implementation. ${ }^{10}$ Currently, federal requirements outline traditional tools for a MHMP public outreach and participation strategy. ${ }^{11}$

\subsubsection{MHMP Branding}

Suitable and consistent branding in all MHMP public outreach and participation material is required. Continual use of the MHMP branding through the traditional, online, and social media tools has the potential to create an emotional connection with the residents of the unincorporated areas of Solano County and increase public participation throughout the MHMP planning project. ${ }^{12}$ The branding package developed for the MHMP project includes a project logo, color scheme and theme. The MHMP theme is Planning for a Resilient Solano County. Figure 3-1 illustrates the MHMP project logo utilized for all MHMP public outreach and participation material.

\footnotetext{
${ }^{6}$ Federal Emergency Management Agency. "Getting Started: Building Support for Mitigation Planning." Federal Emergency Management Agency. http://www.fema.gov/library/viewRecord.do?id=1867 (accessed September 10, 2011); David R. Godschalk, Samuel Brody, and Raymond Burby, "Public Participation in Natural Hazard Mitigation Policy Formation: Challenges for Comprehensive Planning," Journal of Environmental Planning \& Management 46, no. 5 (September 2003): 733. Academic Search Premier, EBSCOhost (accessed September 10, 2011).

7 Ibid; Dennis Day, "Citizen Participation in the Planning Process: An Essentially Contested Concept?," Journal of Planning Literature, no. 11(3) (1997): 421-434.

${ }^{8}$ Valerie Forrestal, "Making Twitter Work: A Guide for the Uninitiated, the Skeptical, and the Pragmatic," Reference Librarian 52, no. 1/2 (January 2011): 146. Academic Search Premier, EBSCOhost (accessed August 7, 2011).

9 Glenn W Mangold and David J. Faulds, "Social Media: The New Hybrid Element of the Promotion Mix," Business Horizons, 52(4), 357. WilsonWeb, EBSCOhost (accessed July 8, 2011).

10 Dave Taylor, "Connect You to Humanity?," Phi Kappa Phi Forum 88, no. 4 (Winter 2008): 18. Academic Search Premier, EBSCOhost (accessed July 8, 2011); Ibid.

${ }^{11}$ Federal Emergency Management Agency. "Local Multi-hazard Mitigation Planning Guidance." (July 1, 2008). http://www.fema.gov/library/viewRecord.do?id=3336 (accessed June 10, 2011).

12 Bruce J Newton, "Environmental Education and Outreach: Experiences of a Federal Agency," BioScience 51, no. 4: (2001): 297. Academic Search Premier, EBSCOhost (accessed July 8, 2011).
} 


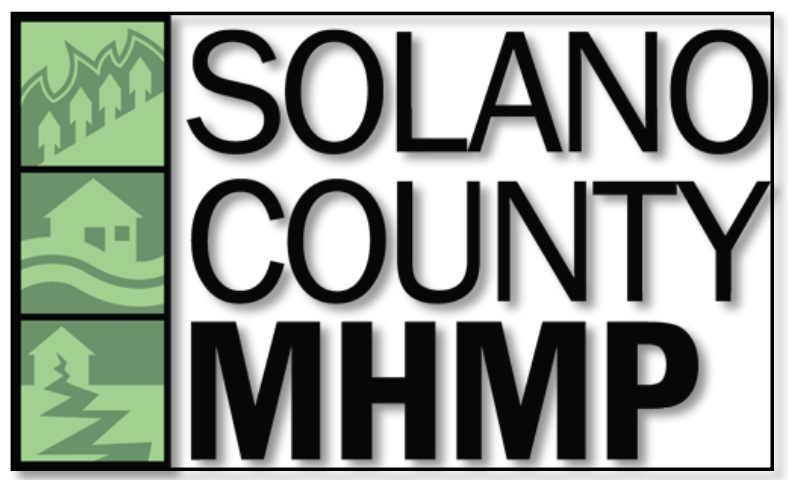

(Source: 2012 Solano County MHMP Document)

Figure 3-1: Solano County MHMP Project Logo

\subsubsection{MHMP Traditional Methods of Communication}

In conjunction with the Solano County Department of Resource Management and Public Communications Officer, the MHMP Planning Team created press releases and public notices for the MHMP public workshops. The press releases were included on the Solano County website at www.SolanoCounty.com. Additionally, the Public Communications Officer circulated the press releases to the County's existing media outlet distribution list. For each MHMP public workshop, public notices were published in the Reporter and Daily Republic newspapers for three days. In addition, the MHMP Planning Team contacted various Solano County community-based services and establishments via telephone and email to publicize the MHMP public workshops. Copies of the MHMP public notices were emailed to community-based services and establishments, such as the American Red Cross, libraries, Lions Club, and school districts. The MHMP Planning Team requested that the public notices be posted in these establishments and emailed to other interested stakeholders in the MHMP planning project, at their discretion.

\subsubsection{Traditional Tools Limitations}

During and after the four-step MHMP planning process, online and social media tools do not incur the same restrictions as traditional methods of communication. With online and social media tools, different methods of publication can transcend traditional methods of communication. ${ }^{13}$ Newspapers, which include information on press releases and public notices have space limitations and are typically published by geographical area daily/weekly. This limits the amount of information published to the residents living in the MHMP planning area. Public workshops provide the public an opportunity to review and submit feedback on the MHMP planning project, but they are restricted to specific locations in the MHMP planning area. Utilizing online and social media tools are techniques to address these limitations.

\footnotetext{
13 Deborah Boyer, "From Internet to iPhone: Providing Mobile Geographic Access to Philadelphia's Historic Photographs and other Special Collections," Reference Librarian 52, no. 1/2 (January 2011): 47. Academic Search Premier, EBSCOhost (accessed August 7, 2011).
} 


\subsubsection{Online Information}

The information posted online during the MHMP planning project needs to contain local specific information. ${ }^{14}$ The public will support a MHMP planning project, if the information directly relates to them and is practical and easy to follow. ${ }^{15}$ The public expects a MHMP public outreach and participation strategy to meet their needs. ${ }^{16}$ In order for the MHMP Planning Team to build relationships with the public, the posted information needs to be consistent. ${ }^{17}$ Contradictory posted information could lead the public to mistrust the MHMP Planning Team and engagement in the MHMP planning project will possibly decrease. ${ }^{18}$

\subsubsection{Online Tool Accessibility}

Currently, online tools are free to use and provide the public easy access to a wide variety of information on a MHMP. Online tools provide the public an invaluable resource of information on MHMP planning project, which can be accessed on-demand from any location. ${ }^{19}$ A sample of MHMP information posted online includes project background, resources, calendar events, and announcements. Methods of publication include interactive mapping of the MHMP planning area, photo albums with captions and descriptions, relevant videos and links to other websites and documents pertaining to the MHMP. The amount of information the MHMP Planning Team can publish online is extensive and can remain online for an indefinite amount of time. ${ }^{20}$ In addition, compared with traditional methods of communication, online tools are interactive and instant feedback to public's comments and questions on the MHMP planning project is feasible.

\subsubsection{Social Media Tools}

The original idea behind social media tools was to provide the public a method of communication between friends and family and enable relationship building with one another. ${ }^{21}$ Social media tools are defined as internet-based applications that allow the development and exchange of information. ${ }^{22}$ Currently, one in five internet users publish information using a social media tool. ${ }^{23}$ Some of the most popular social media tools include Facebook, Twitter, and YouTube. ${ }^{24}$ Access to social media tools can

\footnotetext{
14 Ibid; Andreas M Kaplan, and Michael Haenlein, "Users of the World, Unite! The Challenges and Opportunities of Social Media," BusinessHorizons v. 53, no. 1 (January/February 2010) p. 59. WilsonWeb, EBSCOhost (accessed July 8, 2011).

15 Alex Howard. "Social Data and Geospatial Mapping Join the Crisis Response Toolset." http://radar.oreilly.com/2011/01/esriaustralia-ushahidi.html (accessed August 6, 2011).

${ }_{16}$ Jules Lefcowitz, "Public Outreach: Marketing by Another Name," Journal of Housing \& Community Development 55, no. 2 (March 1998): 12. Academic Search Premier, EBSCOhost (accessed July 8, 2011).

17 Ibid.

18 Ibid.

19 Donovan R Walling, "Idea Networking and Creative Sharing," TechTrends: Linking Research \& Practice to Improve Learning 53, no. 6 (November 2009): 22. Academic Search Premier, EBSCOhost (accessed July 8, 2011).

20 lbid.

${ }^{21}$ Ibid; Kevin Dugan. "Facebook Can Improve Your Media Relations."

http://prblog.typepad.com/strategic public relation/2007/07/facebook-can-im.html (accessed October 24, 2011).

22 Wikipedia. "Social Media." http://en.wikipedia.org/wiki/Social media (accessed May 6, 2012).

${ }^{23}$ Susannah Fox and Amanda Lenhart, "Twitter and Status Updating, Spring 2009," Pew Internet \& American Life Project. http://www.pewinternet.org/Reports/2009/Twitter-and-status-updating.aspx (accessed June 10, 2011); Ibid

24 Dayton Business Journal. "Top 10 Most Visited Social Media Sites." http://www.bizjournals.com/dayton/blog/socialmadness/2012/04/slideshow-top-10-most-visited-social.html?s=image gallery (accessed May 6, 2012).
} 
be through personal and work computers, iPads, and other capable mobile devices such as smart phones.

One of the greatest strengths of social media tools are their availability through smart phones. "It is estimated that, as of February 2010, there were approximately 45.4 million people in the United States who owned a smart phone." ${ }^{25}$ Not all members of the public have access to a computer. In addition, they may not be technical or internet savvy, connected to Facebook and/or Twitter. In order for the MHMP public outreach and communication strategy to be effective it needs to encompasses a mixture of traditional, online, and social media tools.

\subsubsection{Existing Online Tool Usage}

During the review of 52 MHMPs for FEMA Region IX in 2010, less than $50 \%$ of MHMPs utilized a MHMP project website and not one MHMP utilized social media tools to comply with the MHMP public outreach and participation federal requirements. After an initial analysis of other planning documents utilizing Facebook and Twitter, it was found that a limited number of planning projects utilize social media tools to comply with public outreach and participation federal and/or local requirements. Planning projects in the United States searched for in Facebook and Twitter include Environmental Impact Report (EIR), General Plan (GP), MHMP, and Specific Plan (SP).

\subsubsection{Solano County MHMP}

To engage the public throughout the 2012 Solano County MHMP planning project, a public outreach and participation strategy was developed. In order to gather data and information pertinent to the MHMP planning project, the strategy incorporated traditional methods of communication, online and social tools. Utilizing online and social media tools provides a unique opportunity for the MHMP Planning Team to comply with MHMP federal requirements and create a more effective public outreach and participation strategy for residents in the unincorporated areas of Solano County.

According to the U.S. 2010 Census Data, Solano County's total population is 413,344 , with 18,834 people (4.5\% of Solano County's total population) residing in the unincorporated areas of the County. ${ }^{26}$ Since the population density in the unincorporated areas of the County is relatively low, the MHMP online and social media tools are additional methods of communication with residents living in the MHMP planning area. Along with the MHMP project website, social media tools utilized during the MHMP planning project include Facebook and Twitter. These social media tools were chosen to enhance public outreach and participation in the MHMP planning project. ${ }^{27}$ The interconnection between the MHMP project website and MHMP social media tools is illustrated in Figure 3-2.

\footnotetext{
25 Antone Gonsalves. "Android Phone Steals Market Share." http://www.informationweek.com/news/mobility/smart phones/showArticle.jhtml?articlelD=224201745 (accessed September 10, 2011).

${ }^{26}$ U.S. Census Data. "2010 Census Data”. http://2010.census.gov/2010census/data/ (accessed May 6, 2012).

${ }^{27}$ Brian Solis. "14 Best Practices for Long-Term Social Media Success." http://mashable.com/2011/04/28/14-best-practices-forlong-term-social-media-success/ (accessed August 7, 2011); Brian Solis. "21 Rules for Social Media Engagement." http://mashable.com/2010/05/18/rules-social-media-engagment/ (accessed August 7, 2011).
} 


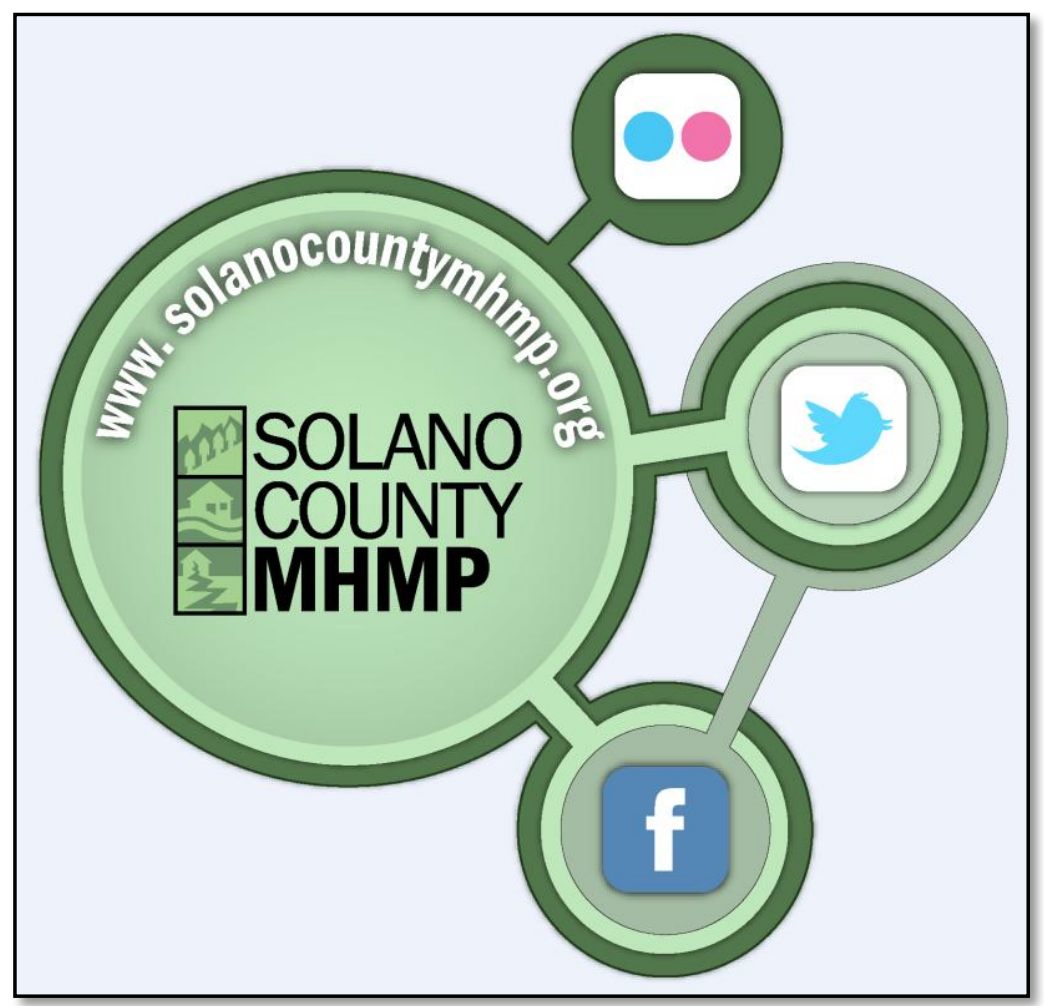

(Source: 2012 Solano County MHMP Document)

Figure 3-2: MHMP Online Tools Interconnection 
Intentional Blank Page 


\section{MHMP Online and Social Media Tool Methodology}

The goal of the MHMP online and social media tools is to publicize the MHMP planning project to the largest possible audience in Solano County. This section describes the methodology used for the MHMP project website, MHMP Facebook fan page, MHMP Twitter page, and provides information on Hazards Fortnights.

\subsection{MHMP Project Website}

Utilizing Google websites, the MHMP project website was developed at the commencement of the MHMP planning project in August 2011. The MHMP project website domain name is www.SolanoCountyMHMP.org. The MHMP project website homepage shown in Figure 4-1 contains the following MHMP planning project related items:

- Project Outline

- MHMP Calendar

- Announcements

Located on the left hand side of the MHMP project website, tabs to other MHMP project website include the following:

- Home

- About the Project

- What is Hazard Mitigation?

- Resource Center

- Mitigation Action Tables

- Nov 2011 Public Workshops

- 2012 DRAFT MHMP Update

- Document Downloads

- Contact Us

Icons linking the MHMP project website to the MHMP Facebook fan page and MHMP Twitter page are included on MHMP project website homepage, as shown in Figure 4-1. Additionally, an icon linking to the Solano County website (www.SolanoCounty.com) is included on the MHMP project website homepage. 


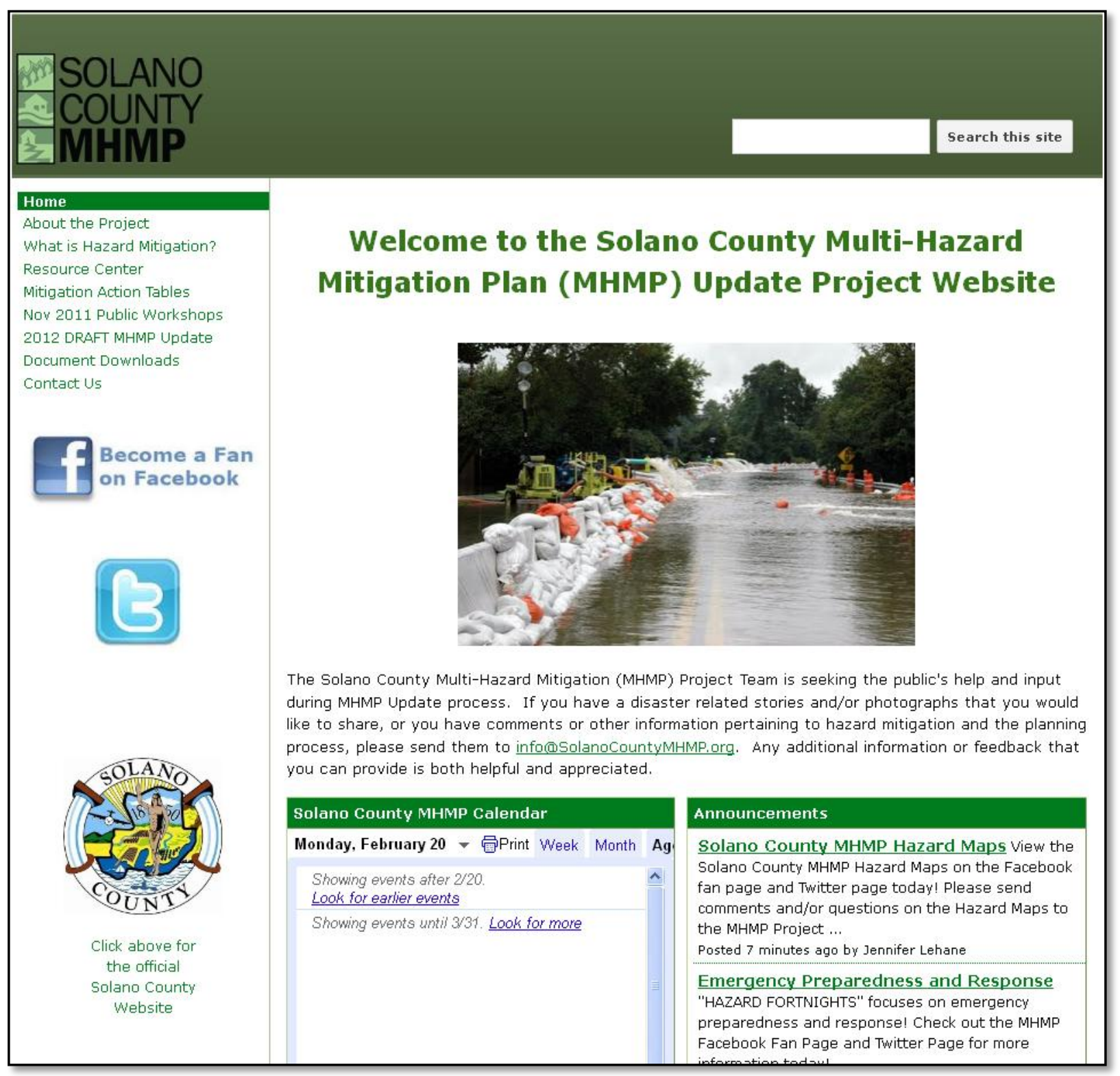

Figure 4-1: MHMP Project Website Homepage

\subsection{MHMP Facebook Fan Page}

The objective of promoting the MHMP on Facebook is for Facebook individual users and fan pages to Like the MHMP Facebook fan page, comment on items posted on the fan page, and share fan page posts on their individual page/fan page. This section describes the development of the MHMP Facebook fan page, basic information, and explains how the MHMP Facebook fan page was promoted to other Facebook users and to the public.

\subsubsection{MHMP Facebook Fan Page Development}

The MHMP Facebook fan page was created in August 2011. To create the MHMP Facebook fan page, a personal MHMP Facebook page was required. The MHMP Facebook personal page was created using the Baker@SolanoCountyMHMP.org email address. After creating the personal page, the MHMP 
Facebook fan page was generated. Development of the MHMP Facebook fan page includes the following steps:

- In the search box located at the top of the MHMP Facebook personal page, the text "Create a Page" was entered.

- For page type, Company, Organization or Institution was selected.

- Under Company, Organization or Institution category, Government Organization was chosen.

- For company name, Solano County MHMP was chosen.

- The MHMP Planning Team agreed to the Facebook fan page terms of agreement.

After the personal MHMP Facebook page and fan page were created, the option of using Facebook as the MHMP Facebook fan page entity was chosen. Choosing this option enables the MHMP Facebook fan page to be the entity the public views and communicates with on the MHMP planning project. In addition, Facebook allows the MHMP Facebook fan page to be connected to the MHMP Twitter page. This enables information posted to the MHMP Facebook fan page to instantly appear on the MHMP Twitter page.

\subsubsection{MHMP Facebook Fan Page Information}

Basic information pertaining to the MHMP planning project is included on the MHMP Facebook fan page. MHMP Facebook fan page basic information includes MHMP project information, a description of how the public can get involved in the MHMP planning project, the MHMP Planning Team phone number and email address, and the MHMP project website address as shown in Figure 4-2.

\begin{tabular}{|ll|}
\hline Basic Information & \\
About & The Solano County Muti-Hazard Mitigation Plan (MHMP) Update will be a \\
& primary tool to reduce or eliminate long-term risk to people and property \\
& from natural hazards in Solano County. \\
& The MHMP Update Planning Team is seeking the public's help and input \\
Description & during the MHMP Update process. If you have disaster related stories \\
& andjor photographs that you would like to share, or you have \\
& comments, please send them to info@SolanoCountyMHMP.org. \\
Phone & 1510.879 .0920 \\
Email & info@SolanoCountyMHMP,org \\
Website & http://iwww. SolanoCountyMHMP,org \\
\end{tabular}

Figure 4-2: MHMP Facebook Fan Page Basic Information

The MHMP project logo was selected as the MHMP Facebook fan page profile picture. Photos uploaded to the MHMP Facebook fan page include MHMP hazard maps, MHMP public workshops, MHMP-related images, and hazard mitigation and disaster preparedness efforts. Example MHMP Facebook fan page photos are shown in Figure 4-3. 


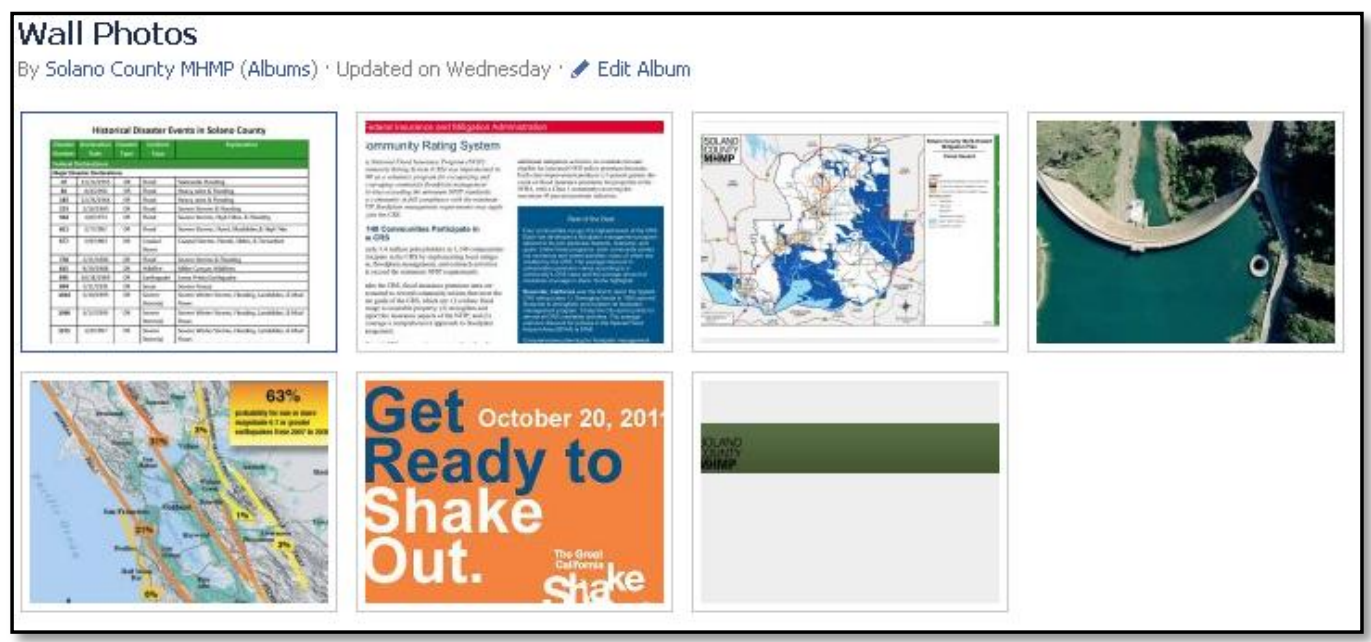

Figure 4-3: Example MHMP Facebook Fan Page Photos

\subsubsection{MHMP Facebook Fan Page Promotion}

To promote the MHMP Facebook fan page to Facebook users and to the public, numerous methods of promotion were utilized. These methods include Liking other Facebook fan pages, sharing posts on other fan pages on the MHMP Facebook fan page, and posting/sending Facebook messages to fan pages with MHMP public workshop details.

\subsubsection{Liking Facebook Fan Pages}

Facebook users and fan pages can Like the MHMP Facebook fan page by clicking the Like button, as shown in Figure 4-4. The MHMP Facebook fan page Liked 106 Facebook fan pages, as listed in Appendix A.1. Liked fan pages include federal, state, and local agencies, interested MHMP stakeholders, local media, non-profits, special interest, and Solano County geographically located Facebook fan pages. Fan pages selected by the MHMP Facebook fan page to Like, provide relevant information to the MHMP planning project and could potentially promote the MHMP Facebook fan page to Facebook users and to the public.

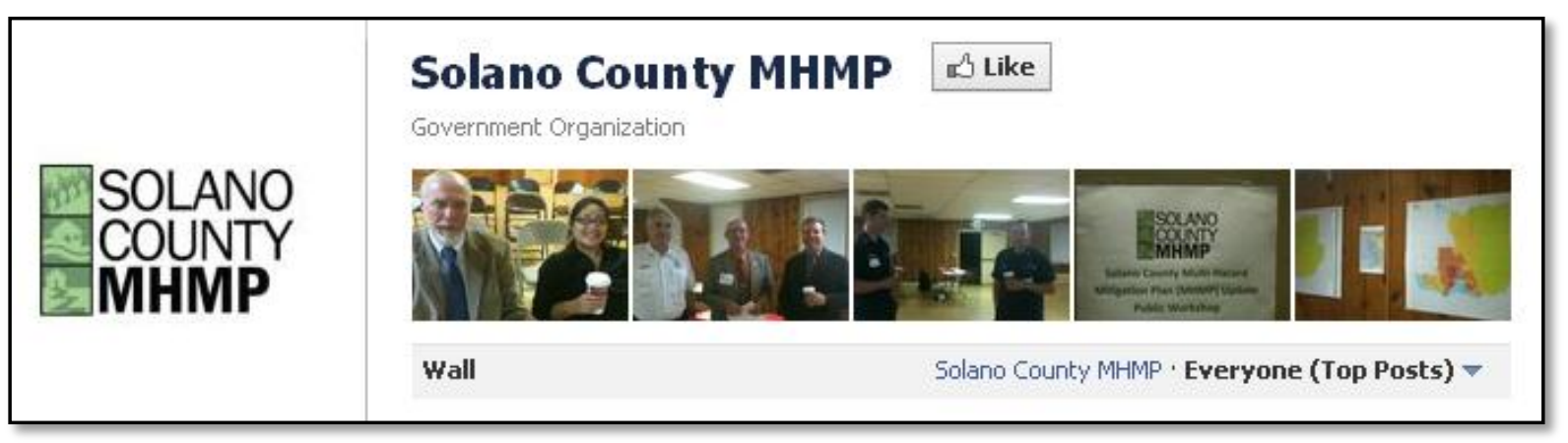

Figure 4-4: MHMP Facebook Fan Page Like Button 


\subsubsection{Sharing Posts}

Another avenue of promoting the MHMP Facebook fan page is sharing posts on other Facebook fan pages on the MHMP Facebook fan page. When a post on a Facebook fan page is shared by the MHMP's Facebook fan page, fans of that page can view the share. Example posts shared by the MHMP Facebook fan page include:

- October 24, 2011, CAL FIRE's photo promoting wildfire preparedness information at www. ReadyForWildfire.org, as shown in Figure 4-5.

- October 20, 2011, The Great California ShakeOut promoting earthquake preparedness information in California at www.shakeout.org.

- October 13, 2011, National Oceanic and Atmospheric Administration (NOAA) promoting information on accurate forecasts and advance warning on severe weather on YouTube at http://www.youtube.com/watch?v=wAUwJGDCOTc.

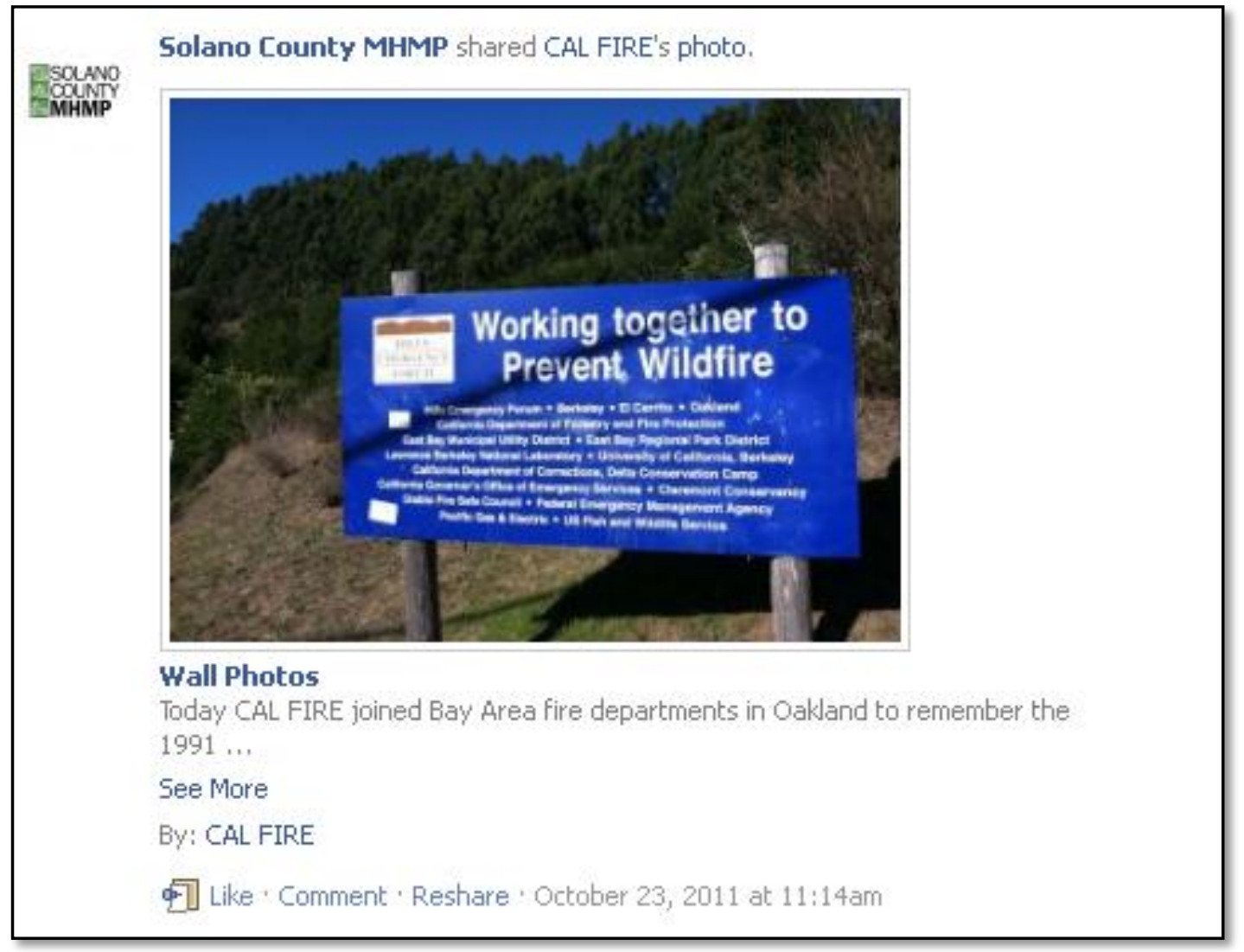

Figure 4-5: CAL FIRE's www.ReadyForWildfire.org Photos

\subsubsection{MHMP Facebook Fan Page Messages}

A limited number of Facebook fan pages allow messages to publicly appear on their fan page. In addition to the message appearing on the Facebook fan page, the message appears in the news feed of fans of that page. Example messages posted to other Facebook fan pages include: 
- The purpose of this project is to update Solano County's existing Multi-Hazard Mitigation Plan (MHMP). Using the most current information and data, conducting a thorough vulnerability analysis, and revising community priorities and subsequent mitigation actions will update the MHMP. (A link to the MHMP public workshop agenda was included in the message).

- MHMP public workshops on Monday 14th at Elmira Fire Station at 6.30pm. See you there! http://www.solanocountymhmp.org/annou/solanocountymhmppublicworkshops.

- The Solano County MHMP public workshops are next week! Please spread the word: http://t.co/RraY7EL.

Table 4-1 illustrates the MHMP Facebook fan pages public message recipients.

Table 4-1: MHMP Facebook Fan Pages Public Message Recip
\begin{tabular}{l|}
\hline \multicolumn{1}{|c|}{ Public Message(s) Recipients } \\
\hline City of Vacaville \\
\hline Downtown Dixon Business Association \\
\hline Fairfield California \\
\hline Fairfield-Suisun Chamber of Commerce \\
\hline Solano County Farm Bureau \\
\hline Solano County Library \\
\hline Solano Grown \\
\hline The Greater Vallejo Recreation District \\
\hline The Reporter \\
\hline Vacaville Chamber of Commerce \\
\hline Vacaville Fire Dept \\
\hline Vacaville, CA \\
\hline Vallejo Chamber of Commerce \\
\hline
\end{tabular}

For Facebook fan pages, which do not permit messages to be publicly posted, the MHMP Facebook fan page privately sent them the same message(s). The goal of sending private messages is for fan pages to post the message to their fan page. As shown in Figure 4-2, private Facebook message(s) were sent to the following Facebook fan pages. 
Table 4-2: MHMP Facebook Fan Pages Private Message(s) Recipients

\begin{tabular}{|l|}
\hline \multicolumn{1}{|c|}{ Private Messages Recipients } \\
\hline American Red Cross Bay Area \\
\hline Benicia Herald \\
\hline Cal EMA \\
\hline California Delta Chambers and Visitors Bureau \\
\hline California Fire Alliance \\
\hline Central Valley Farmland Trust \\
\hline Discover Solano County \\
\hline Green Valley Agricultural Conservancy \\
\hline Rio Vista Chamber of Commerce \\
\hline River News-Herald \\
\hline Solano County, California \\
\hline Solano Fire \\
\hline Solano Transportation Authority \\
\hline Suisun Valley Fruit Growers \\
\hline U.S. Geological Survey (USGS) \\
\hline Vacaville Community Services \\
\hline Vacaville PAL \\
\hline Vallejo Times-Herald \\
\hline
\end{tabular}

\subsection{MHMP Twitter Page}

The goal of the MHMP Twitter page is to promote the page to other Twitter pages and to the public. The objective of the MHMP Twitter page promotion is for Twitter pages to follow the MHMP Twitter page and retweet information tweeted on the MHMP Twitter page. This section describes the MHMP Twitter profile settings, outlines the MHMP Twitter page promotion, and discusses the MHMP Twitter page lists.

\subsubsection{MHMP Twitter Page Development}

The MHMP Twitter page was developed in August 2011, using the info@SolanoCountyMHMP.org email address. Development of the MHMP Twitter page includes entering profile information as shown in Figure 4-6. In addition, Twitter allows the MHMP Twitter page to be connected to the MHMP Facebook fan page. Tweets on the MHMP Twitter page instantly appear on the MHMP Facebook fan page. 


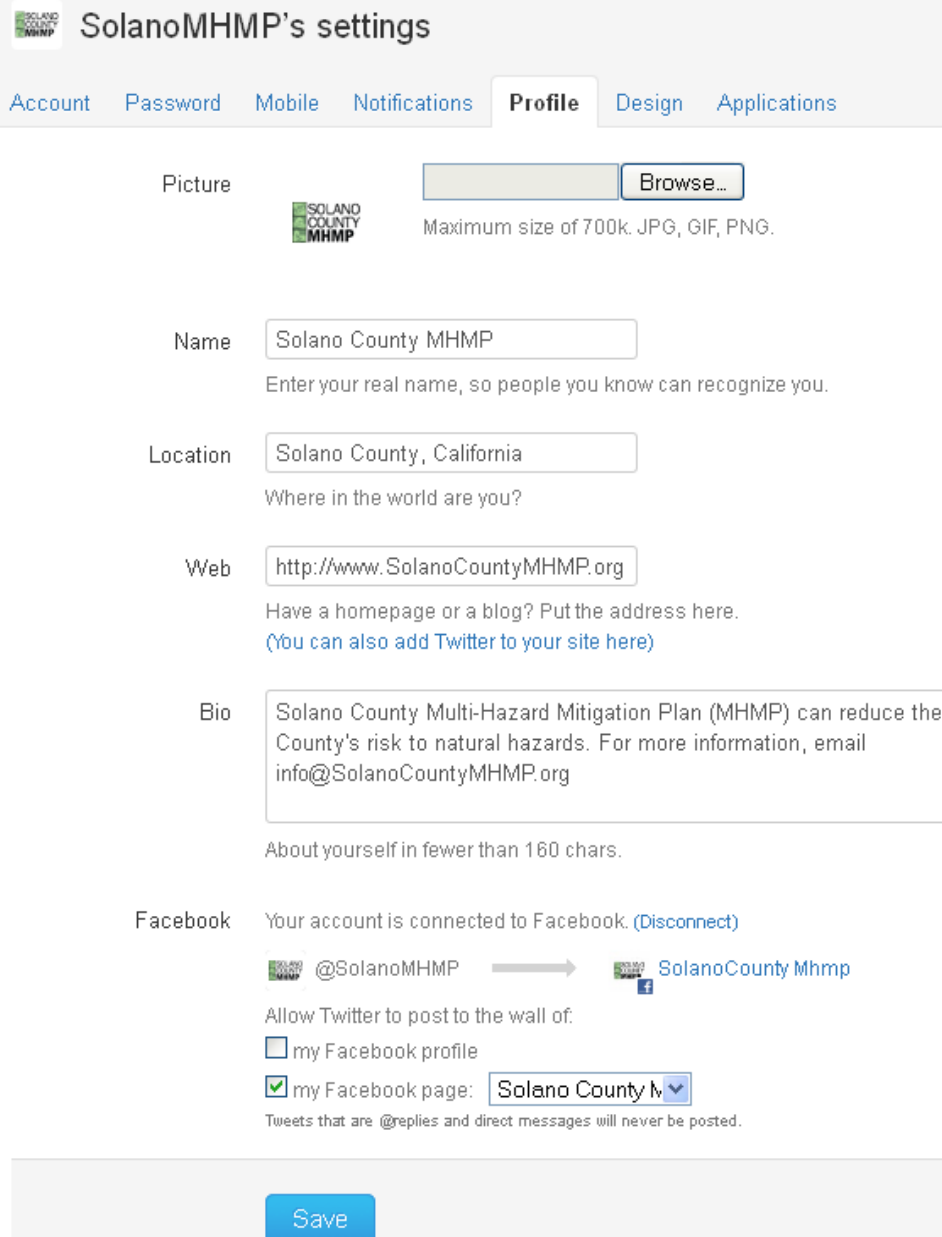

Figure 4-6: MHMP Twitter Page Profile Information

\subsubsection{MHMP Twitter Page Promotion}

To promote the MHMP Twitter page to other Twitter pages and the public, numerous methods of promotion were utilized. These methods include following other Twitter pages, retweeting information posted on other Twitter pages, and sending messages to MHMP Twitter page followers. The MHMP Twitter page public profile is shown in Figure 4-7. 


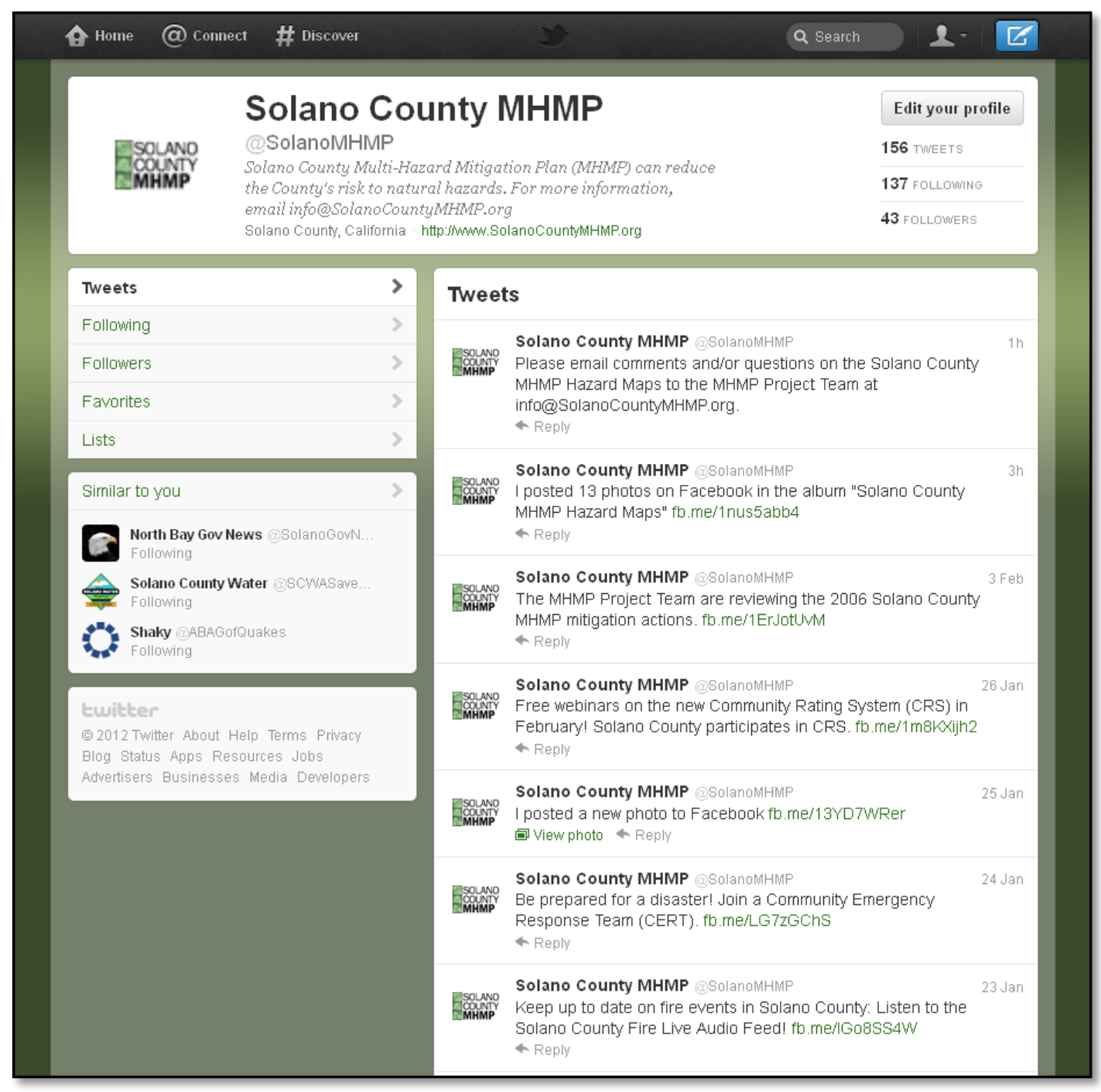

Figure 4-7: MHMP Twitter Page

\subsubsection{MHMP Twitter Pages and Retweets}

Followers of a particular Twitter page can view which Twitter pages the MHMP Twitter page follows. The MHMP Twitter page follows 113 Twitter pages, which include federal, state, and local agencies, interested MHMP stakeholders, local media, nonprofits, special interest, and Solano County geographically located Twitter pages as shown in Table B.1-1. Followed Twitter pages can provide relevant information on the MHMP planning project or data/results during the MHMP planning project and promote the MHMP Twitter page to other Twitter pages and to the public.

\subsubsection{MHMP Twitter Page Followers}

If another Twitter page follows the MHMP Twitter page, a message is sent to that Twitter page, thanking them for following the MHMP Twitter page. Additionally, a link to the MHMP Facebook fan page is included in the message. This communication may encourage the Twitter page to further partake in the MHMP planning project. 


\subsubsection{MHMP Twitter Page Lists}

Twitter page lists are a method of organizing Twitter pages the MHMP Twitter page follows. Twitter page lists provide the MHMP Twitter page an easy method of capturing relevant information pertaining to the MHMP planning project. The MHMP Twitter page includes a list for each natural hazard affecting Solano County, organizations that are not directly tweeting about a specific hazard but could potentially promote the MHMP Twitter page to other Twitter pages and to the public, and general emergency response and preparedness Twitter pages. Listed below are the MHMP Twitter page lists:

- @SolanoMHMP/Dam-Failure

- @SolanoMHMP/Drought

- @SolanoMHMP/Earthquake

- @SolanoMHMP/Emergency-Preparedness

- @SolanoMHMP/Flood

- @SolanoMHMP/Organizations

- @SolanoMHMP/Wildfire

Selected Twitter pages can be added to multiple MHMP Twitter page lists, as their tweets focus on more than one aspect of the MHMP planning project. An example of this occurrence is the U.S Army Corps of Engineers (USACE) Twitter page. Since USACE is responsible for the prevention of dam failures and flooding events and provides emergency preparedness information to the public, its Twitter page was added to the MHMP Twitter page dam failure, emergency preparedness, and flooding lists.

\subsection{Hazard Fortnights}

To promote the MHMP planning project to the public, information posted to the MHMP online and social media tools needs to be MHMP planning project specific. With such a large volume of information available on the MHMP planning project, the MHMP Planning Team decided to divide the information into different topics and create Hazard Fortnights. Hazard Fortnights includes content on each natural hazard affecting Solano County, MHMP public workshops, general mitigation, response and preparedness information, and information pertaining to the MHMP planning project. Information posted to the MHMP online and social media tools on each topic sequentially on a bi-weekly basis includes:

- September 2011 - Wildfire and drought

- October 2011 - Earthquake and dam failure

- November 2011 - MHMP public workshops

- December 2011 - Flooding

- January 2012 - Emergency response and preparedness

- February 2012 - MHMP hazard maps and mitigation actions

- March 2012 - MHMP public workshop

By March 31, 2012, approximately 170 items were posted to the MHMP Facebook fan page and MHMP Twitter page. On average, information was posted to the MHMP online and social media tools every 
two to three days, as shown in Appendix A.2. The information posted to the MHMP Facebook fan page is similar to the MHMP Twitter page tweets. 
Intentional Blank Page 


\section{MHMP Data Analysis}

The 2012 Solano County MHMP planning project and report concluded on March 31, 2012. This section discusses the MHMP public outreach and participation survey, and the MHMP traditional tools, MHMP project website, MHMP Facebook fan page, and MHMP Twitter page data analysis.

\subsection{MHMP Public Outreach and Participation Survey}

The MHMP public outreach and participation survey was conducted to gather information on the public's use of the MHMP traditional, online, and social media tools. Information gathered from the survey responses enables the MHMP Planning Team to understand the effectiveness of engaging the public in the MHMP planning project though these various tools. . The topics of the MHMP survey questions address include demographics, traditional tool usage, MHMP public workshops, the effectiveness of the MHMP online and social media tools, and general comments on the MHMP planning project. The MHMP public outreach and participation survey questions are listed in Appendix C.1. Survey participants are directed through the survey according to their responses.

\subsubsection{Survey Administration}

The MHMP public outreach and participation survey was conducted using Survey Monkey. The survey was sent to participants via the info@SolanoCountyMHMP.org email address on April 2, 2012. Participants were asked to complete the survey by April 9, 2012. To encourage participants to partake in the survey, a reminder email asking participants to complete the survey was sent on April 5, 2012. The survey took approximately five minutes to complete. To ensure confidentiality, the survey was conducted anonymously. An introductory paragraph was included in the survey to provide background information on the survey to participants. The survey introductory paragraph is as follows:

Thank you for participating in the Solano County Multi-Hazard Mitigation Plan (MHMP) Public Outreach and Participation Survey. This survey analyses the effectiveness of public engagement in the MHMP planning process though the Solano County MHMP online tools. These online tools include the MHMP project website, Facebook fan page, and Twitter page. The survey responses will enable the MHMP Planning Team to improve its Public Outreach and Participation Strategies for Solano County and the surrounding Bay Area Counties.

The survey will take approximately 5 minutes to complete and is conducted anonymously. If you have any questions about the survey and/or on the MHMP planning process, please contact the MHMP Planning Team by email at info@SolanoCountyMHMP.org, calling 510-879-0969, or by mail to One Kaiser Plaza, Suite 1150, Oakland, CA 94612.

Your time and effort is greatly appreciated!

In addition, a final paragraph at the end of the survey was included to thank the participants for their participation in the survey. The final paragraph is as follows: 
Thank you for participating in the Solano County MHMP public outreach and participation survey. Your time and effort is greatly appreciated.

\subsubsection{Survey Participants}

Participants in the MHMP public outreach and participation survey include MHMP Steering/Planning Committee members and MHMP public workshop attendees. The survey was sent to 108 participants. The number of MHMP public outreach and participation survey participants is 24 . As shown in Table 5-1, the majority of survey participants are MHMP Steering/Planning Committee members. Survey responses indicate that the role and obligations of the MHMP Steering/Planning Committees members needs to be defined, as six survey participants are unsure if they are committee members. Defining their role and obligations will enable committee members to proactively participate in the MHMP planning project. Failing to understand their role and obligations may contribute to their lack of involvement in the MHMP planning project.

Table 5-1: MHMP Steering/Planning Committee Members

\begin{tabular}{|c|c|}
\hline Response & Count \\
\hline Yes & 13 \\
\hline No & 5 \\
\hline Unsure & 6 \\
\hline
\end{tabular}

As shown in Table 5-2, the majority of survey participants are aged between 30 and 64 years. This information corresponds to Solano County's demographics, as the median age for a resident in the County is aged 35.6 years. Since the MHMP public outreach and participation survey participants are a small sample size, this information may not accurately reflect the demographics of the public who are involved in the MHMP planning project.

Table 5-2: Survey Participants Age

\begin{tabular}{|c|c|}
\hline Response & Count \\
\hline Under 18 & 1 \\
\hline $18-29$ & 1 \\
\hline $30-44$ & 9 \\
\hline $45-64$ & 11 \\
\hline 65 and older & 2 \\
\hline Do not wish to answer & 0 \\
\hline
\end{tabular}

\subsection{MHMP Traditional Tools Analysis}

This section discusses the data analysis of two MHMP traditional tools. This includes information on MHMP public workshop knowledge and attendance, reasons for not attending the MHMP public workshops, and helpfulness of the information provided at the MHMP public workshops. In addition, this section includes the public comments on the MHMP planning project. 


\subsubsection{MHMP Public Workshop Knowledge}

Nearly three quarters of the survey participants knew about the MHMP public workshops as shown in Table 5-3.

Table 5-3: Knowledge of the MHMP Public Workshops

\begin{tabular}{|c|c|}
\hline Response & Count \\
\hline Yes & 17 \\
\hline No & 4 \\
\hline
\end{tabular}

Survey participants learned about the MHMP public workshops through traditional methods of communication such as public notices and word of mouth as shown in Table 5-4.

Table 5-4: How Survey Participants learned about the MHMP Pub
\begin{tabular}{|c|c|}
\hline Response & Count \\
\hline Public Notices & 9 \\
\hline Word of Mouth & 9 \\
\hline Solano County Website & 3 \\
\hline MHMP Project Website & 1 \\
\hline MHMP Facebook Fan Page & 0 \\
\hline MHMP Twitter Page & 0 \\
\hline
\end{tabular}

Eight survey participants had other responses including:

- Meetings and emails

- Email from staff

- Was asked to participate

- Email from other MHMP Steering Committee members

- By invitation

- Email

- Email notice

- Email from MHMP Planning Team

Survey responses illustrate that public notices, word of mouth, and the MHMP project website were more successful in promoting the MHMP public workshops than the MHMP social media tools. In addition, email was successful in promoting the MHMP public workshops, as six survey participants learned about them through this method of communication.

\subsubsection{MHMP Public Workshop Attendance}

As shown in Table 5-5, eight survey participants attended the MHMP public workshops. 
Table 5-5: MHMP Public Workshop Attendance

\begin{tabular}{|c|c|}
\hline Response & Count \\
\hline Yes & 8 \\
\hline No & 8 \\
\hline
\end{tabular}

According to Table 5-6, survey participants who did not attend the MHMP public works, as they were not interested. Survey responses indicate that distance was not a reason for not attending the MHMP public workshops.

Table 5-6: Reasons for not attending the MHMP Public Workshops

\begin{tabular}{|c|c|}
\hline Response & Count \\
\hline Not Interested & 3 \\
\hline Forgot & 2 \\
\hline Too Busy & 2 \\
\hline Too Far to Travel & 0 \\
\hline
\end{tabular}

The MHMP Planning Team need to analyze why some survey participants were not interested in attending the MHMP public workshops. One possible explanation is that the MHMP public workshop information is provided on the MHMP project website. Without having to attend the MHMP public workshops, the MHMP Steering/Planning Committee members and public can review this information online. In addition, survey responses indicate that the MHMP Planning Team chose feasible locations for the MHMP public workshops.

\subsubsection{MHMP Public Workshop Information Helpfulness}

As shown in Table 5-7, survey participants found the MHMP public workshops a helpful source of information on the MHMP planning project.

Table 5-7: MHMP Public Workshop Information Helpfulnes
\begin{tabular}{|c|c|}
\hline Response & Count \\
\hline 5 - Very Helpful & 6 \\
\hline 3 - Neither Helpful nor Unhelpful & 1 \\
\hline 1 - Unhelpful & 1 \\
\hline
\end{tabular}

The MHMP Planning Team should provide the same information at future MHMP public workshops. This information includes:

- Agenda

- Hazard maps

- PowerPoint presentation

- Tables

- Worksheets 


\subsubsection{MHMP Planning Project Comments}

As shown in Table 5-8, 12 survey participants provided comments on the MHMP planning project.

Table 5-8: MHMP Planning Project Comments

\begin{tabular}{|c|c|}
\hline Response & Count \\
\hline Yes & 12 \\
\hline No & 8 \\
\hline
\end{tabular}

The top three avenues for providing comments on the MHMP planning project include the MHMP Steering/Planning Committee meetings, utilizing the MHMP email address, and attending the MHMP public workshops as shown in Table 5-9. Survey participants did not provide comments on the MHMP planning project utilizing the MHMP Facebook fan page or MHMP Twitter page.

Table 5-9: Methods Used to Comment on the MHMP Planning project

\begin{tabular}{|c|c|}
\hline Response & Count \\
\hline MHMP Steering/Planning Committee Meetings & 8 \\
\hline MHMP Email Address & 5 \\
\hline MHMP Public Workshop & 4 \\
\hline MHMP Public Comment Form & 3 \\
\hline Phone call to the MHMP Planning Team & 1 \\
\hline MHMP Facebook Fan Page & 0 \\
\hline MHMP Twitter Page & 0 \\
\hline
\end{tabular}

The MHMP Steering/Planning Committee members and public can provide key information pertaining to the MHMP planning project and validate existing information. Survey responses highlight the importance of conducting MHMP Steering/Planning Committee meetings. Additionally, the survey responses compound the effectiveness of utilizing email as a method of communication with the MHMP Steering/Planning Committee members and public.

\subsubsection{MHMP Survey Comments}

From the survey responses, the following comments were received on the MHMP planning project:

- It was well thought and complete (in regards to the MHMP project website).

- The process was very professional and the team was well versed on Solano County.

These comments demonstrate that the MHMP Planning Team was successful in developing an effective MHMP project website and MHMP planning document.

\subsection{MHMP Project Website}

This section details the MHMP project website Google Analytics (GA) reports and metrics from August 1, 2011 to March 31, 2012, and relevant MHMP public outreach and participation survey responses. 


\subsubsection{MHMP Project Website GA Reports and Metrics}

GA is a free service offered by Google that generates comprehensive statistics on the MHMP project website visitors. GA enables the MHMP Planning Team to gauge the public use of the MHMP project website. ${ }^{28}$ The following reports and metrics are analyzed utilizing GA on the MHMP project website:

- Visits (total number of visits to the MHMP project website and new versus returning visitors)

- Average visit duration

- Page views and pages viewed per visit

- Smart phone access

- Traffic source

- Language

- City of access

To ensure that GA accurately reflects the public's use of the MHMP project website, GA is filtered to exclude the Michael Baker Jr. Inc., company domain (www.mbakercorp.com), Coraopolis City, and the continents of Africa, Asia, Australia, and Europe. ${ }^{29}$ The Michael Baker Jr. Inc., company domain is the principle domain for the MHMP Planning Team and its server is located in the City of Coraopolis. MHMP project website visits from the continents of Africa, Asia, Australia, and Europe are typically spam related and are excluded from GA.

\subsubsection{MHMP Project Website Knowledge}

Survey responses indicate that nearly three quarters of the survey participants knew about the MHMP project website as shown in Table 5-10. This shows that the promotion of the MHMP project website to the public was a success.

Table 5-10: MHMP Project Website Knowledge

\begin{tabular}{|c|c|}
\hline Response & Count \\
\hline Yes & 17 \\
\hline No & 6 \\
\hline
\end{tabular}

As shown in Table 5-11, nearly half of the survey participants source information on Solano County's general planning projects through the Solano County website at www.SolanoCounty.com. Another popular source of information is public notices. Limited survey participants source information through social media tools.

\footnotetext{
${ }^{28}$ Google. "Enterprise-Class Web Analytics Made Smarter, Friendlier and Free." http://www.google.com/analytics/ (accessed October 24, 2011).

${ }^{29}$ Kate Marek, "Chapter 3: Installing and Configuring Google Analytics," Library Technology Reports 47, no. 5 (July 2011 ): 17. Academic Search Premier, EBSCOhost (accessed August 7, 2011).
} 
Table 5-11: Source of Information for Solano County General Planning Projects

\begin{tabular}{|c|c|}
\hline Response & Count \\
\hline Solano County Website & 11 \\
\hline Public Notices & 9 \\
\hline Do not Source Information & 4 \\
\hline Social Media Tools & 1 \\
\hline
\end{tabular}

Eight survey participants had other responses including:

- Notified by the County - we are a government agency

- Newspaper and word of mouth

- Notices mailed to district

- Emails

- Word of Mouth

- Solano County Planning Department

- Directly from Solano County staff

- Helped create the MHMP planning project

As shown in Table 5-12, over half of the survey participants learned about the MHMP project website through word of mouth, public notices, and through the Solano County website. Survey participants did not learn about the MHMP project website through the MHMP social media tools.

Table 5-12: How Survey Participants Learned about the MHMP Project Website

\begin{tabular}{|c|c|}
\hline Response & Count \\
\hline Word of Mouth & 13 \\
\hline Public Notice & 5 \\
\hline Solano County Website & 2 \\
\hline MHMP Facebook Fan Page & 0 \\
\hline MHMP Twitter Page & 0 \\
\hline
\end{tabular}

Five survey participants had other responses including:

- Advised at staff meetings about the MHMP

- Through my job at the fire department

- Email

- Initial email from MHMP Planning Team

- Directly involved in the revision

Survey responses demonstrate they the public learn about Solano County's general planning projects through the Solano County website, public notices, and word of mouth. This highlights that these methods of communication are valid methods for promoting Solano County's planning projects and increasing public outreach and participation in the MHMP planning project. In addition, survey 
responses demonstrate the influence of communication between Solano County's governmental departments.

\subsubsection{MHMP Project Website Visits}

As shown in Figure 5-1, from August 1, 2011 to March 31, 2012, there were 474 visits to the MHMP project website. During this period, the MHMP project website had 325 new visitors and 149 returning visitors. Survey participants visited the MHMP project website on numerous occasions.

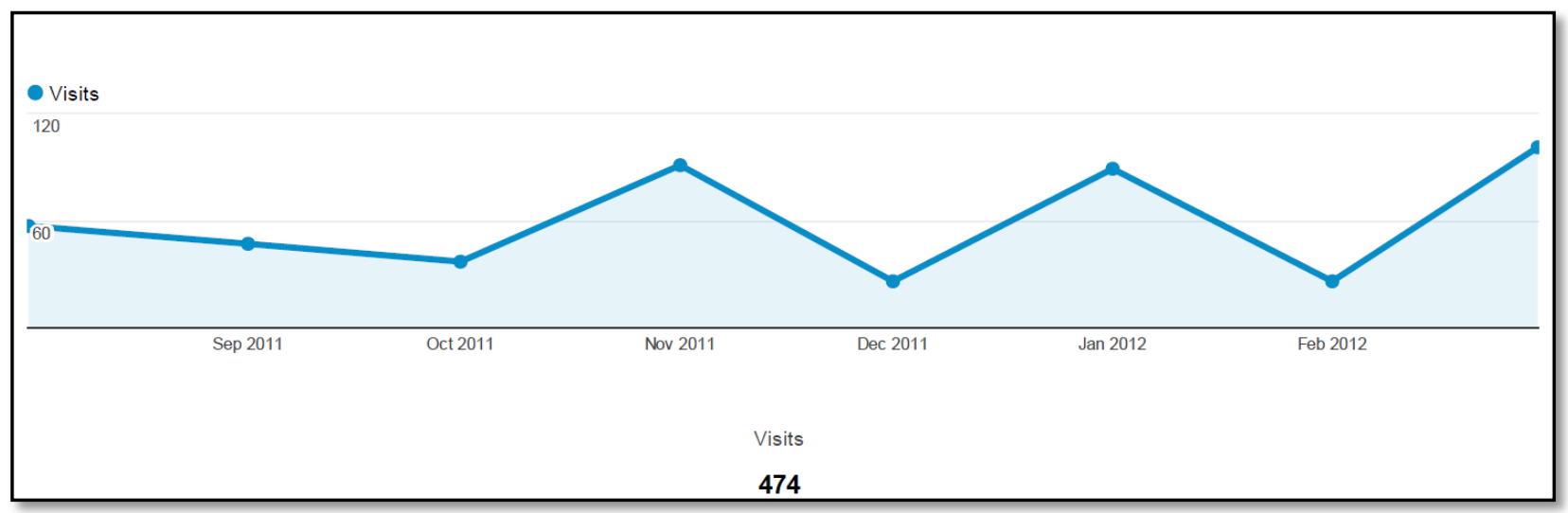

Figure 5-1: MHMP Project Website Visits per Month

Figure 5-1 illustrates that certain key events during the MHMP planning project increased visits to the MHMP project website. The first and third spike in MHMP project website visits occurred during November 2011 and March 2012. This is possibly due to the promotion of the MHMP public workshops through public notices, emails, and posting information to the Solano County website, MHMP project website, MHMP Facebook fan page, and MHMP Twitter page. These spikes suggest that information on the MHMP project website should be uploaded at key events during the MHMP planning project. Key events need to be chosen before the commencement of the MHMP planning project to ensure the MHMP project website is viewed during these events. The second spike in MHMP project website visits is possibly due to Mr. David Cliché of the Solano County Department of Resource Management and MHMP Project Manager emailing the MHMP Steering/Planning Committee members requesting their review of the MHMP project website mitigation action tables.

\subsubsection{MHMP Project Website Visit Duration}

As shown in Figure 5-2, from August 1, 2011 to March 31, 2012, the MHMP project website average visit duration is 4 minutes 16 seconds. The longest MHMP project website average visit duration is in September 2011, at 16 minutes 40 seconds. The second longest average visit duration is in March 2012, at 5 minutes 2 seconds. Increasing MHMP project website average visit duration relates to increasing public participation in the MHMP planning project. 


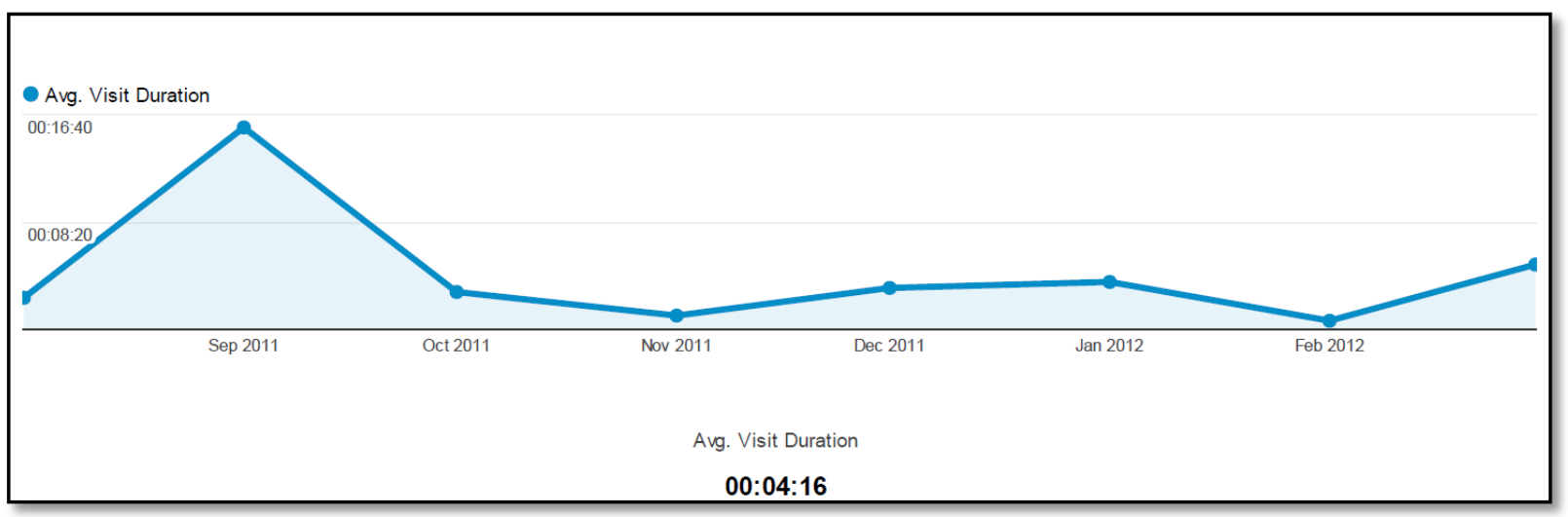

Figure 5-2: MHMP Project Website Average Visit Duration

The increase in MHMP project website average visit duration in September could be due to the MHMP Planning Team calling MHMP Steering/Planning Committee members. With input from the Solano County government officials, in September 2011, the MHMP Planning Team identified key stakeholders in the MHMP planning project. The MHMP Planning Team called 80 members of the public with information on the MHMP planning project and provided them an opportunity to become a MHMP Planning Committee member. Included in the information provided by the MHMP Planning Team during these phone calls was the MHMP project website domain. In March 2012, the MHMP Planning Team called 30 MHMP Steering/Planning Committee members, asking them to complete the MHMP mitigation action tables posted to the MHMP project website. The MHMP mitigation action tables took approximately 5 minutes to complete. The GA report analysis suggests that the MHMP Planning Team could increase public outreach and participation by requesting the completion of forms pertaining to the MHMP planning project on the MHMP project website.

\subsubsection{MHMP Project Website Tab Views}

The number of MHMP project website tabs views from August 12011 to March 31, 2012, is 1,401 as shown in Figure 5-3. This GA report illustrates that the numbers of tab views increases at various times during the MHMP planning project. Throughout the MHMP planning project, additional information was added to the MHMP project website. In November 2011 and March 2012, there is a spike in the number of tab views. This is possibly due to uploading MHMP public workshop information to the MHMP project website. In January 2012, the spike in views is probably due to the creation of the MHMP mitigation action table tab. This GA report illustrates that when information is posted to the MHMP project website, tab views increase. The MHMP Planning Team needs to ensure that a link is included on each MHMP project website tab to other relevant tab(s). This encourages the public to visit additional MHMP project website tabs. 


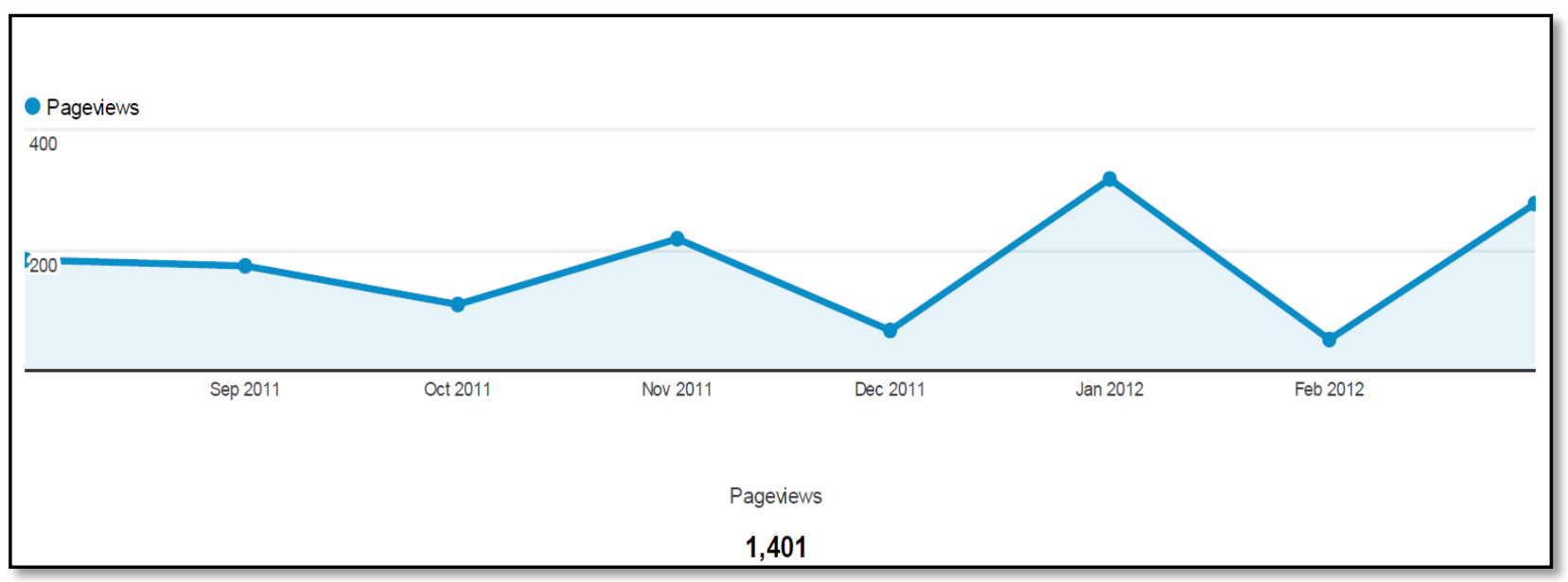

Figure 5-3: MHMP Project Website Page Views

Starting with the webpage with the highest number of views, the top 10 MHMP project website tabs viewed from August 1, 2011 to March 31, 2012, are listed in Table 5-13. This GA report is a great indication on the type of information viewed by the public. It provides insights on how the MHMP Planning Team can improve the MHMP project website to be more engaging to the public.

Table 5-13: MHMP Project Website Top 10 Webpages

\begin{tabular}{|c|l|c|}
\hline Ranking & \multicolumn{1}{|c|}{ Webpage } & Views \\
\hline 1 & $\underline{\text { http://www.SolanoCountyMHMP.org }}$ & 428 \\
\hline 2 & $\underline{\text { http://www.SolanoCountyMHMP.org/Announcements }}$ & 155 \\
\hline 3 & $\underline{\text { http://www.SolanoCountyMHMP.org/Document-Downloads }}$ & 140 \\
\hline 4 & $\underline{\text { http://www.SolanoCountyMHMP.org/2012-Draft-MHMP-Update }}$ & 86 \\
\hline 5 & $\underline{\text { http://www.SolanoCountyMHMP.org/Resource-Center }}$ & 78 \\
\hline 6 & $\underline{\text { http://www.SolanoCountyMHMP.org/About-the-Project }}$ & 75 \\
\hline 7 & $\underline{\text { http://www.SolanoCountyMHMP.org/Mitigation-Action-Tables }}$ & 65 \\
\hline 8 & $\underline{\text { http://www.SolanoCountyMHMP.org/What-is-Hazard-Mitigation }}$ & 61 \\
\hline 9 & $\underline{\text { http://www.SolanoCountyMHMP.org/Contact-Us }}$ & 58 \\
\hline 10 & $\underline{\text { http://www.SolanoCountyMHMP.org/Document-Downloads/Hazard-Maps }}$ & 35 \\
\hline
\end{tabular}

At 428 views, the MHMP project website homepage has the most views. The MHMP project website homepage is one of the key elements for engaging the public in the MHMP planning project. The homepage needs to be appealing to the public for them to view additional MHMP project website tabs. One method of analyzing the effectiveness of the MHMP project website homepage is the bounce rate. The bounce rate corresponds to the percentage of visitors who enter the MHMP project website and leave rather than viewing additional MHMP project website tabs. The MHMP project website homepage average bounce rate from August 1, 2011 to March 31, 2012, is 50.6 percent. This bounce 
rate is within industry standards. ${ }^{30}$ This illustrates that the MHMP project website homepage is engaging enough for the public to view additional MHMP project website tabs.

The Announcement tab is the second most viewed tab on the MHMP project website, with 155 views. The Announcement tab includes two to three sentences on various topics during the MHMP planning project. These short but informative announcements update the public on events during the MHMP planning project, including Hazard Fortnights and MHMP public workshop information. Compared to other MHMP project website tabs, the Announcement tab is a component of the MHMP project website homepage. This could explain why this tab has the second most views by the public.

At 140 views, the Document Download tab is the third most viewed tab on the MHMP project website. This tab is a key component of the MHMP planning project. It contains information on MHMP Steering/Planning Committee meetings and MHMP public workshops. It informs the public on the progress of the MHMP planning project and decisions made at MHMP Steering/Planning Committee meetings, which could potentially affect them. In addition, it provides the ability to download documents relevant to the development of the MHMP document. The high number of views of this tab suggests that the public was engaged throughout the MHMP planning project and the MHMP Planning Team should continue to upload information/documents to this tab.

The fourth tab on the MHMP project website with the most views is the 2012 Draft MHMP Update tab, with 86 views. This tab was meant to include the final MHMP document, but as of March 31, 2012, it was not uploaded. By not uploading the MHMP document, the MHMP Planning Team missed a key opportunity to engage the public in the MHMP planning project. Misleading the public by not uploading information they think will be included on the tab could potentially encourage the public to exit the MHMP project website. MHMP project website tabs should not be created unless information is uploaded to them. If a tab needs to be included without the relevant information, it should always include a link to another MHMP project website tab that may be of interest to the public.

The Resource Center tab is the fifth most viewed tab on the MHMP project website, with 78 views. This tab provides links to planning documents pertinent to the MHMP planning project. These documents include but not limited to the 2006 Solano County MHMP, the 2008 Solano County GP, and FEMA's MHMP How to Guides. The high number of views of this tab indicates that the public wants to review background information on the MHMP planning project and not just the final 2012 Solano County MHMP Update document.

The About the Project tab is the sixth most viewed tab on the MHMP project website, with 75 views. This information indicates that the public wants to learn background information on the MHMP planning project. This tab could be improved upon by including an image of a MHMP project timeline and information on natural hazards affecting Solano County. Links to other MHMP project website tabs should be included on this tab.

\footnotetext{
30 Matt Quinn. "How to Reduce Your Website's Bounce Rate". http://www.inc.com/guides/2011/01/how-to-reduce-yourwebsite-bounce-rate.html. (accessed April 22, 2012).
} 
The Mitigation Action Table tab is the seventh most viewed tab on the MHMP project website, with 65 views. In consultation with the MHMP Steering Committee, the MHMP Planning Team identified the MHMP mitigation actions. The MHMP Mitigation Action Tables are available for public review and comment and include a prioritization process. The MHMP Planning Team highlighted this tab at the MHMP Steering/Planning Committee meetings and Mr. Cliché followed up by emailing committee members requesting their input on these tables. These actions could explain the high number of views.

The What is Hazard Mitigation? tab is the eighth most viewed tab on the MHMP project website, with 61 views. For members of the public who are unfamiliar with the term hazard mitigation, this tab provides information to help them understand it and the MHMP planning project. To further aid the public in understanding hazard mitigation, information on existing hazard mitigation projects currently taking place in Solano County should be included on this tab.

The Contact Us tab is the ninth most viewed tab on the MHMP project website, with 58 views. This tab provides an avenue for the public to contact the MHMP Planning Team by completing a form. Completing a form could potentially put off members of the public from contacting the MHMP Planning Team as it may be viewed as time consuming and difficult to complete. To facilitate ease of communication with the MHMP Planning Team, a contact us button should be placed on the MHMP project website homepage, since it receives the most views. The placement of the contact us button could be under the Facebook and Twitter buttons on the left hand side of the MHMP project website homepage.

The Hazard Maps tab is the tenth most viewed tab on the MHMP project website, with 35 views. This tab contains maps of natural hazards affecting the unincorporated areas of Solano County. These hazards maps were developed with input from the MHMP Steering/Planning Committee members and the public. Members of public were encouraged on numerous occasions to review and provide comments on the hazard maps, as the information depicted could directly affect their community.

The survey responses match the MHMP project website GA report. As shown in Table 5-14, approximately half of the survey participants reviewed the MHMP hazard maps and MHMP mitigation action tables on the MHMP project website. Additionally, survey participants reviewed the resource center documents, MHMP Steering/Planning Committee documents, and MHMP public workshop information documents.

Table 5-14: MHMP Project Website Reviewed Documents

\begin{tabular}{|c|c|}
\hline Response & Count \\
\hline MHMP Hazard Maps & 13 \\
\hline MHMP Mitigation Action Tables & 11 \\
\hline Resource Center & 9 \\
\hline MHMP Steering/Planning Committee Documents & 8 \\
\hline MHMP Public Workshop Information & 7 \\
\hline
\end{tabular}


It is important to note that some of the MHMP project website tabs were created at different steps of the MHMP planning process. Seven of the top 10 visited MHMP project website tabs were created at the commencement of the MHMP planning project. The Document Downloads tab (number 3) was created in September 2011 and was updated continuously throughout the MHMP planning project. The Hazards Maps tab (number 10) was created in December 2011 and the Mitigation Action Table tab (number seven) was created in February 2012. These two tabs are the most important tabs of the MHMP planning project, since public outreach and participation are necessary for verifying the risk assessment results and creating suitable mitigation actions. Since these two tabs were created during the MHMP planning project and not at the commencement of the MHMP planning project, it demonstrates that the public were engaged throughout the MHMP planning project. Widgets to these two tabs should be located on the MHMP project website homepage. Including these widgets could potentially decrease the MHMP project website bounce rate.

\subsubsection{MHMP Project Website Smart Phone Access}

At 426 visits, the majority of visitors accessed the MHMP project website through a computer. Only 48 visitors accessed it from a smart phone. As shown in Table 5-15, nearly three quarters of the survey participants used a work computer to access the MHMP project website. Limited survey participants used a home computer and a smart phone. Survey participants did not access the MHMP project website utilizing an iPad.

Table 5-15: MHMP Project Website Methods of Access

\begin{tabular}{|c|c|}
\hline Response & Count \\
\hline Computer (Work) & 17 \\
\hline Computer (Home) & 1 \\
\hline Smart Phone & 1 \\
\hline iPad & 0 \\
\hline
\end{tabular}

Survey responses indicate that the public are only engaged in the MHMP project website during normal business hours (Monday to Friday 9.00am to $5.00 \mathrm{pm}$ ). This does not take into account the fact that some MHMP Steering/Committee members and public may take a work computer home with them and check the MHMP project website outside of these hours. Based on this information, the optimal time for updating the MHMP project website, MHMP Facebook fan page, and MHMP Twitter page is during normal business hours. Literature indicates that when you post information online is as important as what you post. The majority of the MHMP project website information was posted during normal business hours, but approximately $90 \%$ of the MHMP Facebook fan page and MHMP Twitter page information was posted after $6.00 \mathrm{pm}$ and on weekends. Posting information to the MHMP social media tools during non-critical times/days may have contributed to the low public engagement of the MHMP social media tools.

\subsubsection{MHMP Project Website Traffic Source}

As shown in Table 5-16, the MHMP project website traffic came from various web sources. At 231 visits, the main traffic source is direct through www.SolanoCountyMHMP.org. Additionally, numerous search 
engines are traffic sources for the MHMP project website. These include www.Bing.com, www.Google.com and www.Yahoo.com. The only social media tool traffic source is www.Facebook.com, at 29 visits.

Table 5-16: MHMP Project Website Traffic Source

\begin{tabular}{|c|l|c|c|}
\hline Ranking & \multicolumn{1}{|c|}{ Traffic Source } & Visits & Percentage \\
\hline 1 & www.SolanoCountyMHMP.org & 231 & $49.0 \%$ \\
\hline 2 & www.Google.com & 86 & $18.1 \%$ \\
\hline 3 & www.SolanoCounty.com & 77 & 16.2 \\
\hline 4 & www.Facebook.com & 29 & $6.1 \%$ \\
\hline 5 & www.Yahoo.com & 16 & $3.4 \%$ \\
\hline 6 & www.Bing.com & 10 & $2.0 \%$ \\
\hline 7 & www.Compass.Mbakercorp.com & 7 & $1.5 \%$ \\
\hline 8 & www.Comcast.com & 3 & $0.6 \%$ \\
\hline 9 & www.Forex-Ninjas.com & 3 & $0.6 \%$ \\
\hline 10 & www.SlowzFoodOttawaGatineau.org & 2 & $0.4 \%$ \\
\hline 11 & www.TheReporter.com & 2 & $0.4 \%$ \\
\hline
\end{tabular}

The largest traffic source is direct, demonstrating that the MHMP project website URL was easy for the public to remember. To increase the effectiveness of the MHMP branding and decrease areas of ambiguity, the MHMP project website URL should end with the same URL as the Solano County website. Solano County website ends with dot com, compared to the MHMP project website, which ends in dot org. The GA metric results illustrate again, how important the Solano County's website is for promoting the MHMP planning project to the public. By nearly 30 times, Facebook was more effective in promoting the MHMP project website than Twitter. This highlights that Facebook is the social media tool of choice for the public. Additionally, this information illustrates that having the MHMP project website appear at the top of search results in search engines is important. This can be accomplished by utilizing search engine optimization (SEO). ${ }^{31}$ SEO is the process of improving the visibility of the MHMP project website in search engine results. Traffic sources from the websites www.Forex-Ninjas.com and www.SlowzFoodOttawaGatineau.org are spam and should be filtered in future MHMP project websites GA reports and metrics. ${ }^{32}$

\subsubsection{MHMP Project Website Visitor Language}

English was the predominant MHMP project website visitor language at 461 visits. Of the 13 remaining visits, 10 did not set their language, and one visitor spoke German, Spanish, and Zulu. Each of the 24 survey participants speaks English. This figure does not correspond to the demographics of Solano County. In 2010, among residents at least five years old living in Solano County, 30 percent spoke a language other than English. Of those residents, speaking another language, 55 percent spoke Spanish

\footnotetext{
31 Google. "Search Engine Optimization Starter Guide". http://static.googleusercontent.com/external content/untrusted dlcp/www.google.com/en/us/webmasters/docs/searchengine-optimization-starter-guide.pdf. (accessed April 30, 2012).

32 Martin Jarvis. "Forex Ninjas in your Analytics? - You have Referrer Spam!". http://dmjcomputerservices.com/blog/2012/01/13/forex-ninjas-in-your-analytics-you-have-referrer-spam/. (accessed April 30, 2012).
} 
and 45 percent spoke another language. ${ }^{33}$ Survey responses demonstrate that the residents speaking Spanish and other languages in Solano County were not engaged in the MHMP planning project.

\subsubsection{MHMP Online Tools City of Access}

Visitors to the MHMP project website are from 102 cities in the United States. Starting with the city with the largest number of MHMP project website visits, the top 20 cities are shown in Table 5-17. Visitors to the MHMP project website are from 11 counties. Over half the cities are located in one of the nine Bay Area Counties. Bay Area Counties include Alameda, Contra Costa, Marin, Napa, San Francisco, San Mateo, Santa Clara, and Sonoma County. Sacramento County and Solano County each have five cities in the top 20 list.

Table 5-17: Top 20 Cities MHMP Project Website Visits

\begin{tabular}{|c|l|c|l|c|}
\hline Ranking & \multicolumn{1}{|c|}{ City } & Visits & \multicolumn{1}{c|}{ County } & Bay Area County \\
\hline 1 & Fairfield & 97 & Solano & Yes \\
\hline 2 & San Francisco & 62 & San Francisco & Yes \\
\hline 3 & Washington & 41 & Washington & No \\
\hline 4 & Vacaville & 34 & Solano & Yes \\
\hline 5 & Oakland & 18 & Alameda & Yes \\
\hline 6 & Sacramento & 15 & Sacramento & No \\
\hline 7 & San Jose & 14 & San Jose & Yes \\
\hline 8 & Vallejo & 10 & Solano & Yes \\
\hline 9 & Stockton & 7 & Sacramento & No \\
\hline 10 & Windsor & 7 & Sonoma & Yes \\
\hline 11 & Davis & 6 & Sacramento & No \\
\hline 12 & Napa & 6 & Napa & Yes \\
\hline 13 & San Diego & 6 & San Diego & No \\
\hline 14 & Carmichael & 5 & Sacramento & No \\
\hline 15 & Ontario & 5 & Ontario & No \\
\hline 16 & Rancho Cordova & 5 & Sacramento & No \\
\hline 17 & Benicia & 4 & Solano & Yes \\
\hline 18 & Suisun City & 4 & Solano & Yes \\
\hline 19 & West Sacramento & 4 & Yolo & No \\
\hline 20 & Berkeley & 4 & Alameda & Yes \\
\hline
\end{tabular}

As shown in Table 5-18, over half of the survey participants live in the incorporated areas of Solano County and eight survey participants live in one of the other Bay Area counties.

${ }^{33}$ Ibid. 
Table 5-18: MHMP Survey Participants Residence

\begin{tabular}{|c|c|}
\hline Response & Count \\
\hline Solano County (Incorporated Areas) & 14 \\
\hline Solano County (Unincorporated Areas) & 1 \\
\hline Bay Area County & 8 \\
\hline Yolo County & 4 \\
\hline Placer County & 1 \\
\hline
\end{tabular}

The MHMP planning area is the unincorporated areas of Solano County. Survey responses illustrate that only one survey participant was engaged in the MHMP planning project from the MHMP planning area. As per GA metrics, Solano County has the most cities where MHMP project website visitors reside in. This suggests that the MHMP project website has limited impact in the MHMP planning area but is influential in the surrounding cities. One possible reason for a greater number of survey participants and MHMP project website visitors residing in the incorporated areas of Solano County is that the majority of government departments are located in these cities. The majority of the MHMP Steering/Planning Committee members work for Solano County's government departments. It is possible that these government staff members live near where they work. Possible reasons for Yolo County residents having interest in the MHMP planning project include:

- Yolo County is a neighboring County to Solano County.

- Many of the same natural hazards affecting Solano County affect Yolo County.

- Yolo County is updating its MHMP the same time as Solano County.

\subsubsection{Usefulness of MHMP Planning Project Online Information}

As shown in Table 5-19, nearly half of the survey participants found the MHMP project website a useful source of information on the MHMP planning project. Survey participants did not find the MHMP project website information unhelpful.

Table 5-19: MHMP Project Website Information Usefulness

\begin{tabular}{|c|c|}
\hline Response & Count \\
\hline 5 - very helpful & 11 \\
\hline 3 - neither helpful or unhelpful & 4 \\
\hline 1 - unhelpful & 0 \\
\hline
\end{tabular}

\subsection{MHMP Social Media Tools Data Analysis}

This section describes the MHMP social media tools limitations and usage, MHMP Facebook fan page Likes and shares, and MHMP Twitter page follows and retweets. Additionally, this section includes information on the relevant MHMP public outreach and participation survey responses.

\subsubsection{MHMP Social Media Tools Limitations}

Analyzing the MHMP Facebook fan page is limited, as Facebook restricts comprehensive data analysis to fan pages with more than 30 Facebook fan page Likes. In addition, the data analysis is limited as the MHMP project website was created using Google websites. Google websites does not provide the 
MHMP project website owner/developer the ability to add computer code to the MHMP project website to analyze MHMP Facebook fan page usership. Insight into the public's engagement of the MHMP Twitter page is limited to the amount of Twitter page followers and retweets.

\subsubsection{Social Media Tools Usage}

As shown in Table 5-20, over half of the survey participants use social media tools.

Table 5-20: Social Media Tools Usage

\begin{tabular}{|c|c|}
\hline Response & Count \\
\hline Yes & 14 \\
\hline No & 9 \\
\hline
\end{tabular}

As shown in Table 5-21, the majority of survey participants frequently use Facebook and a limited number of survey participants frequently use YouTube. Survey participants do not frequently use Flickr or Twitter.

Table 5-21: Social Media Tools Frequently Used

\begin{tabular}{|c|c|}
\hline Response & Count \\
\hline Facebook & 12 \\
\hline YouTube & 4 \\
\hline Flickr & 0 \\
\hline Twitter & 0 \\
\hline
\end{tabular}

Survey responses indicate that Facebook is the most popular social media tool among survey participants. This is not reflected in the number of Likes on the MHMP Facebook fan page, but is reflected in the MHMP project website traffic source information. One possible explanation for survey participants not frequently using Flickr and Twitter is that it may be blocked on work computers. Since 100 percent of survey participants stated they use a work computer to access the MHMP online tools, they may not have had the ability to use social media tools due to restrictions on access.

\subsubsection{MHMP Social Media Tools Knowledge and Visits}

As shown in Table 5-22, less than half of the survey participants knew about the MHMP Facebook fan page.

Table 5-22: MHMP Facebook Fan Page Knowledge

\begin{tabular}{|c|c|}
\hline Response & Count \\
\hline Yes & 5 \\
\hline No & 8 \\
\hline
\end{tabular}

As shown in Table 5-23, half of the survey participants learned about the MHMP Facebook fan page through word of mouth. Additional, two survey participants learned about it through the Solano County website and MHMP project website. Survey participants did not learn about the MHMP Facebook fan page through the MHMP Twitter page. 
Table 5-23: How Survey Participants Learned about the MHMP Facebook Fan Page

\begin{tabular}{|c|c|}
\hline Response & Count \\
\hline Word of Mouth & 3 \\
\hline Solano County Website & 2 \\
\hline MHMP Project Website & 1 \\
\hline MHMP Twitter Page & 0 \\
\hline
\end{tabular}

As shown in Table 5-24, only a small number of survey participants visited the MHMP Facebook fan page. Survey participants used a work computer to access the MHMP Facebook fan page

Table 5-24: MHMP Facebook Fan Page Vis
\begin{tabular}{|c|c|}
\hline Response & Count \\
\hline 5+ occasions & 1 \\
\hline $2-4$ occasions & 1 \\
\hline Once & 1 \\
\hline Never & 3 \\
\hline
\end{tabular}

As shown Table 5-25, the majority of survey participants did not know about the MHMP Twitter page. For the survey participants who did know about the MHMP Twitter page, they learned it through word mouth. Only one survey participant visited the MHMP Twitter page once and accessed it utilizing a work computer.

Table 5-25: MHMP Twitter Page Knowledge

\begin{tabular}{|c|c|}
\hline Response & Count \\
\hline Yes & 3 \\
\hline No & 10 \\
\hline
\end{tabular}

A high percentage of survey responses indicated that they do not know about the MHMP Facebook fan page and MHMP Twitter page. Compared to the MHMP project website, MHMP Facebook fan page and MHMP Twitter page visits were limited. Unlike the MHMP project website, they were not impacted by the different MHMP planning project key events. This illustrates that promoting the MHMP social media tools was not effective, even though Facebook and Twitter buttons are located on the MHMP project website and discussed at the MHMP Steering/Planning Committee meetings and MHMP public workshops. In addition, the public may not know what Facebook and Twitter are in general. Additional methods of promotion are required for the MHMP social media tools to be utilized by the public. Contrary to existing literature, the public did not access the MHMP social media tools utilizing smart phone technology.

\subsubsection{MHMP Social Media Tool Usefulness and Frequency}

Two survey participants found the MHMP Facebook fan page a useful source of information on the MHMP planning project. One survey participant found the MHMP Twitter page information neither helpful nor unhelpful. Survey participants did not find the MHMP social media tools information 
unhelpful. Three survey participants found the frequency of the MHMP Facebook fan page status updates to be just right. One survey participant found the frequency of the MHMP Twitter tweets to be just right. Survey responses indicate that the information posted by the MHMP Project Team to the MHMP social media tools was helpful to the MHMP Steering/Planning Committee members and public and posted at the right frequency.

\subsubsection{MHMP Facebook Fan Page Likes and Shares}

As of March 31, 2012, the MHMP Facebook fan page has eight Likes. Four survey participants (100 percent of survey responses) Liked the MHMP Facebook fan page. MHMP Facebook Fan page information was Liked eight times (approximately 4.7 percent of posted information) and shared four times (approximately 1.2 percent of posted information) by one Facebook user. MHMP Facebook fan pages private message recipients did not post the messages they received from the MHMP Facebook fan page to their Facebook fan pages.

\subsubsection{MHMP Twitter Page Follows and Retweets}

As of March 31, 2012, the MHMP Twitter page has 47 followers as shown in Table A.1-1. Federal, state and local agencies follow the MHMP Twitter page, which illustrates their increasing use of social media tools in public outreach and participation strategies. Of the two respondents to the MHMP Twitter page follow survey question, one followed the MHMP Twitter page, while the other did not. The MHMP Twitter page information was retweeted four times (approximately 1.8 percent of posted information) by two Twitter pages. These include the Fairfield CA News Twitter page (twice) and the Solano Library Twitter page (once). The MHMP Twitter page was mentioned four times by other Twitter pages. These Twitter pages include Earthquake Shakes, Personal Prep Inc, Totally Unprepared, and Travis Air Force Base.

\subsubsection{MHMP Social Media Tools Data Analysis Summary}

From the number of MHMP Facebook Fan Page Likes and survey responses, it appears that the MHMP Facebook fan page has limited impact on residents in the planning area and other interested stakeholders. Even though the same information was posted to the MHMP Twitter page, the MHMP Twitter page was five times more successful than the MHMP Facebook fan page. Posting to the MHMP Facebook fan page takes more time than posting to the MHMP Twitter page, as an associated weblink and photo are included with a Facebook fan page status update, compared to Twitter, which limits tweets to 140 characters. If the MHMP Facebook fan page has more than 30 Likes, the information gathered on the MHMP Facebook fan page insights can be very useful for analyzing the demographics of the MHMP Facebook fan page likes. The information posted to a MHMP Facebook fan page along with the other online tools can be tailored accordingly.

One of the goals of posting information to the MHMP social media tools was for information to be engaging enough that Facebook and Twitter users would be compelled to Like, share, and retweet the information. The data analysis demonstrates that the MHMP social media tool information needs to be more engaging to the public. Further analysis on the information posted to the MHMP social media tools is required to understand how to increase public engagement. 
Intentional Blank Page 


\section{Recommendations}

Based on the data analysis in Section 5, this section outlines additional recommendations for future MHMP public outreach and participation strategies, the MHMP project website, and MHMP social media tools. These recommendations can be utilized for any planning project similar to the MHMP.

\subsection{MHMP Public Outreach and Participation Future Strategy}

This section describes various recommendations the MHMP Planning Team can implement for future MHMP public outreach and participation strategies. These recommendations include identifying nearby MHMP planning projects, defining the role of the MHMP Steering/Planning Committee members, conducting surveys, utilizing email more frequently as a method of communication with the public, building on existing relationships the Agency has with residents in the MHMP planning area, and publishing MHMP planning project information in other languages.

\subsubsection{Nearby MHMP Planning Projects}

The MHMP Planning Team should check if nearby counties, cities, tribes, and/or special districts are updating their MHMPs at the same time. The MHMP Planning Team should reach out to these communities and possibly coordinate MHMP public outreach and participation strategies. Combining strategies could increase public outreach and participation in the MHMP planning project as additional resources would be available.

\subsubsection{MHMP Steering/Planning Committee Members Role}

For MHMP Steering/Planning Committee members to proactively participate in the MHMP planning project, they need to understand their role and obligations. The MHMP Planning Team should outline this information when they first contact possible committee members via phone and at each MHMP Steering/Planning Committee meeting.

\subsubsection{MHMP Survey}

A survey gauging the public's preferred methods of communication should be conducted at the commencement of the MHMP planning project. Survey responses will indicate the methods of communication to be utilized in a MHMP public outreach and participation strategy. By knowing the public's use of different tools, the MHMP Planning Team will ensure that the most effective methods of communication are utilized. This will save the MHMP Planning Team time and budget. In addition, surveys can enable the public to help identify natural hazards in the MHMP planning area, potential mitigation actions, and determine public's awareness of and preparedness levels for hazards and potential disasters.

\subsubsection{Email}

The data analysis highlights the effectiveness of utilizing email as a method of communication with the public and as a means of promoting the MHMP planning project. Email is a quick and easy method of communication and it is recommended that the MHMP Planning Team utilize this method of communication more extensively in future MHMP planning projects. The MHMP Planning Team should create and send a monthly email to the MHMP Steering/Planning Committee members and MHMP public workshop attendees, updating them on the progress of the MHMP planning project and other 
possible items of interest. This email could be a called the MHMP News Bulletin and designed to resemble a flyer.

\subsubsection{Existing Relationships}

To increase public outreach and participation in the MHMP planning project, the MHMP Planning Team should build on existing relationships the Agency has with residents in the MHMP planning area. The data analysis highlights that when Mr. Cliché contacts MHMP Steering/Planning Committee members, visits to the MHMP project website and particular tabs that required public input and review increases. Mr. Cliché has existing relationships with the MHMP Steering/Planning Committee members and public due to working on Solano County's planning projects for numerous years. The public is more likely to become involved in the MHMP planning project if there is name recognition of an individual and/or agency associated with the MHMP planning project. ${ }^{34}$

\subsubsection{Language}

With nearly 100 percent of the MHMP project website visitors speaking English, it is important to remember to analyze the audience in the MHMP planning area. In Solano County, 55 percent of the population is Spanish speaking. This percentage is not reflected in the data analysis. It is recommended that if a significant portion of the population in the MHMP planning area speaks other languages, the MHMP public outreach and participation tools should be made available in these languages. This supports the idea that it is not the volume of people who are involved in the MHMP planning project that is important, but the particular few who may have critical information pertaining to the MHMP planning project. ${ }^{35}$

\subsection{MHMP Project Website}

Based on survey responses, the Solano County website (www.SolanoCounty.com) played a key role for increasing public outreach and participation in the MHMP planning project. It is recommended that the MHMP Planning Team work more closely with Solano County's Communications Officer to promote the MHMP planning project on the County's website. Currently, the MHMP project website is a separate website from the Countys. The MHMP project website could be within the County's website, under the Office of Emergency Services and/or Planning Department webpage. In addition, a button should be located on Solano County's website homepage, linking it to the MHMP project webpage.

\subsection{MHMP Social Media Tools}

Based on the data analysis in Section 5, if Facebook and Twitter are to be used in a MHMP public outreach and participation strategy, promotion of these tools needs to be more effective. The data analysis highlights the public's limited knowledge of the MHMP social media tools. For survey participants who did know about these tools, the majority of them learned about them through word of mouth and the Solano County website. This proves the need to continue utilizing traditional method of communication along with social media tools to increase public outreach and participation in a MHMP planning project. In addition, before the commencement of a MHMP planning project, the MHMP Planning Team should discuss if social media tools are accessible on the Agency's computers.

\footnotetext{
34 Ibid.

35 Ibid.
} 


\section{Conclusion}

There is general agreement that utilizing online tools will increase public outreach and participation in a MHMP planning project. $^{36}$ This report demonstrates that by integrating traditional methods of communication with online tools, public outreach and participation increases. Utilizing social media tools increases public outreach and participation in a MHMP planning project, but the MHMP project website is the core of the MHMP planning project. The MHMP project website serves as the key avenue for public engagement in the MHMP planning project. Without the MHMP project website, the public outreach and participation in the MHMP planning project may be limited.

This report highlights that the MHMP public outreach and participation strategy is a three-step process. The first step is promoting the MHMP planning project utilizing traditional methods of communication such as word of mouth and press releases. The second step is engaging the public on the Agency's website, MHMP project website, and email. The third step is integrating social media tools into the MHMP public outreach and participation strategy.

One major concern for utilizing online and social media tools in a MHMP planning project is security issues. The MHMP Twitter account was hacked on April 6, 2012. The MHMP Twitter page received a message with a link from another Twitter page. The MHMP Planning Team opened the link, leading the hackers to obtain the MHMP Twitter page username and password. When utilizing online and social media tools in a MHMP planning project, the username and password should be different for each online and social media tool. The password should be regularly changed and more than one MHMP Planning Team member should have access to the MHMP online and social media tools usernames and passwords.

Finally, the amount of time spent posting information to the MHMP Facebook page and MHMP Twitter page was more than the time spent on other methods of communication due to the development of this report. This time was not cost-effective, as other methods of communication were more successful in engaging the public in the MHMP planning project. As outlined in FEMA's 381-6 guidance document, it is important to understand which method of communication will work based on the size of the targeted community. ${ }^{37}$ The population of the unincorporated areas of Solano County is 20,165 spread over a large geographical area. The failing of the social media aspect of the MHMP public outreach and participation strategy is that social media is largely used by younger people and those in the MHMP planning area are older and more attuned to the more traditional outreach methods. ${ }^{38}$ Utilizing social media tools in a MHMP planning project can be effective, just not with the particular demographic of Solano County.

For future MHMP public outreach and participation strategies, time and budget spent on each method of communication needs to reflect the amount of population in the MHMP planning area and the

\footnotetext{
${ }^{36}$ Alex Howard. "Emergency Social Data Summit Highlights the Role of Social Media During Crises." http://www.huffingtonpost.com/alexander-howard/emergency-social-data-sum b 682292.html (accessed August 6, 2011).

37 Ibid.

38 Ibid.
} 
potential effectiveness of public engagement through each tool. In addition, contrary to the literature, GA metrics did not reflect the public's increasing use of smart phone technology. This could be again due to the lack of population in the MHMP planning area and the demographics of its residents. This is valuable knowledge, as preparing the MHMP project website to be accessible by smart phone technology can be an expensive process. 


\section{Bibliography}

Boyer, Deborah. "From Internet to iPhone: Providing Mobile Geographic Access to Philadelphia's Historic Photographs and other Special Collections. "Reference Librarian 52, no. 1/2 (January 2011): $47-$ 56. Academic Search Premier, EBSCOhost (accessed August 7, 2011).

Day, D. "Citizen Participation in the Planning Process: An Essentially Contested Concept?" Journal of Planning Literature, 11(3), (1997): 421-434 (accessed September 6, 2011).

Dugan, Kevin. "Facebook Can Improve Your Media Relations." (2012). http://prblog.typepad.com/strategic public relation/2007/07/facebook-can-im.html (accessed October 24, 2011).

Federal Emergency Management Agency. "Getting Started: Building Support for Mitigation Planning." (September 2002). http://www.fema.gov/library/viewRecord.do?id=1867 (accessed June 10, 2011).

Federal Emergency Management Agency. "Local Multi-hazard Mitigation Planning Guidance." (July 1, 2008). http://www.fema.gov/library/viewRecord.do?id=3336 (accessed June 10, 2011).

Federal Emergency Management Agency. "Multi-Hazard Mitigation Planning." (2010).

http://www.fema.gov/plan/mitplanning/ (accessed September 10, 2011).

Federal Emergency Management Agency. "Resource Record Details Disaster Mitigation Act of 2000." (October 3, 2010). http://www.fema.gov/library/viewRecord.do?id=1935 (accessed September 10, 2011).

Forrestal, Valerie. "Making Twitter Work: A Guide for the Uninitiated, the Skeptical, and the Pragmatic." Reference Librarian 52, no. 1/2 (January 2011): 146-151. Academic Search Premier, EBSCOhost (accessed August 7, 2011).

Fox, Susannah and Amanda Lenhart. "Twitter and Status Updating, Spring 2009." Pew Internet \& American Life Project. (2009). http://www.pewinternet.org/Reports/2009/Twitter-and-statusupdating.aspx (accessed June 10, 2011).

Godschalk, David R, Samuel Brody, and Raymond Burby. "Public Participation in Natural Hazard Mitigation Policy Formation: Challenges for Comprehensive Planning." Journal of Environmental Planning \& Management 46, no. 5 (September 2003): 733-754. Academic Search Premier, EBSCOhost (accessed September 10, 2011).

Google. "Enterprise-Class Web Analytics Made Smarter, Friendlier and Free." http://www.google.com/analytics// (accessed October 24, 2011).

Google. "Search Engine Optimization Starter Guide". (2010). http://static.googleusercontent.com/external content/untrusted dlcp/www.google.com/en/us/webma sters/docs/search-engine-optimization-starter-guide.pdf (accessed April 30, 2012). 
Gonsalves, Antone. "Android Phone Steals Market Share." (April 7, 2010).

http://www.informationweek.com/news/mobility/smart phones/showArticle.jhtml?articlelD=2242017 $\underline{45}$ (accessed September 10, 2011).

Howard, Alex. "Emergency Social Data Summit Highlights the Role of Social Media During Crises."

(2011). http://www.huffingtonpost.com/alexander-howard/emergency-social-data-

sum b 682292.html (accessed August 6, 2011).

Howard, Alex. "Social Data and Geospatial Mapping Join the Crisis Response Toolset." (2011).

http://radar.oreilly.com/2011/01/esri-australia-ushahidi.html (accessed August 6, 2011).

Jarvis, Martin. "Forex Ninjas in your Analytics? - You have Referrer Spam!". (2012).

http://dmjcomputerservices.com/blog/2012/01/13/forex-ninjas-in-your-analytics-you-have-referrer-

spam/ (accessed April 30, 2012).

Kaplan, Andreas M and Michael Haenlein. "Users of the World, Unite! The Challenges and Opportunities of Social Media." BusinessHorizons v. 53, no. 1 (January/February 2010) p. 59-68. WilsonWeb, EBSCOhost (accessed July 8, 2011).

Lefcowitz, Jules. "Public Outreach: Marketing by Another Name." Journal of Housing \& Community Development 55, no. 2 (March 1998): 12. Academic Search Premier, EBSCOhost (accessed July 8, 2011).

Mangold, Glenn W and David Faulds J. "Social Media: The New Hybrid Element of the Promotion Mix." Business Horizons, 52(4), 357-65. WilsonWeb, EBSCOhost (accessed July 8, 2011).

Marek, Kate. "Chapter 3: Installing and Configuring Google Analytics." Library Technology Reports 47, no. 5 (July 2011): 17-25. Academic Search Premier, EBSCOhost (accessed August 7, 2011).

Marek, Kate. "Chapter 4: Reporting and Analysis." Library Technology Reports 47, no. 5 (July 2011): 26-

32. Academic Search Premier, EBSCOhost (accessed August 7, 2011)

National Archives and Records Administration. "A Report on Federal Web 2.0 Use and Record Value 2010." (2010). http://www.egov.vic.gov.au/website-practice/web-2-0-a/social-networks-and-socialmedia-in-government/a-report-on-federal-web-2-0-use-and-record-value-2010.html (accessed July 31, 2011).

Newton, Bruce J. 2001. "Environmental Education and Outreach: Experiences of a Federal Agency." BioScience 51, no. 4: 297. Academic Search Premier, EBSCOhost (accessed July 8, 2011).

Plaza, Beatriz. "Monitoring Web Traffic Source Effectiveness with Google Analytics." Aslib Proceedings 61, no. 5 (October 2009): 474-482. Academic Search Premier, EBSCOhost (accessed August 7, 2011).

Quinn, Matt. “How to Reduce your Website's Bounce Rate.” (2011).

http://www.inc.com/guides/2011/01/how-to-reduce-your-website-bounce-rate.html (accessed April 22, 2012). 
Solis, Brian. "14 Best Practices for Long-Term Social Media Success." (2011).

http://mashable.com/2011/04/28/14-best-practices-for-long-term-social-media-success/ (accessed August 7, 2011).

Solis, Brian. "21 Rules for Social Media Engagement." (2010). http://mashable.com/2010/05/18/rulessocial-media-engagment/ (accessed August 7, 2011).

Taylor, Dave. "Connect You to Humanity?" Phi Kappa Phi Forum 88, no. 4 (Winter 2008): 18-21. Academic Search Premier, EBSCOhost (accessed July 8, 2011).

U.S. Census Data. "2010 Census Data”. (2010). http://2010.census.gov/2010census/data/ (accessed May 6, 2012).

Wagenet, Linda P and Max J. Pfeffer. "Organizing Citizen Engagement for Democratic Environmental Planning." Society \& Natural Resources, 20, no. 9 (2007): 801-813. Academic Search Premier, EBSCOhost (accessed July 8, 2011).

Walling, Donovan R. "Idea Networking and Creative Sharing." TechTrends: Linking Research \& Practice to Improve Learning 53, no. 6 (November 2009): 22-23. Academic Search Premier, EBSCOhost (accessed July 8, 2011).

Waters, Richard D, Emily Burnett, Anna Lamm, and Jessica Lucas. "Engaging Stakeholders through Social Networking: How Nonprofit Organizations are Using Facebook." Public Relations Review 35, no. 2 (June 2009): 102-106. Academic Search Premier, EBSCOhost (accessed August 7, 2011).

Wikipedia. "Social Media." (2012). http://en.wikipedia.org/wiki/Social media (accessed May 6, 2012). 
Intentional Blank Page 
Appendix A. MHMP Facebook Fan Page 
Intentional Blank Page 
Table A.1-1: MHMP Facebook Fan Page Likes

\begin{tabular}{|c|c|c|c|c|c|c|c|}
\hline Federal Agency & State Agency & Local Agency & Interested Stakeholder & Local Media & Non-Profits & Special Interest & Geographical Location \\
\hline EPA - Water is Worth It & CAL FIRE & Bay Area Rapid Transit & $\begin{array}{l}\text { California Delta Chambers } \\
\text { and Visitors Bureau }\end{array}$ & The Reporter & American Planning Association & Dam failure & City of Fairfield, CA \\
\hline Bureau of Reclamation & Cal EMA & Dixon Fire Department & Discover Solano County & Vallejo Times-Herald & American Red Cross Bay Area & Earthquake Report & City of Vacaville \\
\hline EPA WaterSense & $\begin{array}{l}\text { California Department of Water } \\
\text { Resources }\end{array}$ & Fairfield Fire Department & $\begin{array}{l}\text { Northern Solano County } \\
\text { Association of REALTORS }\end{array}$ & & $\begin{array}{l}\text { California Delta Chambers and } \\
\text { Visitors Bureau }\end{array}$ & FireLink & $\begin{array}{l}\text { Downtown Vacaville } \\
\text { Official Facebook Page }\end{array}$ \\
\hline $\begin{array}{l}\text { Federal Emergency } \\
\text { Management Agency }\end{array}$ & California Earthquake Authority & $\begin{array}{l}\text { Fairfield Fire Department } \\
\text { Explorer Post } 8651\end{array}$ & $\begin{array}{l}\text { Rio Vista Chamber of } \\
\text { Commerce }\end{array}$ & & $\begin{array}{l}\text { California Earthquake } \\
\text { Authority }\end{array}$ & NFIP & Fairfield California \\
\hline $\begin{array}{l}\text { National Fire Protection } \\
\text { Association (NFPA) }\end{array}$ & $\begin{array}{l}\text { California Emergency Medical } \\
\text { Services Authority (EMSA) }\end{array}$ & Fairfield Fire Rescue & $\begin{array}{l}\text { Rio Vista Chamber of } \\
\text { Commerce }\end{array}$ & & $\begin{array}{l}\text { California Farm Water } \\
\text { Coalition }\end{array}$ & Smokey Bear & Fairfield, CA \\
\hline $\begin{array}{l}\text { National Oceanic and } \\
\text { Atmospheric Administration } \\
\text { (NOAA) }\end{array}$ & $\begin{array}{l}\text { California Farm Bureau } \\
\text { Federation }\end{array}$ & Fairfield Police Department & Solano Community College & & $\begin{array}{l}\text { California Foundation for } \\
\text { Agriculture in the Classroom } \\
\text { (CFAITC) }\end{array}$ & $\begin{array}{l}\text { Solano County } \\
\text { Dive/Rescue Team }\end{array}$ & $\begin{array}{l}\text { Solano County, } \\
\text { California }\end{array}$ \\
\hline National Park Service & $\begin{array}{l}\text { California Fire \& Rescue } \\
\text { Training Authority }\end{array}$ & $\begin{array}{l}\text { Fairfield Rural Fire } \\
\text { Department }\end{array}$ & Solano Connection & & CaliforniaVolunteers & Solano Fire & Suisun Valley \\
\hline NOAA Fisheries Service & California Fire Alliance & $\begin{array}{l}\text { Montezuma Fire Protection } \\
\text { District }\end{array}$ & $\begin{array}{l}\text { Solano County Black } \\
\text { Chamber of Commerce }\end{array}$ & & Central Valley Farmland Trust & $\begin{array}{l}\text { Solano Napa Commuter } \\
\text { Information }\end{array}$ & Vacaville, CA \\
\hline $\begin{array}{l}\text { San Francisco District, US } \\
\text { Army Corps of Engineers }\end{array}$ & $\begin{array}{l}\text { California Regional Fire } \\
\text { Academy }\end{array}$ & $\begin{array}{l}\text { Solano County Office of } \\
\text { Education }\end{array}$ & Solano County Business & & Delta Stewardship Council & $\begin{array}{l}\text { Specialized Fire and } \\
\text { Rescue Training Inc. }\end{array}$ & \\
\hline Travis Air Force Base & $\begin{array}{l}\text { California Seismic Safety } \\
\text { Commission }\end{array}$ & $\begin{array}{l}\text { Solano Deputy Sheriff's } \\
\text { Association }\end{array}$ & $\begin{array}{l}\text { Solano County Educational } \\
\text { Consortium (Cal-SOAP) }\end{array}$ & & Discover Solano County & $\begin{array}{l}\text { The Great California } \\
\text { ShakeOut }\end{array}$ & \\
\hline $\begin{array}{l}\text { U.S Environmental Protection } \\
\text { Agency }\end{array}$ & California State Parks & $\begin{array}{l}\text { Solano Transportation } \\
\text { Authority }\end{array}$ & Solano County Fairgrounds & & $\begin{array}{l}\text { Dixon Professional Firefighters } \\
\text { Association - IAFF Local } 4665\end{array}$ & $\begin{array}{l}\text { The Red Guide to } \\
\text { Recovery }\end{array}$ & \\
\hline $\begin{array}{l}\text { U.S. Army Corps of Engineers, } \\
\text { Headquarters }\end{array}$ & $\begin{array}{l}\text { California Task Force } 5 \text { - Urban } \\
\text { Search \& Rescue Team }\end{array}$ & Vacaville Fire Dept & $\begin{array}{l}\text { Solano County Firemen's } \\
\text { Association }\end{array}$ & & Fairfield Fire Rescue & Totally Unprepared & \\
\hline U.S. Coast Guard & & $\begin{array}{l}\text { Vacaville Fire Protection } \\
\text { District }\end{array}$ & Solano County Library & & $\begin{array}{l}\text { Fairfield Main Street } \\
\text { Association }\end{array}$ & & \\
\hline $\begin{array}{l}\text { U.S. Department of } \\
\text { Agriculture }\end{array}$ & & $\begin{array}{l}\text { Solano Transportation } \\
\text { Authority }\end{array}$ & Travis Air Force Base & & $\begin{array}{l}\text { Green Valley Agricultural } \\
\text { Conservancy }\end{array}$ & & \\
\hline U.S. Forest Service & & & $\begin{array}{l}\text { Vallejo Chamber of } \\
\text { Commerce }\end{array}$ & & $\begin{array}{l}\text { National Voluntary } \\
\text { Organizations Active in } \\
\text { Disaster (National VOAD) }\end{array}$ & & \\
\hline U.S. Geological Survey (USGS) & & & $\begin{array}{l}\text { Vallejo Convention and } \\
\text { Visitors Bureau }\end{array}$ & & $\begin{array}{l}\text { Solano County Educational } \\
\text { Consortium (Cal-SOAP) }\end{array}$ & & \\
\hline U.S. National Weather Service & & & & & Solano County Farm Bureau & & \\
\hline \multirow[t]{2}{*}{ USACE Sacramento District } & & & & & $\begin{array}{l}\text { Solano County Firemen's } \\
\text { Association }\end{array}$ & & \\
\hline & & & & & $\begin{array}{l}\text { The California State } \\
\text { Firefighters' Association }\end{array}$ & & \\
\hline
\end{tabular}




$$
\text { = }
$$




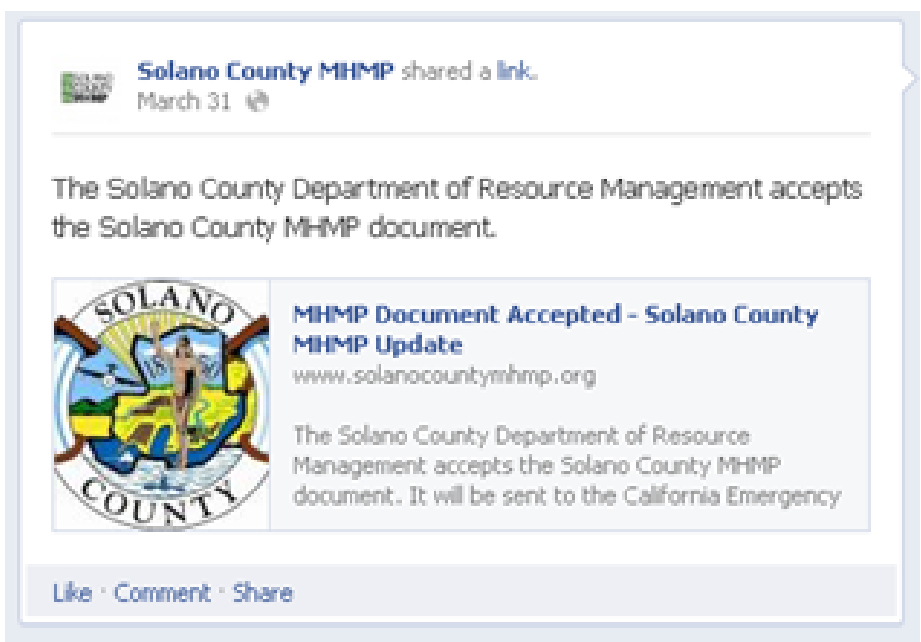

\begin{tabular}{|c|c|}
\hline \multicolumn{2}{|c|}{ 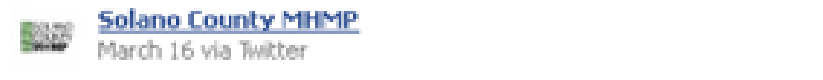 } \\
\hline \multicolumn{2}{|c|}{$\begin{array}{l}\text { Thanks to everyone who came to the Solano County MHMP Public } \\
\text { workshop last night. } \\
\text { פSolanoMHMP on Twitter ' via Tiutter }\end{array}$} \\
\hline \multicolumn{2}{|c|}{$\begin{array}{l}\text { Solano County MHMP } \\
\text { March } 15 \text { via Twetter }\end{array}$} \\
\hline \multicolumn{2}{|c|}{$\begin{array}{l}\text { Review hazard mitigation actions that could affect you and your' } \\
\text { family at the Solano County M-MP Public Workshop tonight. } \\
\text { GSolanomiMP on witter ' vis Twitter }\end{array}$} \\
\hline \multicolumn{2}{|c|}{$\begin{array}{l}\text { Solano County MHMP shared a link. } \\
\text { March } 14 \text { o }\end{array}$} \\
\hline \multicolumn{2}{|c|}{$\begin{array}{l}\text { Solano County MHMP Public Workshop picked by the Vacaville } \\
\text { Reporter! Check out the link. }\end{array}$} \\
\hline & $\begin{array}{l}\text { Public input sought on Solano County hazard } \\
\text { plan - The Reporter } \\
\text { www.thereporter.com } \\
\text { Solano Counky is in the process of updating its Multi- } \\
\text { Hazard Migation Flan that, seeks to reduce the } \\
\text { impacts of such natural disasters as flooding, }\end{array}$ \\
\hline \multicolumn{2}{|c|}{ Like - Comment ' Share } \\
\hline
\end{tabular}




\section{Solano County MHMP}

March 21 e

The Solano County Project Team are busy incorporating the public comments into the MHMP document!
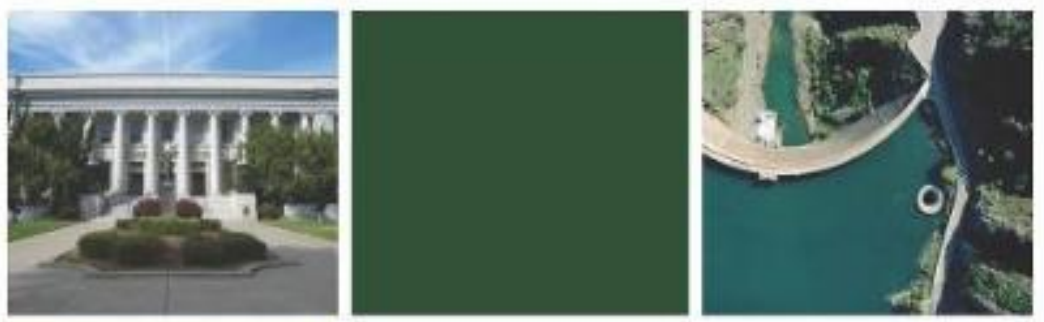

\section{SOLANO COUNTY} Local Muib-Harard Niticutation Plan

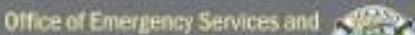
Department of Researce Mangestient of 6 Moreh 2022 ross
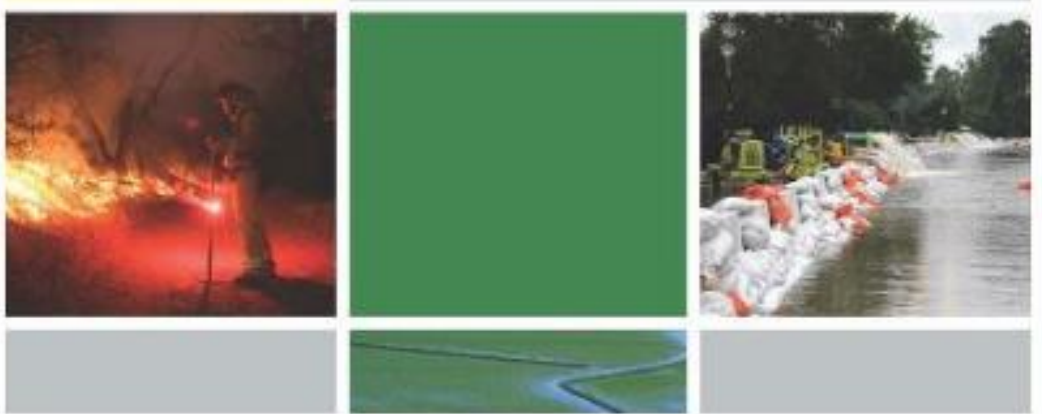

Like ' Comment ' Share

Solano County MHMP shared a link.

March 14 (a)

Solano County MHMP Public Workshop picked by the Vacaville Reporter! Check out the link.

Public input sought on Solano County hazard
plan - The Reporter
www.thereporter.com


Solano County MHMP

March 12 iे

Learn about natural hazards in your area today! Check out the Solano County MHMP Public Notice!
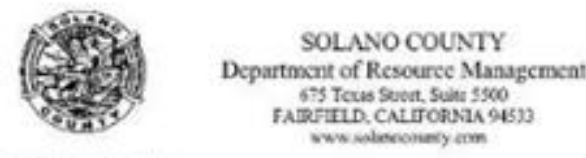

Public Notice:

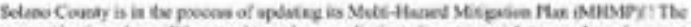

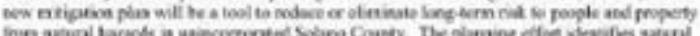

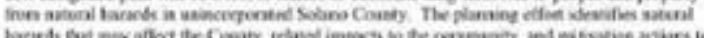

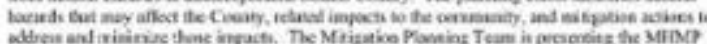

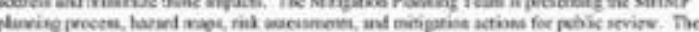

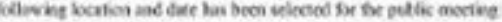

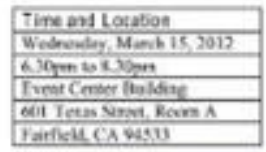

Farickic Costis

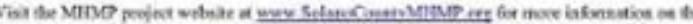

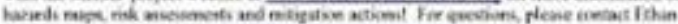
Motoy a

Like ' Comment Share

Solano County MHMP updated their cover photo.

March 10 e

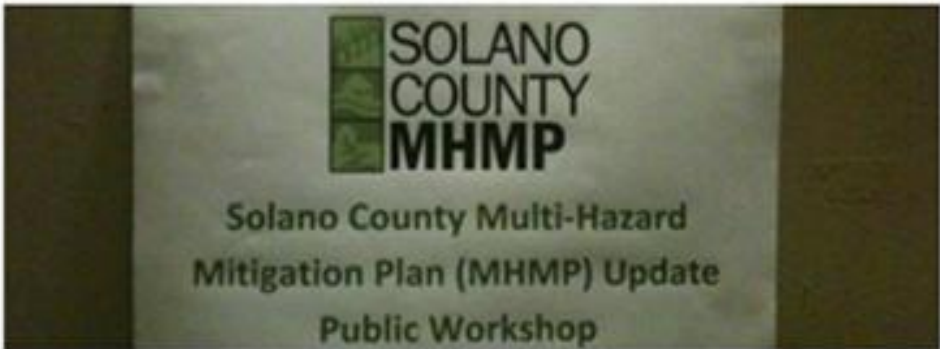

Like - Comment - Share 
Solano County MHMP shared a ink.

March 10 :

Solano County MHMP Public Workshop! The MHMP Planning Team is seeking public review of the hazards maps, risk assessments, and mitigation actions. Check out the MHMP website for more info!

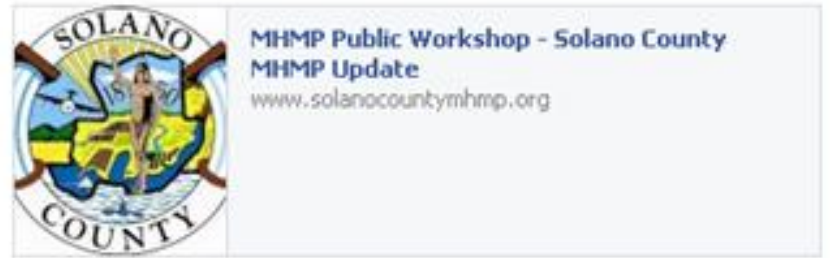

Like ' Comment - Share

Solano County MHMP shared a link vio Cal EMA.

March 5 ie

Today's Shaker Serves to Remind Californian's to Be Prepared for Emergencies

ow ly

"The following news release was issued by Cal EMA on Monday, March 5 , 2012.* MATHER - This morring's magnitude-4.0 earthquake on the Hayward fault is a reminder that all Calfornians need to...

Lke Comment share

\section{Solano County MHMP shared a link.}

March 4 (2)

The Solano County MHMP Project Team is busy preparing for the March 15, 2012 M-MP Public Workshop. More information to follow! in the meantime, click the link provided to view the Nov 2011 MHMP Public Workshop information.

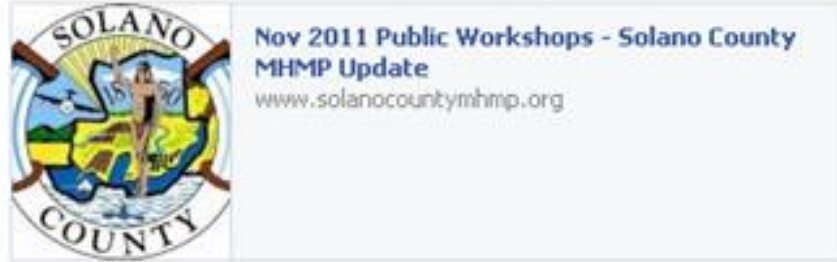

Uke + Comment - Share 


\section{Solano County MHMP}

Please email comments andior questions on the Solano County MHMP Hazard Maps to the MHMP Project Team at info@SolanoCountyMHMP,org.

Like ' Comment ' Share ' February 20 at 5:42pm ' o

Solano County MHMP added 11 new photos to the album Solano County MHMP Hazard Maps.

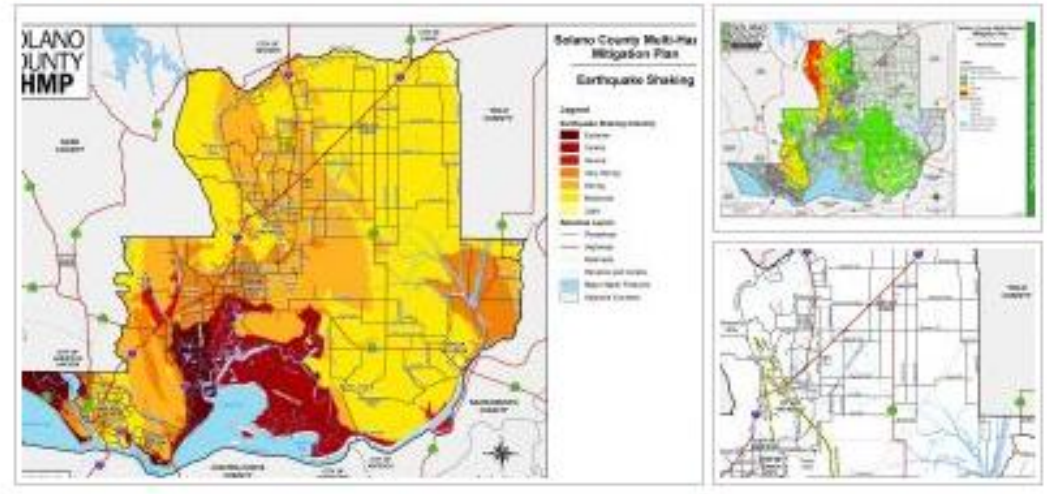

[1] Like ' Comment ' Share ' February 20 at 4:02pm ' (2)

Mark Scott likes this.

Write a comment...

\section{Solano County MHMP}

The MHMP Project Team are reviewing the 2006 Solano County MHMP mitigation actions.

\section{ABAG Hazard Mitigation Information}

www.abag.ca.gov

The above information is for the strategies and strategy priorities for the 2005

Local Hazard Mitigation Plan (LHMP) and Annexes.

f] Like ' Comment ' Share ' February 3 at 8:51am ' $\mathrm{O}$

\section{Solano County MHMP}

Free webinars on the new Community Rating System (CRS) in February! Solano County participates in CRS.

Click here to
dowwnloud
of all changes
PDF

Manual Change Webinars I The 2012 CRS Manual www.crs2012.org

We hope to have another round of webinars starting in February 2012. There will be a mix of sessions on general overviews of the approved changes and individual activities. We know well have one or more on 330 and the 600 series. We welcome suggestions for topics, and CRS users groups can also requ...

क] Like ' Comment ' Share ' January 26 at 9:26am ' 
Solano County MHMP added a new photo.

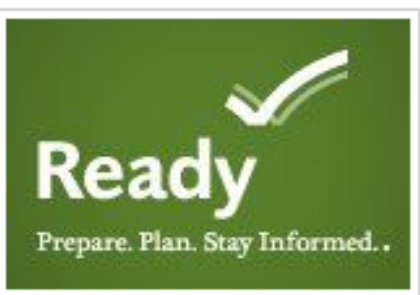

[1] Like ' Comment ' Reshare ' January 25 at 10:53am

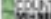

Solano County MHMP http://www, ready,govi

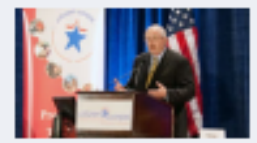

Home | Ready.gov

www,ready,gov

Ready, gov has a variety of publications for download covering various topics about planning and preparation for disasters and emergencies.

January 25 at 10:54am ' Like ' Remove Preview

Write a comment...

\section{Solano County MHMP}

Be prepared for a disaster! Join a Community Emergency Response Team (CERT).

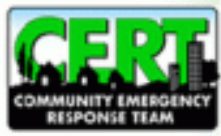

CERT : Community Emergency Response Teams (CERT)

www, citizencorps,gow

The Community Emergency Response Team (CERT) Program educates people about disaster preparedness for hazards that may impact their area and trains them in basic disaster response skills, such as fire safety, light search and rescue, team organization, and disaster medical operations. Using the train...

] Like ' Comment ' Reshare ' January 24 at 9:36pm

'S Mark Scott likes this.

\section{1 share}

Write a comment... 


\section{Solano County MHMP}

Keep up to date on fire events in Solano County: Listen to the Solano County Fire Live Audio Feed!

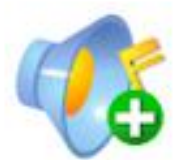

Solano County Fire 1 Live Scanner Audio Feed www.radioreference.com

Solano County Fire 1 Live Scanner Audio Feed on

RadioReference.com

o7] Like ' Comment ' Reshare ' January 23 at 9:56pm

\section{Solano County MHMP}

Check out the new iPad app from the CDC! Useful info on health related topics.

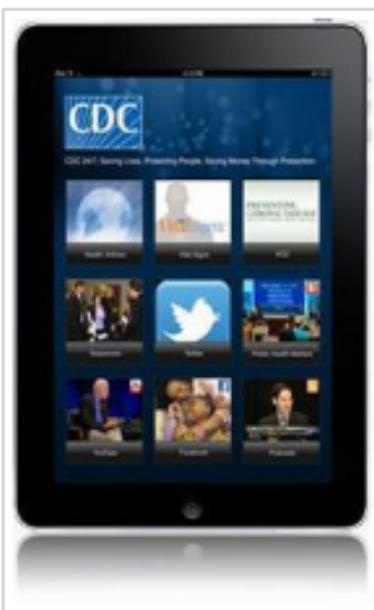

\section{Wall Photos}

Have an iPad? If so, get the new CDC app! Get current feature stories, breaking

See More

By: $C D C$

D] Like ' Comment ' Reshare ' January 23 at $3: 55 \mathrm{pm}$ 
Solano County MHMP via California Department of Water Resources

Yes \& No. Current water Conditions

www.water.ca.gov

Drought Portal

Like ' Comment ' Reshare ' Yesterday at 12:50pm

\section{Solano County MHMP}

Register today! Panel Discussion on Making the Bay Area Resilient to

Earthquakes, Jan 25, USGS Menlo Park, CA

8th Annual Northern California Earthquake Hazards Workshop

sslearthquake.usgs.gov

USGS Earthquake Hazards Program, responsible for monitoring, reporting, and

researching earthquakes and earthquake hazards

D] Like ' Comment ' Reshare ' Yesterday at 10:16am

\section{Solano County MHMP}

Improve the Bay Area's ability to recover from a major earthquake - Check out the Draft framework for the Bay Area Disaster Resilience Action Plan

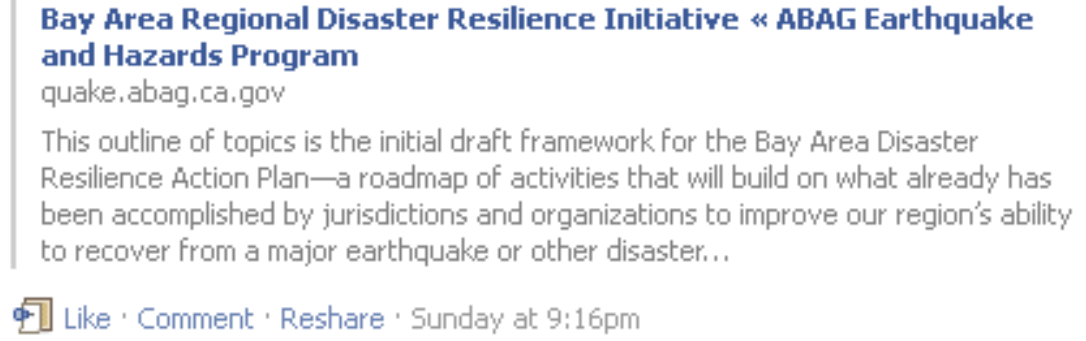




\section{Solano County MHMP}

Be prepared for weather storms. Check out this cool link from FEMA!

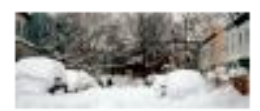

Winter Storms \& Extreme Cold | Ready.gov

whw, ready,gov

While the danger from winter weather varies across the country, nearly all Americans, regardless of where they live, are likely to face some type of severe winter weather at some point in their lives. Winter storms can range from a moderate snow over a few hours to a blizzard with blinding, wind-dri...

Like ' Comment ' Reshare ' January 18 at 6:00pm

Solano County MHMP via U.S. Geological Survey (USGS)

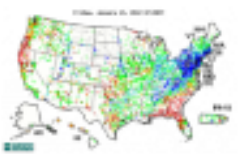

USGS WaterAlert

water.usgs.gov

USGS WaterÁlert

므 Like ' Comment ' Reshare ' January 13 at 5:29pm

Solano County MHMP shared a link.

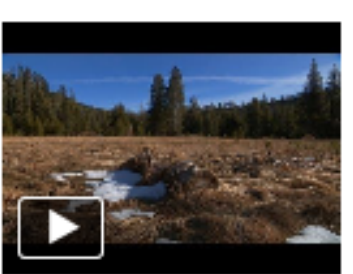

Dry Winter has CAL FIRE on Alert

www. youtube.com

The lack of rain across the state has lead to one

of the driest winters on record. Watch this video

for more on what this dry weather means for

California's...

缉职 Like ' Comment ' Reshare ' January 12 at 9:45pm

Solano County MHMP

Social Media: A Seismic Opportunity!

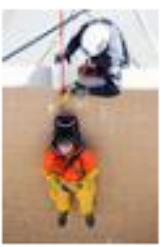

Social Media: A Seismic Opportunity

calemanews,wordpress.com

*The following article is a Cal EMA contribution to the Domestic

Preparedness Journal. The article was printed on Wednesday,

January 11, 2012.* On 23 August 2011, a 5.9-magnitude earthquake struck...

क] Like ' Comment ' Reshare ' January 12 at 7:35pm

\section{Solano County MHMP}

Be prepared for a natural disaster! Use this toolkit from Cal EMA today!

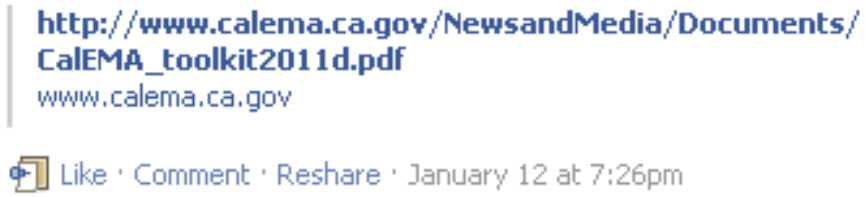




\section{Solano County MHMP}

Be prepared for a natural disaster! Use this toolkit from Cal EMA today!

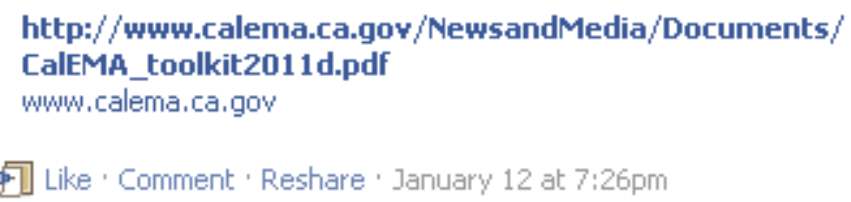

\section{Solano County MHMP via Federal Emergency Management Agency} The Solano County MHMP Planning Team are using FEMA's Preparedness iPhone App! You should too!

FEMA Blog: There's an App for That

blog,fema.gov

After we launched the App for Android devices, we received feedback from users and have made some updates to the version for Apple devices. One of the things that people said is that the popup box in the map section was cumbersome on a phone's small screen, so we:

D] Like ' Comment ' Reshare ' January 8 at 2:11pm

\section{Solano County MHMP}

Solano County Office of Emergency Services (OES) informs residents on how to prepare for an earthquake!

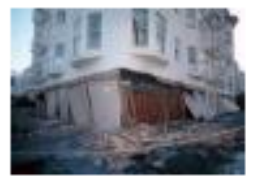

\section{Solano County - Earthquake}

admin.solanocounty, com

With some basic planning and thinking ahead, preparing your

home or workplace for an earthquake is easy. These tips on what to do before, during and after an earthquake may help save you or your loved ones the next time around.Before An Earthquake

of Like ' Comment ' Reshare ' January 8 at $12: 47 \mathrm{pm}$

\section{Solano County MHMP}

It is time to get prepared! "HAZARD FORTNIGHTS" focuses on emergency response and preparedness!

Like ' Comment ' Reshare ' January 8 at $12: 37 \mathrm{pm}$ 
Solano County MHMP via U.S. Geological Survey (USGS)

Want to know the damage an earthquake can cause? Check out this image

from the USGS!

\section{UUSGS}

"San Francisco in Ruins" by George Lawrence

earthquake.usgs.gov

USGS Earthquake Hazards Program, responsible for monitoring, reporting, and researching earthquakes and earthquake hazards

क7 Like ' Comment ' Reshare ' December 19, 2011 at 10:46am

\section{Solano County MHMP}

Weather Report for December!

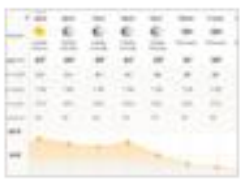

Sacramento, CA 95814 Month Weather Report AccuWeather.com

www. accuweather.com

Get Sacramento, CA 95814 monthly weather forecasts for current and past months including average and historical temperatures from AccuWeather.com

क Like ' Comment ' Reshare ' December 19, 2011 at 10:36am

\section{Solano County MHMP}

Check out Page 4 and 5 for the USACE's Flood Contingency Mapping \& Emergency Response Planning effort in the Delta!

http://www.spk.usace.army.mil/projects/civil/Delta/Docs/ Delta_News_Issue69.pdf

wWw.spk.usace.army,mil

क] Like ' Comment ' Reshare ' December 16, 2011 at 3:14pm

\section{Solano County MHMP}

Are you at risk from flooding? Check out DWR's Flood Risk Map Web Viewer to know today!

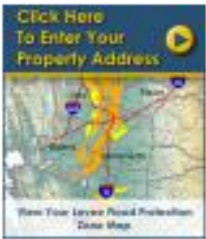

Division of Flood Management

www.water.ca.gov

California Department of Water Resources, Flood Management

Division homepage

क] Like ' Comment ' Reshare ' December 10, 2011 at 5:38pm

'3 Mark Scott likes this.

Write a comment... 
Solano County MHMP added 8 new photos to the album Solano County MHMP Public Workshop, - at Cordelia Fire District.
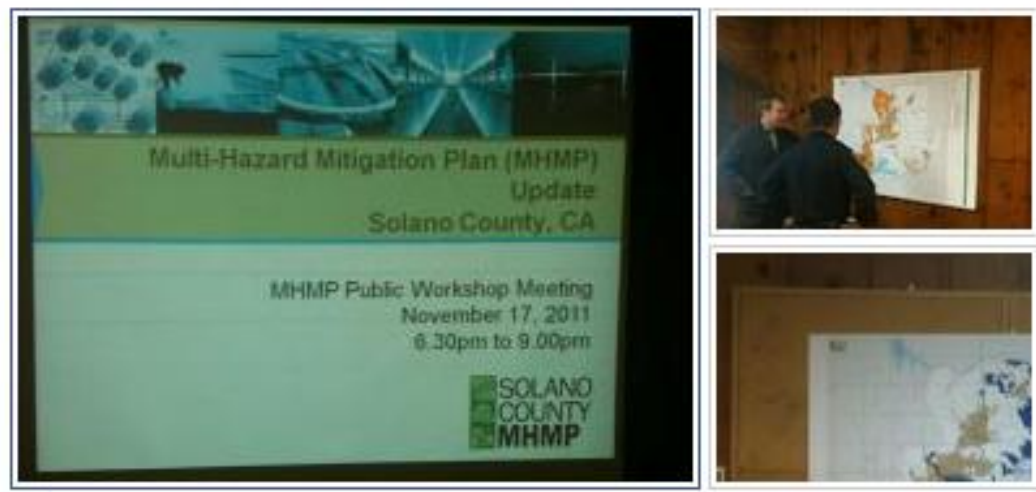

[1 Like ' Comment ' Share ' December 10 at 12:06pm ' (a)

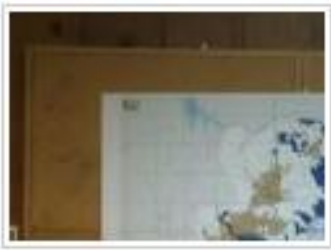

\section{Solano County MHMP}

This video is a reminder that flooding can cause serious damage to Solano County!

\section{Documentary: Spring Storm 2011}

www.calema.ca.gov

California suffered more than $\$ 50$ million in damages after a relentless series of wet and windy storms hit the state for weeks in March. Major roadways washed away, cities were flooded and landslides trapped residents. This is the story of how it happened and what's next for the disaster prone state...

D] Like ' Comment ' Share ' December 10 at 11:14am ' a

Solano County MHMP

See here for a list of Historical Disaster Events in Solano County!

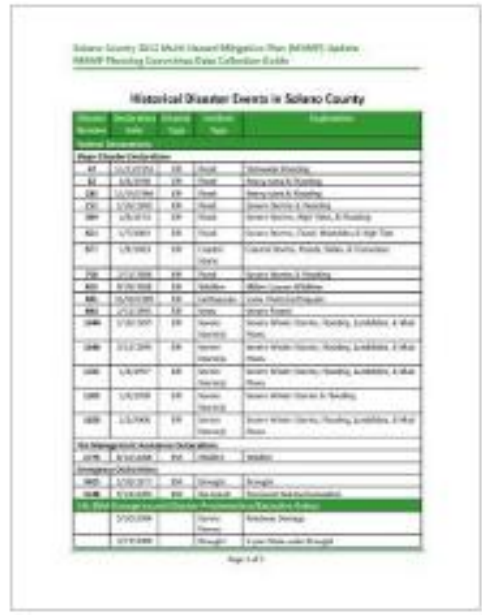

[1] Like ' Comment ' Share ' December 7 at 6:22pm ' a 
Solano County: Be prepared for Winter Storms. Check out www. Ready,gov for more info!

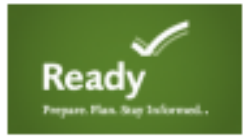

Winter Storms \& Extreme Cold I Ready.gov wWW,ready.gov

While the danger from winter weather varies across the country, nearly all Americans, regardless of where they live, are likely to face some type of severe winter weather at some point in their lives. Winter storms can range from a moderate snow over a few hours to a blizzard with blinding, wind-dri...

Like ' Comment ' Share ' December 5 at 9:28pm ' Q

\section{Solano County MHMP}

Fun Flood Fact: Solano County lowers flood insurance premiums for its residents through FEMA's Community Rating System (CRS)

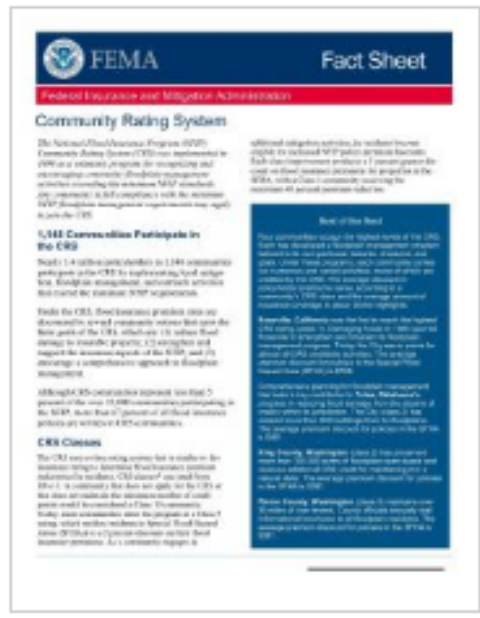

[圆 Like ' Comment ' Share ' December 5 at 9:12pm ' a

\section{Solano County MHMP \\ Freeze Warnings in place for Northern California counties!}

\section{Cal EMA Urges Californians to Prepare for Severe Cold}

campaign,r20.constantcontact.com

MATHER, Calif, -The California Emergency Management Agency (Cal EMA) today urged residents throughout the State of California to accelerate their winter weather preparedness efforts in response to a forecast by the National Weather Service for temperatures in the 20 s to low 30 s and possibly lower la...

of Like ' Comment ' Share ' December 5 at 11:33am '

' Mark Scott likes this.

1 share

Write a comment... 
Solano County MHMP

Check out Solano County's Flood Hazard map!

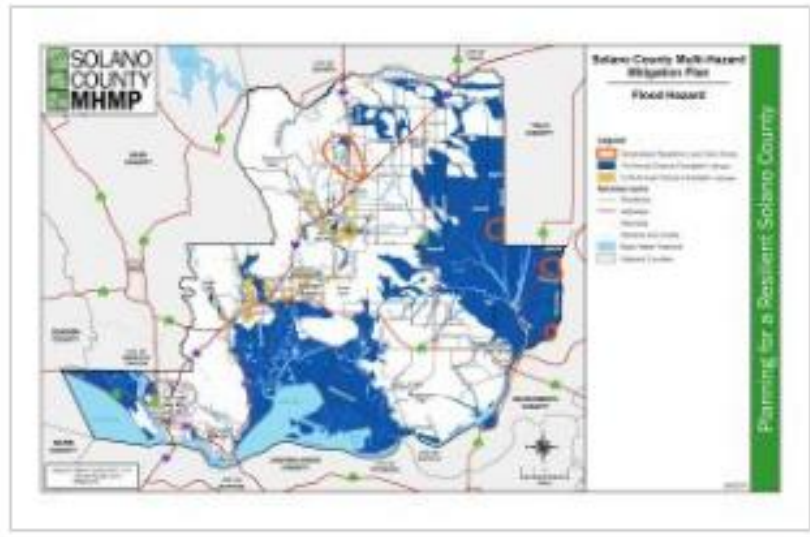

[圆 Like ' Comment ' Share ' December 3 at $1: 28 \mathrm{pm}$ ' (2)

\section{Solano County MHMP}

Solano County's Office of Emergency Services (OES) talks about flooding!

\section{Solano County - Flood}

www.co.solano.ca.us

Before, During and After As in the past, rising tides and torrential rainfalls have led to flooding here in Solano County. There are actions you can take to protect your family and keep your property losses to a minimum. Mitigation helps. It lessens the damaging effects from flooding. Participating...

क] Like ' Comment ' Share ' December 3 at 11:09am ' $\theta$

\section{Solano County MHMP}

Fun Flood Fact: Solano County participates in FEMA's National Flood Insurance Program (NFIP)

FEMA www fema.gov

FEMA: The National Flood Insurance Program

NFIP Reauthorization Guidance - Updated November 19, 2011

On November 18, 2011, President Obama signed the continuing resolution that includes a provision reauthorizing the NFIP through December 16,2011 , we will continue to update you on the NFIP reauthorization status.

Like ' Comment : Share ' December 1 at $2: 13 \mathrm{pm} \cdot \mathrm{a}$

\section{Solano County MHMP}

"HAZARD FORTNIGHTS" focuses on Flooding! Check out the MHMP website to see how flooding affects Solano County.

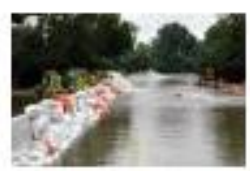

Solano County MHMP Update

www, solanocountymhmp,org

Sign in | Terms | Report Abuse | Print page | ...

Like ' Comment : Share ' November 29 at 9:18pm ' e 
Solano County MHMP

Check out the Solano County MHMP Public Meeting Agenda!

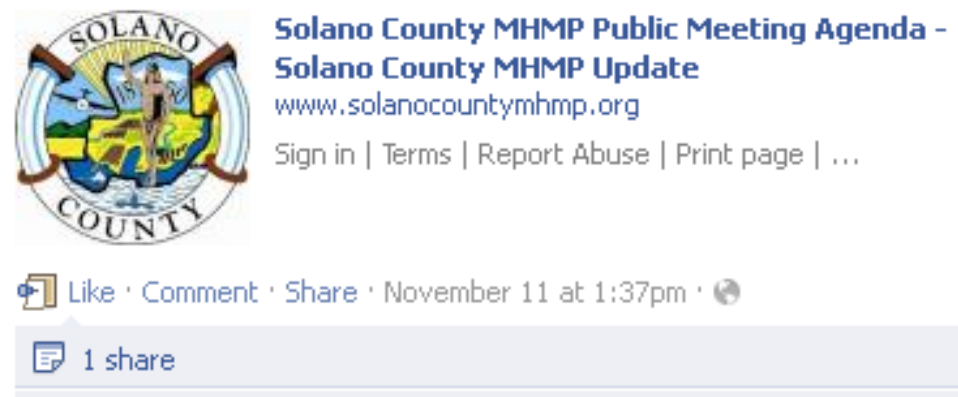

Write a comment...

Solano County MHMP shared a link.

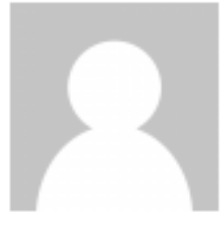

Solano County schedules two disaster plan meetings I Daily Republic

www.dailyrepublic,com

The plan is to reduce the impacts of natural disasters such as earthquakes, fires and flooding in rural areas of the county. Two meetings each from 6:30 to $9: 30 \mathrm{p} . \mathrm{m}$. are planned:

Like ' Comment ' Share ' November 8 at $6: 18 \mathrm{pm}$ ' $Q$

\section{Solano County MHMP}

Public Notice: The Solano County MHMP Public Workshops are next week!

\section{SOLANO COUNTY Department of Resource Management 675 Texas} Street, Suite 5500 FAIRFIELD, CALIFORNIA 9

reporter,kaango,com

Item Listed In Legal \& Public Notices On The Reporter- Vacaville - SOLANO

COUNTY Department of Resource Management 675 Texas Street, Suite 5500

FAIRFIELD, CALIFORNIA 94533...

की Like ' Comment ' Share ' November 7 at 7:34pm ' (2)

\section{Solano County MHMP}

Solano County is talking about the MHMP!

\section{Solano County - Homepage}

www. solanocounty,com

The Solano County Multi-Hazard Mitigation Plan (MHMP) Update will be the county's primary tool to reduce or eliminate long-term risk to people and property from natural hazards in Solano County. The MHMP will identify the natural hazards that affect the County, their impacts, and mitigation actions ...

of Like ' Comment ' Share ' October 29 at 11:30am ' a 


\section{Solano County MHMP}

Solano County is talking about the MHMP!

\section{Solano County - Homepage}

www.solanocounty.com

The Solano County Multi-Hazard Mitigation Plan (MHMP) Update will be the county's primary tool to reduce or eliminate long-term risk to people and property from natural hazards in Solano County. The MHMP will identify the natural hazards that affect the County, their impacts, and mitigation actions...

of] Like ' Comment ' Share ' October 29 at 11:30am ' e

Solano County MHMP

Solano County MHMP Update Public Meeting

31 Like ' Comment ' View ' Join ' November 17 at 6:30pm

\section{Solano County MHMP}

Dam FACT: According to the USACE NID a high hazard dam is - when the loss of one human life is likely if the dam fails

Like ' Comment ' Share ' October 27 at 6:53pm ' $\theta$

\section{Solano County MHMP}

Great photos from the \#USGS on earthquake events!

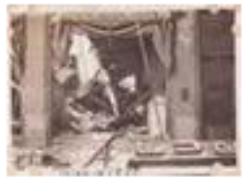

Earthquake Photo Collections

earthquake.usgs,gov

USGS Earthquake Hazards Program, responsible for monitoring, reporting, and researching earthquakes and earthquake hazards

Like ' Comment ' Share ' October 27 at 2:31pm ' $\theta$

\section{Solano County MHMP}

3.2 Magnitude \#Earthquake in the Bay Area!

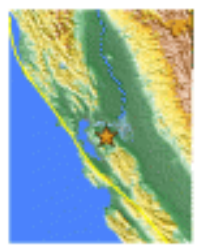

Magnitude 3.2 - SAN FRANCISCO BAY AREA, CALIFORNIA

earthquake.usgs.gov

USGS Earthquake Hazards Program, responsible for monitoring, reporting, and researching earthquakes and earthquake hazards

of Like ' Comment ' Share ' October 26 at 6:02pm + Q

\section{RECENT ACTIYITY}

40 "Solano County Multi Hazard..." on Fairfield Fire Department's Wall.

\section{Solano County MHMP}

Solano County Residents, what are your most pressing fire issues?

What are the most pressing fire issues in your community? Asked by National Fire Protection Association (NFPA)

그 Like ' Comment ' Share ' October 26 at 3:42pm ' a 


\section{Solano County MHMP}

The Solano County MHMP Team are using FEMA's iPhone App!

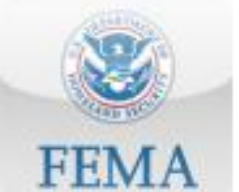

\section{App Store - FEMA}

itunes.apple.com

Read reviews, get customer ratings, see screenshots, and learn more about FEMA on the App Store. Download FEMA and enjoy it on your iPhone, iPad, and iPod touch.

Like ' Comment ' Share ' October 26 at 11:46am ' A

Solano County MHMP

CalEMA has a new website that shows the risk potential (earthquake, flooding, fire, tsunami) for your home. Visit http: ('/bit. ly/ucdkhi for details!

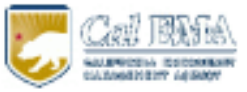

My Hazards Awareness Map

myhazards.calema.ca.gov

Use this website to discover the hazards that exist in your area and learn how to reduce YOUR risk! Remember, the best way to recover from disasters is by reducing the risks before a disaster strikes.

Like ' Comment' Share ' October 25 at 11:22pm '

['] Mark Scott likes this.

Write a comment...

\section{Solano County MHMP}

Solano County MHMP Update Public Meeting

31 Like ' Comment ' Wiew ' Join ' November 14 at 6:30pm

\section{Solano County MHMP}

Dam Fact: Dams included in the NID are either greater than 25 feet high, hold more than 50 acre-feet of water, or are considered a significant hazard if they were to fail.

Like ' Comment ' Share ' October 25 at 8:26pm ' a

Solano County MHMP According to the USACE NID, there are 22 dams in Solano County!

October 25 at 8:29pm ' Like

Write a comment...

\section{Solano County MHMP}

Fun Fact on Dams: USACE maintains the National Inventory of Dams (NID)

\section{National Inventory of Dams}

www.usace. army.mil

"; document, write(newContent); // var sourceContent = document.getElementById("MSO_ContentTable"); //

document.write(sourceContent.innerHTML); \}

에 Like ' Comment ' Share ' October 25 at 9:16am ' 
Solano County MHMP

Great video from Cal EMA. Thanks!

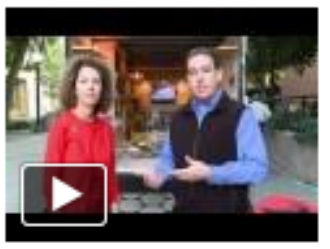

How to Survive and Prepare for a Major

Earthquake

www. youtube.com

Asst. Secretary of Cal EMÁ Kelly Huston and American

Red Cross' CEO of the Capitol Region Dawn Lindblom

show how to survive a major earthquake and how to bui...

前 Like ' Comment ' Share ' October 25 at 9:11am ' Q

' Mark Scott likes this.

Write a comment...

Solano County MHMP shared a link.

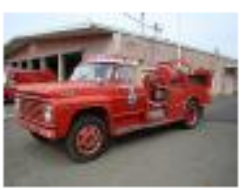

Solano County Fire Apparatus - a set on Flickr

www. Flickr.com

Flickr is almost certainly the best online photo management and sharing application in the world. Show off your favorite photos and videos to the world, securely and privately show content to your friends and family, or blog the photos and videos you take with a cameraphone.

Like ' Comment ' Share ' October 24 at 3:12pm ' e

Solano County MHMP shared a link.

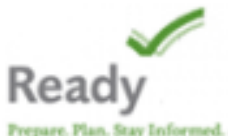

FEMA Blog: New Digital Tools: FEMA App and Text Message Updates

blog.fema.gov

Just making sure the first text message address is correct. It reads "Text PREPARE to 4336 (4FEMA)" When ALL of the other addresses read "Text [blank] to 44362 (4FEMA)"]ust making sure the correct information gets to the massesBrothaTech

\$7 Like ' Comment ' Share ' October 23 at 9:36pm ' a

Solano County MHMP shared Federal Emergency Management Agency's status update.

\section{Federal Emergency Management Agency}

FEMA Download the FEMA app (available for Android users) where you can enter your family emergency meeting locations, review safety tips on what to do before, during \& after a disaster, and more. More details on our blog: http://go.usa.gov/kox And sign up to get monthly preparedness tips via text message updates: text "PREPARE" to 43362.

on] Unlike ' Comment ' Share ' October 23 at 9:21pm ' 8

' You like this.

Write a comment... 
Why does dam failure occur? FEMA has some answers for you.

FEMA www, fema.gov

A "dam" is an artificial barrier that has the ability to impound water, wastewater, or any liquid-borne material for the purpose of storage or control of water (different types of dams). Dams can fail for one or a combination of the following reasons:

Like ' Comment ' Share ' October 23 at 9:16pm ' e

\begin{tabular}{|c|c|}
\hline & Solano County MHMP \\
\hline 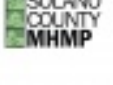 & $\begin{array}{l}\text { Fun Fact on \#Dam Failure in \#Solano County: No officially declared events in the } \\
\text { past! }\end{array}$ \\
\hline & Like ' Comment ' Share ' October 23 at 3:58pm ' \\
\hline & Solano County MHMP shared a link. \\
\hline \multirow[t]{5}{*}{ MHMP } & $\begin{array}{l}\text { 8. FEMA } \text { FEMA: About the National Dam Safety Program } \\
\text { www.fema.gov }\end{array}$ \\
\hline & $\begin{array}{l}\text { For } 30 \text { years, the Federal Government has been working to } \\
\text { protect Americans from dam failure through the National Dam } \\
\text { Safety Program (NDSP). The NDSP, which is led by FEMA, is a } \\
\text { partnership of the states, federal agencies, and other } \\
\text { stakeholders to encourage individual and community } \\
\text { responsibility fo... }\end{array}$ \\
\hline & D Like ' Comment ' Share ' October 23 at 2:35pm ' O \\
\hline & ' Mark Scott likes this. \\
\hline & Write a comment... \\
\hline
\end{tabular}

\section{RECENT ACTIYITY}

4ig "Great use of digital tools!" on Federal Emergency Management Agency's status.

\section{Solano County MHMP \\ Read about Dam Failure here!}

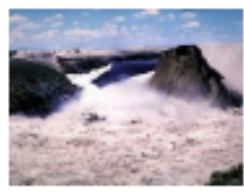

\section{Dam failure}

A dam is a barrier across flowing water that obstructs, directs or slows down the flow, often creating a reservoir, lake or impoundments. Most dams have a section called a spillway or weir over which, or through which, water flows, either intermittently or continuously, and some have hydroelectric power generation syst...

See More

Page: 2 like this

Like ' Comment' Share 'October 23 at 1:44pm ' 


\section{Solano County MHMP}

"HAZARD FORTNIGHTS" focuses on Dam Failure and how it affects Solano County. - at Monticello Dam, Napa County.

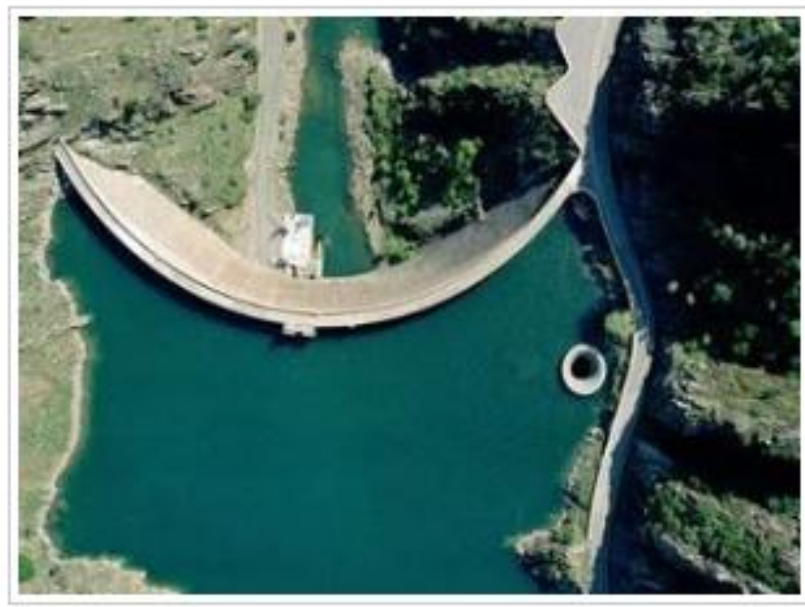

[目 Like ' Comment ' Share ' October 23 at $1: 40 \mathrm{pm}$ ' a

\section{Solano County MHMP}

Probability of Earthquake with a magnitude 6.7 or greater before 2036:

San Francisco Bay Area $=63 \%$

Concord-Green Valley Fault $=3 \%$

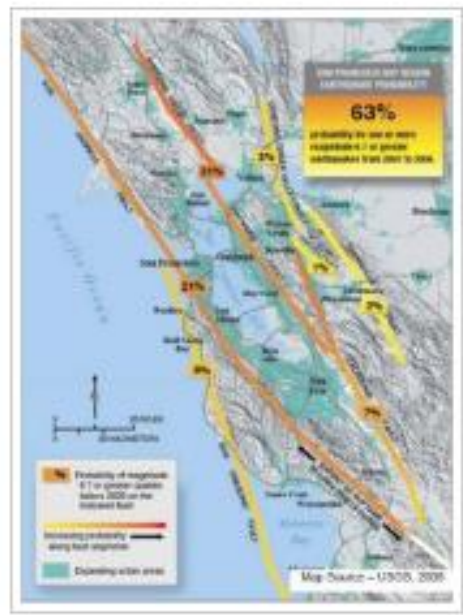

Like 'Comment ' Share 'October 23 at 12:35pm ' (2)

1 share

Write a comment... 


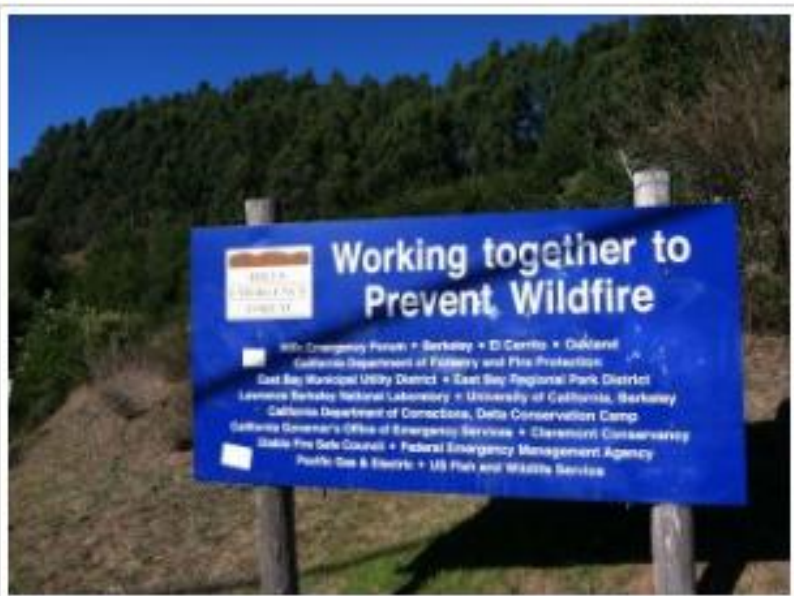

\section{Wall Photos}

Today CAL FIRE joined Bay Area fire departments in Oakland to remember the $1991 \ldots$

See More

BY: CAL FIRE

क] Like ' Comment ' Share ' October 23 at 11:14am ' a

\section{Solano County MHMP}

Magnitude 4.2 !

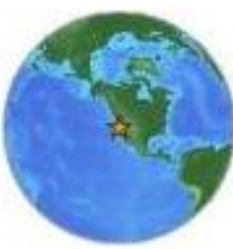

Magnitude ? (uncertain or not yet determined) - SAN FRANCISCO BAY AREA, CALIFORNIA

earthquake.usgs.gov

USGS Earthquake Hazards Program, responsible for monitoring, reporting, and researching earthquakes and earthquake hazards

\$] Like ' Comment' Share ' October 20 at 2:48pm ' 8

\section{Solano County MHMP}

Did you feel the earthquake!!!!!!!!!

Like ' Comment ' Share 'October 20 at 2:44pm + a

\section{Solano County MHMP via CAL FIRE}

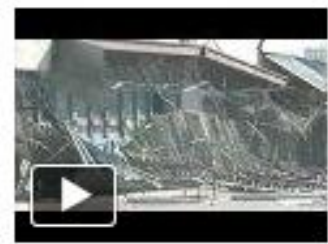

Earthquake Preparedness www, youtube.com

All across the state, earthquakes remain an inevitable part of California life. Preparation is the best defense against these potentially devastating events....

㳕 Like ' Comment ' Share ' October 20 at 10:13am ' a 
Solano County MHMP via The Great California ShakeOut

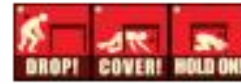

ShakeOut - Get Ready to ShakeOut!

www, shakeout, org

In 2010, more than 7.9 million Californians practiced Drop, Cover, and Hold On to practice how they will protect

themselves during earthquakes, and increased their overall preparedness. Join us in 2011!

요 Like ' Comment ' Share ' October 20 at 10:09am ' a

Solano County MHMP

Solano County: Get ready to Drop, Cover and Hold On!

Like ' Comment ' Share ' October 20 at 10:08am ' (a)

Mark Scott likes this.

Write a comment...

\section{Solano County MHMP}

Solano County: Learn how you can participate in The Great California Shakeout!

\section{CEA ShakeOut - How to Participate}

THE STRENGTH WWW, shakeout,org

There are many ways for individuals, businesses, schools, faith-based organizations, community groups, scouts, and others to participate in the Shakeout. The links below have customized ideas for what you or your organization can do.

D] Like ' Comment ' Share ' October 16 at 10:41am ' $\theta$

\section{Solano County MHMP}

The Solano County MHMP Team is preparing for "ShakeOut". Drop, Cover and Hold On!

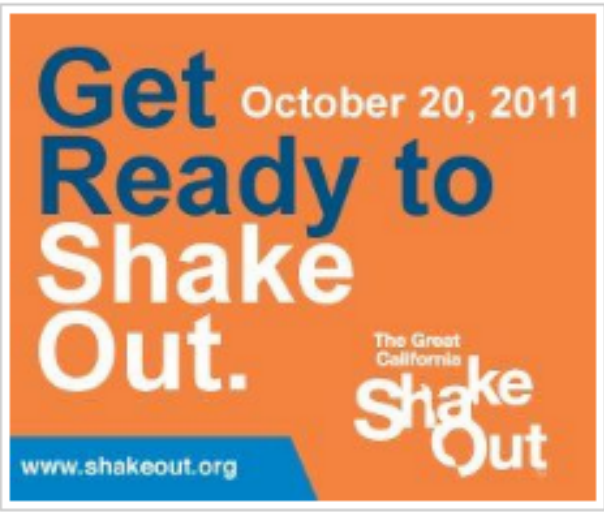

圆 Like ' Comment ' Share ' October 16 at 10:27am ' e 
Solano County MHMP

Solano County MHMP Public Workshop information coming soon!

Like ' Comment ' Share ' October 13 at 9:36pm ' $\theta$

Solano County MHMP via National Oceanic and Atmospheric

Administration (NOAA)

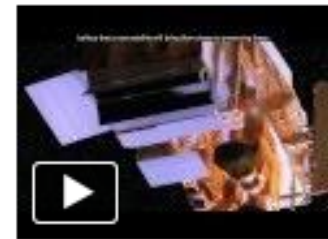

NPP: The Future of Earth Observations

whw. youtube.com

The launch of a new polar-orbiting environmental satellite enables NOẢÁ to continue issuing accurate forecasts and provide advance warning for severe weather...

䀧 Like ' Comment ' Share ' October 13 at 9:20pm ' a

\section{Solano County MHMP}

One of America's most costly natural disasters are wildland fires, and wildland-urban interface (WUI) fires rank among the worst of these. Solano County: Be prepared!

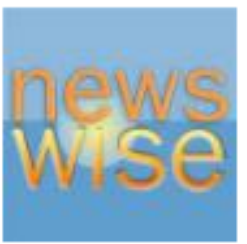

Spreading Like Wildfire? Maybe, Maybe Not www. newswise.com

DHS-funded research, with The Dragon, and Baby Dragon, helps define fire standards to protect homes. Yhey are conduction experimental fire research to discover when and how quicky wildfire embers ignite fires in structures along the wildland urban interface, and what we can do to prevent it.

97 Like ' Comment ' Share ' October 13 at 9:02pm ' Q

\section{Solano County MHMP}

Learn what to do during an earthquake here!

Ready.gov: Earthquakes Redirect www.Ready.gov

Ready Earthquakes Redirect

6] Like ' Comment ' Share ' October 13 at 7:42pm ' (a)

\section{Solano County MHMP via City of Vacaville}

City Council Meetings | City of Yacaville General Plan Update

www.vacavillegeneralplan.org

City Council meetings and study sessions are an important part of the General Plan Update process. We encourage your participation throughout the General Plan

Like ' Comment ' Share ' October 13 at 7:32pm ' 


\section{Solano County MHMP via CAL FIRE}

Watch this special message for steps you can take to help "Protect Your Family From Fire".

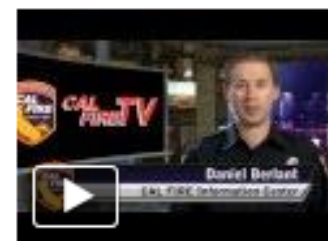

National Fire Prevention Week - The Fire Situation Report

www. youtube.com

In recognition of National Fire Prevention Week, CAL

FIRE presents a special message for the week of

October 9, 2011.

㳕萛 Like ' Comment ' Share ' October 13 at $7: 30 \mathrm{pm}$ ' e

\section{Solano County MHMP}

At 10:20 a.m. on October 20, 2011, Solano County residents will participate in the largest earthquake drill ever! Register today at www. ShakeOut.org

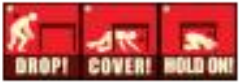

\section{Shake0ut - Get Ready to Shake0ut!}

wин, ShakeOut.org

In 2010, more than 7.9 million Californians practiced Drop, Cover, and Hold On to practice how they will protect themselves during earthquakes, and increased their overall preparedness. Join us in 2011!

67 Like ' Comment ' Share ' October 12 at 10:23pm ' (a)

\section{RECENT ACTIYITY}

四 "Interesting statistics on fires..." on CAL FIRE's link.

\section{Solano County MHMP}

Want to get your family prepared for an earthquake? Click the link to see what a family in San Diego are doing to prepare.

http://www.youtube.com/weareunprepared\#p/a/u/2/AjyF1qsi7e0

whw. youtube.com

क Like ' Comment ' Share ' October 12 at 9:10pm ' a

\section{Solano County MHMP via City of Vacaville}

\section{Solano County - News Details}

whw. solanocounty.com

Solano County Public Health will join a state-wide drill to test local hospitals abilities to treat a large influx of ill people in the event of a real disaster. Solano County Public Health is recruiting volunteers to play the role of victims of the mock-terrorism event on Thursday, Nov. 17, 2011....

9] Like ' Comment ' Share ' October 10 at 9:01pm ' Q

Solano County MHMP Be a part of disaster preparedness!

October 10 at 9:03pm ' Like

Write a comment... 
Want to decrease the impact of fire in your community? Be apart of Fire Prevention Week today!

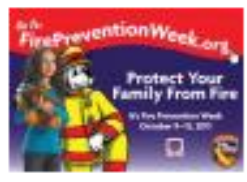

CAL FIRE - Fire Prevention Week whw, fire.ca.gov

Each year, the week surrounding the date of October 9th is celebrated as National Fire Prevention Week, Why October 9th? The date commemorates the infamous "Great Chicago Fire" of 1871 that killed 250 people and destroyed over 17,000 homes. Every 39 minutes someone in the U.S. is injure...

으 Like ' Comment ' Share ' October 10 at 8:31pm ' Q

\section{Solano County MHMP}

Magnitude 1.2 earthquake in the San Francisco Bay Area. Click on the link provided for more information.

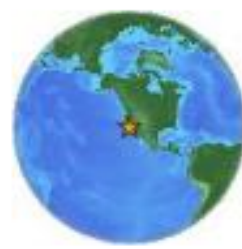

Magnitude 1.2 - SAN FRANCISCO BAY AREA, CALIFORNIA

earthquake.usgs.gov

USGS Earthquake Hazards Program, responsible for monitoring, reporting, and researching earthquakes and earthquake hazards

क] Like ' Comment ' Share ' October 10 at 8:27pm '

Solano County MHMP

Check out these Wildfire hazard photos from CAL FIRE!

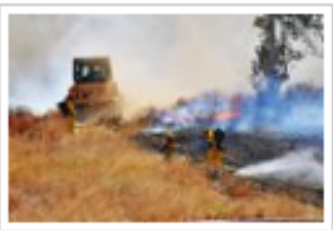

\section{Wildfires}

By: CAL FIRE

Photos: 5

] Like ' Comment ' Share ' October 9 at 11:09pm ' a

Solano County MHMP Wildfire events can happen in Solano County!

October 10 at 9:37am ' Like

Write a comment... 


\section{Solano County MHMP}

Solano County Residents: Higher seismic shaking potential in the western portion of County.

Like ' Comment ' Share ' October 9 at 2:33pm ' a

Solano County MHMP via The Great California ShakeOut

Solano County Residents: Learn what to do during an earthquake - Join the CA Shakeout in 2 weeks time!

\section{Join Us \\ for the Largest \\ in U.S. History.

10/6/11 California ShakeOut Update: 2 weeks until ShakeOut!

us1,campaign-archive1,com

Read the latest update emailed to participants.

Like ' Comment ' Share ' October 9 at 1:00pm ' $\theta$

Solano County MHMP On October 20th is your date with The

October 9 at 1:08pm ' Like

Write a comment...

\section{Solano County MHMP}

ALERT SF Bay Area Residents: Earthquake Today - 2.5 Magnitude!

$7 \mathrm{~km}$ (4 miles) from Vallejo, $\mathrm{CA}$

$11 \mathrm{~km}$ (7 miles) from Green Valley, CA

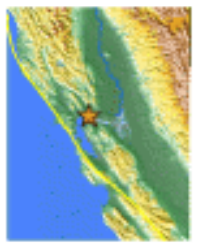

Magnitude 2.5 - SAN FRANCISCO BAY AREA, CALIFORNIA

earthquake.usgs.gov

USGS Earthquake Hazards Program, responsible for monitoring, reporting, and researching earthquakes and earthquake hazards

그 Like ' Comment ' Share ' October 9 at 12:33pm '

\section{Solano County MHMP}

Fun Fact: 11 earthquakes with a magnitude $\geq 6.0$ within 50 miles of Solano County have occurred from 1836 to present.

Like ' Comment ' Share ' October 9 at 12:25pm ' a 


\section{Solano County MHMP}

Fun Fact on Earthquakes: An earthquake fault line is a fracture in the crust along which one side has moved relative to the other side.

3. Like ' Comment ' @SolanoMHMP on Twitter · October 5 at 9:12pm via Twitter

\section{Solano County MHMP}

Calling Solano County residents: Keep up to date with earthquake activity in your area today! Check out this map for recent CA earthquakes!

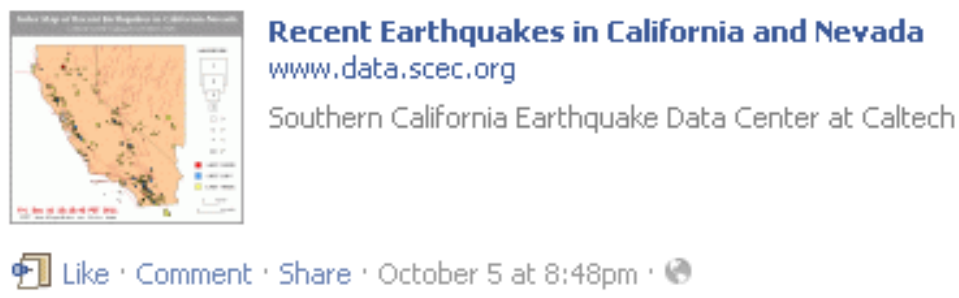

\section{RECENT ACTIYITY}

"Thanks for the photos CAL FIRE..." on CAL FIRE's album.

\section{Solano County MHMP}

When was the last earthquake in Solano County?....... You guessed it!!! 1989

Loma Prieta.

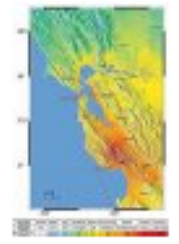

1989 Loma Prieta earthquake - Wikipedia, the free encyclopedia

en. wikipedia.org

The Loma Prieta earthquake, also known as the Quake of '89 and the world Series Earthquake, [4] was a major earthquake that struck the San Francisco Bay Area of California on October 17, 1989 , at 5:04 p.m. local time. Caused by a slip along the San Andreas Fault, the quake lasted 10-15 seconds[1] and...

Like ' Comment ' Share ' October 5 at 8:04pm ' $\theta$

Solano County MHMP Last "MA]OR" earthquake!

\section{October 5 at 10:40pm · Like}

Write a comment...

Solano County MHMP via Totally Unprepared

Social Media and earthquakes unite!

\section{Arobdelaney}

Did anyone 1 have a boyfriend die in the

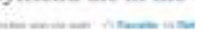

The Best Twitter Responses To The Earthquake www. buzzfeed.com

The Best Twitter Responses To The Earthquake: The east coast just had an Earthquake. I know it's scary, we're still recovering ourselves. But some people have already been funny about it. Here are some of those people... 
Solano County MHMP

"HAZARD FORTNIGHTS" focuses on Earthquakes! Check out the MHMP Facebook and Twitter page to see how earthquakes affect Solano County.

3 Like ' Comment ' @SolanoMHMP on Twitter ' October 5 at 7:35pm via Twitter

Solano County MHMP

Fun Fact on Drought in CA: There have been 8 drought emergencies/State Emergency Proclamations.

Like ' Comment ' Share ' September 29 at 8:47am ' o

Solano County MHMP

For Solano County, there have been 5 drought events since 1896.

Like ' Comment ' Share ' September 28 at 10:21am ' $\theta$

Solano County MHMP All of Solano County is subject to drought!

September 28 at 10:22am · Like

Write a comment...

Solano County MHMP

Learn about Drought in California...Check of the State's Department of Water Resources Drought Page... current conditions in California are NORMAL...

Drought Conditions

www. water.ca.gov

Drought Portal

क] Like ' Comment ' Share ' September 20 at 3:49pm ' 8

Solano County MHMP

Drought also affects wildlife...

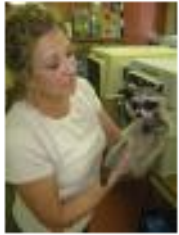

Texas Drought Takes Its Toll On Wildlife : NPR

www. חpr.org

The unfolding calamity that is the Texas drought has thrown nature out of balance. Many of the wild things that live in this

state are suffering.

क] Like ' Comment ' Share ' September 20 at 3:40pm ' (2)

Solano County MHMP

See what's going on in Texas, where citizens are experiencing drought conditions and wildfires...

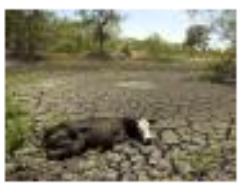

Dismal Sights of The Texas Drought : NPR

whw. npr.org

These photos might help explain unusually high dairy prices.

Like ' Comment ' Share ' September 20 at 3:39pm ' 8 


\section{Solano County MHMP}

The second half of September HAZARD FORTNIGHT focuses on Drought...

Like ' Comment ' Share ' September 20 at 3:36pm ' $\theta$

\section{Solano County MHMP}

Are you prepared for a fire event in your home? Check out FEMA's Fire Emergency Preparedness Guide at http://it. co/ptqn 1 XE

4. Like ' Comment ' @SolanoMHMP on Twitter ' September 12 at 10:12am via Twitter

\section{Solano County MHMP}

Talk of the Nation on NPR is discussing the devastating wildfires across Texas and the Southwest!!! Drought conditions and extreme winds are fueling the wildfires!!!

Wildfires Tak Fire Crews Across Texas, Southwest : NPR WWW.nprorg

Wildfires continue to sweep across drought-stricken central Texas, forcing evacuations of thousands of residents near Austin and stretching firefighters resources of. As in Texas, prolonged droughts have also helped fuel devastating

fires in California and Arizona this year.

क7 Like ' Comment ' Share ' September 6 at 11:31am ' (2)

\section{Solano County MHMP}

Have you created defensible space around your home??? Check out this link to a short paper about the 15 reasons homeowners don't create defensible space...

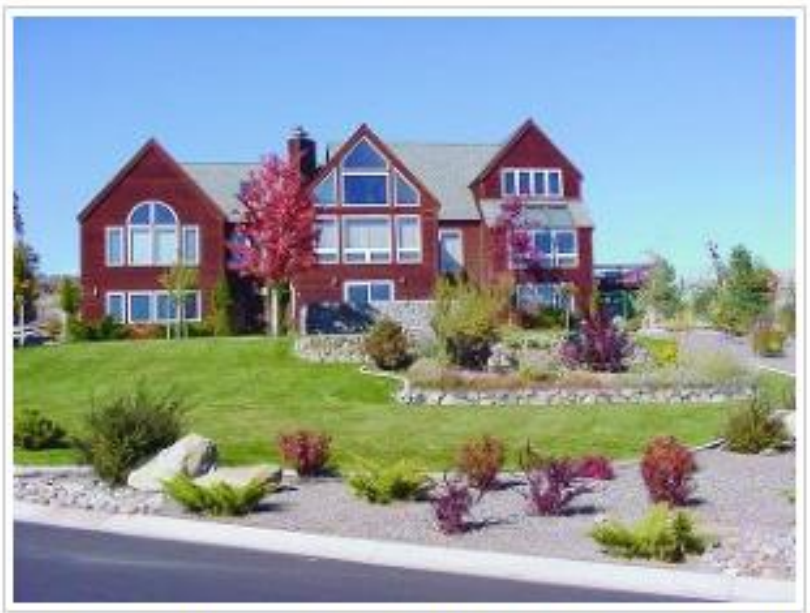

15 Reasons Homeowners Don't Create Defensible Space

Denial, fatalism, futility and irresponsibility are just a few of the 15 most co...

See More

By: Living with Fire

\$7 Like ' Comment 'Share ' September 6 at 11:09am ' 


\section{Solano County MHMP}

Due to the current Texas Wildfires, HAZARD FORTNIGHTS kicks off focusing on WILDFIRES...

Like ' Comment ' Share ' September 6 at 11:07am ' $\theta$

\section{Solano County MHMP}

souw To promote awareness for the hazards that affect Solano County, the Solano

MHMP MHMP Team is kicking off HAZARD FORTNIGHTS today... Every two weeks, we will focus on one specific hazard and provide information, fun facts, links, and other good stuff on the hazard...

Like ' Comment ' Share ' September 6 at 11:00am ' a

\section{Solano County MHMP}

This week the MHMP Team are analyzing the natural hazards affecting Solano County,

3. Like ' Comment ' @SolanoMHMP on Twitter ' September 6 at 9:39am via Twitter

\section{Solano County MHMP}

Follow this information from Cal FIRE to be safe this weekend!

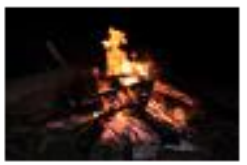

CAL FIRE Urges Extra Safety over Labor Day Weekend

www. Fire.ca.gov

As Labor Day weekend approaches, millions of people will plan to recreate in the outdoor areas found throughout California. In anticipation of the increased outdoor activities, CAL FIRE officials are urging everyone to exercise extra caution and safety this holiday weekend.

으 Like ' Comment ' Share ' September 2 at 9:21am ' e

\section{Solano County MHMP}

Have a safe Labor Day weekend from the Solano MHMP Team!

3. Like ' Comment ' @SolanoMHMP on Twitter ' September 2 at 8:59am via Twitter

\section{Solano County MHMP}

Do you have photos of natural hazards affecting Solano County? Email them to info@solanocountymhmp.org. The MHMP Team would love to showcase them on the MHMP website.

Like ' Comment ' Share ' September 1 at 6:01pm ' a 
It's National Preparedness Month - learn how you \& your family can prepare for a fire emergency!

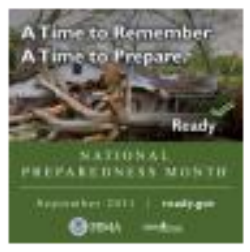

Focus on Fire Safety: Emergency Preparedness whw, usfa.dhs.gov

Focus on Fire Safety Árchives - Select -Âlcohol and

FireÁppliance FiresÂrsonBurn Áwareness \&

PreventionCampus Fire SafetyCandlesChildrenCookingDi

sasters \& Fire SafetyElectricalEmergency

PreparednessFireworksHeatingHoliday Fire SafetyNovelty and

Toy Lightersolder AdultsPeople with DisabilitiesPr...

Like ' Comment ' Share ' September 1 at 9:36am ' e

\section{Solano County MHMP}

Check out the new logo for the Solano County MHMP at www. SolanoCountyMHMP,org

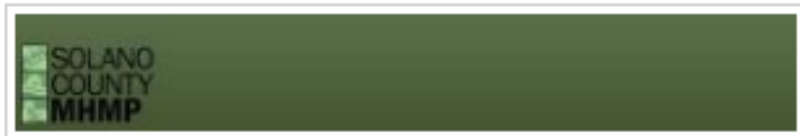

Like ' Comment ' Share ' September 1 at 9:26am ' e

\section{Solano County MHMP}

More photos of the Beacon fire in Cement Hill.

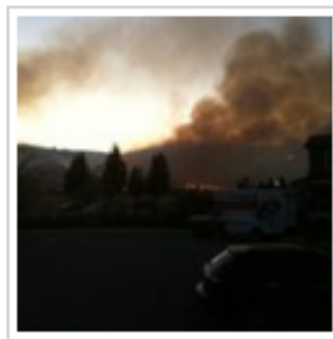

Cement Hill Fire August 27, 2011

By: Solano Fire

Photos: 7

Like ' Comment ' Share ' August 28 at 9:58pm ' $\theta$

\section{Solano County MHMP}

The Beacon fire is $100 \%$ contained!

CAL FIRE - Incidents

cdfdata,fire.ca.gov

क7 Like ' Comment ' Share ' August 28 at $8: 33 \mathrm{pm} \cdot$ ?

Solano County MHMP Check out the CAL FIRE incident link above for more information on the Beacon Fire.

August 28 at $8: 34 \mathrm{pm} \cdot$ Like

Write a comment... 
Click the link below for action photos from the Beacon Fire.

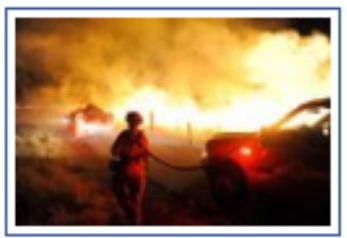

8-Alarm Fire, August 27, 2011

By: The Reporter

Photos: 22

] Like ' Comment ' Share ' Áugust 28 at 4:54pm ' o

\section{Solano County MHMP}

The Fire Danger in Solano County has been updated to HIGH!

Like ' Comment ' Share ' August 28 at $12: 27 \mathrm{pm}$ ' $\theta$

\section{Solano County MHMP via American Red Cross}

Do you know about the America Red Cross Safe \& Well tool? It can help you get in touch with loved ones during an emergency.

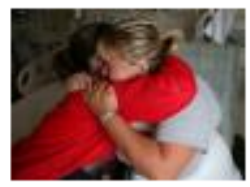

American Red Cross Safe and Well

safeandwell, communityos,org

After a disaster, letting your family and friends know that you are safe and well can bring your loved ones great peace of mind. This website is designed to help make that communication easier.

Like ' Comment ' Share ' August 28 at 12:08pm ' (8)

Solano County MHMP Let your family know today that you are safe.

August 28 at 1:25pm ' Like

Write a comment...

\section{Solano County MHMP}

Beacon Fire (Solano County) Incident Information:

Location: Cement Hill, East of Interstate 80, Fairfield

Containment: 750 acres - $60 \%$ contained.

Threatened: 40 residences

Conditions: Significant progress was made over night. Full containment of the fire is expected later today.

Like ' Comment ' Share ' Áugust 28 at 11:29am ' O

Solano County MHMP Keep up to date on the latest news for the Beacon Fire with the Solano County MHMP Team!!!

August 28 at $12: 04 \mathrm{pm} \cdot$ Like

Write a comment... 
Solano County MHMP via CAL FIRE

Check out this fire alert for Solano County residents from CAL FIRE. Remember to be safe and aware of your surroundings at all times.

CAL FIRE - Incidents

cdfdata,fire.ca.gov

그 Like ' Comment ' Share ' August 28 at 11:22am ' Q

\section{Solano County MHMP}

Check out this documentary produced for the Green Valley Agricultural Conservancy. This group is dedicated to preserve the beautiful Green Valley, in Solano County.

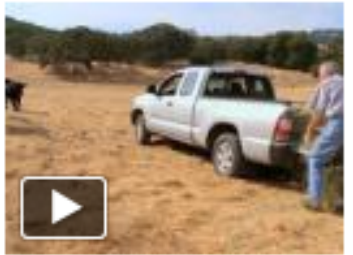

\section{Green Valley Documentary}

vimeo.com

Documentary produced for the Green Walley Agricultural Conservancy, a group dedicated to preserving the beautiful Green Valley, which is located in Solano County in Northern California. For more info: http://www,gvagconservancy,orgl' Documentary produced...

聠 Like ' Comment ' Share ' August 23 at $3: 15 \mathrm{pm}$ ' Q

\section{Solano County MHMP}

Great video from CAL FIRE on how to mitigate against the impacts of a wildfire event and be prepared!

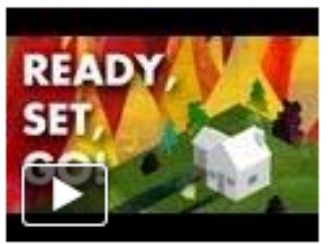

CAL FIRE's Ready Set Go Video

whw. youtube.com

In California, wildfires aren't a question of if, but only a question of when. If you choose to live near a natural area of the state, you are at risk for wi...

睍見 Like ' Comment ' Share ' Áugust 21 at 10:38pm ' e

Solano County MHMP Calling Solano County residents. Use information in this video to be prepared for a wildfire event! August 28 at 5:02pm ' Like

Write a comment... 


\section{Solano County MHMP}

We are now on Twitter. Check us out!

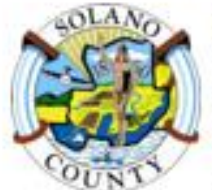

Solano County MHMP (@SolanoMHMP) on Twitter twitter.com

Sign up for Twitter to follow Solano County MHMP

(@SolanoMHMP). Solano County Multi-Hazard Mitigation Plan will reduce risk from natural hazards, Email info@solanocountymhmp.org

क] Like ' Comment ' Share ' August 17 at 5:58pm ' a

Solano County MHMP shared a link.

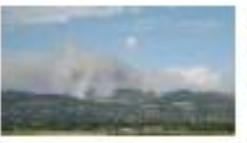

Napa-Solano wildfire 80 percent contained, 3,700 acres burned I abc7news.com

abclocal.go.com

The wild fire near Solano and Napa counties is 80 percent contained.

Like ' Comment ' Share ' August 12 at 6:42pm ' a

Solano County MHMP View this abc7 news report on the Solano/Napa County 2008 Wildfire event. It burned 4,102 acres! August 15 at 11:42am - Like

Write a comment...

Solano County MHMP added 2 new photos to the album Hazard Mitigation Projects.

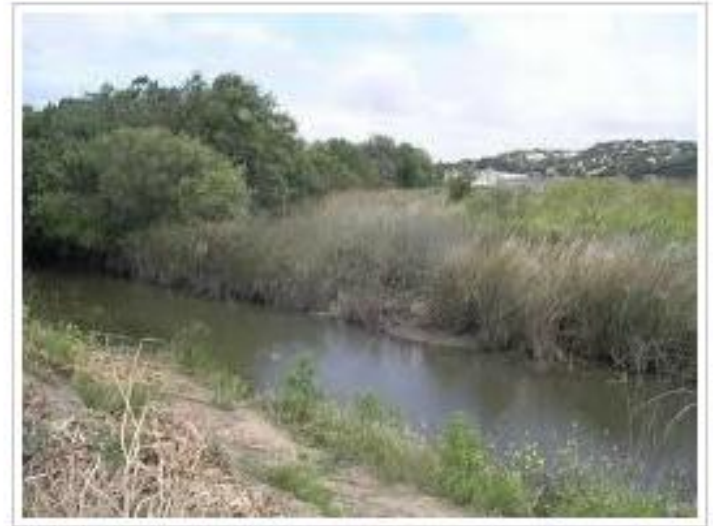

Hazard Mitigation Projects

[ Like ' Comment ' Share ' August 12 at 6:22pm + (2) 
Solano County MHMP added 5 new photos to the album Solano County Natural Hazards.
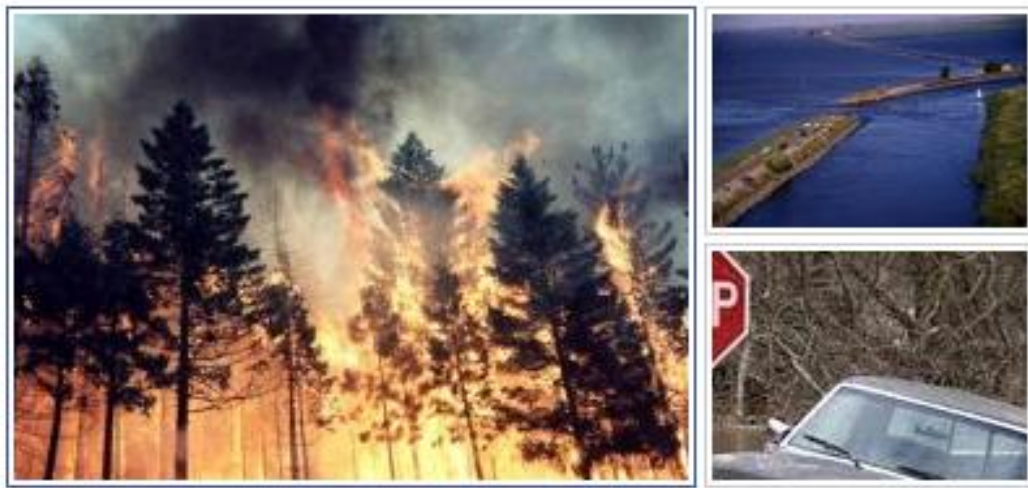

[1] Like ' Comment ' Share ' August 12 at 6:13pm ' (a)

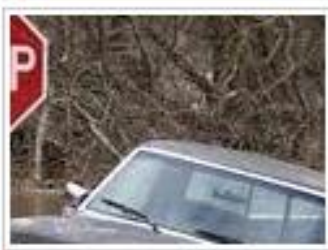

\section{Solano County MHMP}

http://www,co.solano.ca.usi

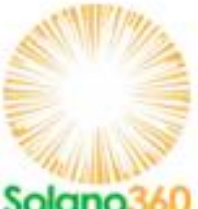

Solano County - Homepage

www.co.solano.ca.us

The County of Solano, in partnership with the City of Vallejo and the Solano County Fair Association, is working to create a new economic future for the Solano County Fairgrounds. The project

Solanosso is is dubbed Solano 360 in recognition that the future of this community asset requires a vision beyond the fiv...

Like ' Comment ' Share ' August 12 at 6:07pm ' i

\section{Solano County MHMP}

The Solano County Multi-Hazard Mitigation Planning Team is seeking the public's help and input during the Multi-Hazard Mitigation Plan Update process. If you have disaster related stories andjor photographs that you would like to share, or you have comments, please send them to info@solanocountymhmp.org.

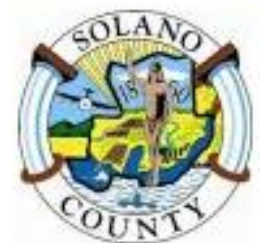

Solano County MHMP Update

www. solanocountymhmp,org

Sign in Terms Report Ábuse Print page | ...

क7 Like ' Comment ' Share ' August 12 at 6:04pm ' e

Solano County MHMP Check out the Solano County MHMP Update website for more information on this project!

August 12 at 6:09pm - Like

Write a comment...

\section{RECENT ACTIYITY}

Solano County MHMP joined Facebook. ' Like ' Comment 
Appendix B. MHMP Twitter Page 
Intentional Blank Page 
Table B.1-1: MHMP Twitter Page Follows

\begin{tabular}{|c|c|c|c|c|c|c|c|}
\hline Federal Agency & State Agency & Local Agency & $\begin{array}{l}\text { Interested } \\
\text { Stakeholder }\end{array}$ & Local Media & Nonprofit & Special Interest & $\begin{array}{l}\text { Geographical } \\
\text { Location }\end{array}$ \\
\hline Dept. of Agriculture & CA - DWR & $\begin{array}{l}\text { Solano County } \\
\text { Water }\end{array}$ & Chief Ken Pimlott & Fairfield CA News & American Red Cross & Bay Area Earthquakes & City of Vacaville \\
\hline FEMA & CA Water | USGS & Vacaville Fire Dept & DiscoverSolanoCounty & $\begin{array}{l}\text { KCBS } 740 \text { AM/106.9 } \\
\text { FM }\end{array}$ & California ShakeOut & California Delta & Solano County \\
\hline Fema Region 9 & $\begin{array}{l}\text { CA.gov } \\
\text { (California) }\end{array}$ & Vacaville Fire Dist & Dixon Chamber CA & KGO Assignment Desk & CaliforniaVolunteers & Center for Water & Suisun City \\
\hline NFPA & CAL FIRE & & Joffe Emergency & Vacaville Reporter & Conserv Lands Found & DeltaCouncil & \\
\hline NOAA & CalFireUpdates & & Large Quakes SF & Vacaville TV & Delta Watch & Disaster Warnings & \\
\hline NOAA's Ocean Service & California EPA & & Matt Weiser - Sacbee & Vallejo Buzz & Discover the Delta & Earthquake Info & \\
\hline NWS & California Guide & & San Fran News One & Vallejo Times-Herald & FIRESCOPE & Earthquake Robot & \\
\hline Sacramento District & EMSA Director & & Solano Library & & Friends of the River & Earthquakes Tsunamis & \\
\hline U.S. Coast Guard & & & Travis Air Force & & ReadydotGov & Esri & \\
\hline USCG (Official) & & & & & & QuakeFactor & \\
\hline USDA Forest Service & & & & & & SF QuakeBot & \\
\hline USFA & & & & & & Shaky & \\
\hline USGS Earthquake CA & & & & & & Smokey Bear & \\
\hline \multirow[t]{3}{*}{$\begin{array}{l}\text { USGS Earthquake } \\
\text { NorC }\end{array}$} & & & & & & Solano County Fire & \\
\hline & & & & & & The Weather Channel & \\
\hline & & & & & & TotallyUnprepared & \\
\hline
\end{tabular}


Table B.2-1: MHMP Twitter Page Followers

\begin{tabular}{|c|c|c|c|c|c|c|c|}
\hline Federal Agency & Local Agency & Local Business & Business & Local Media & Nonprofit & Individual & Special Interest \\
\hline USACE HQ & Solano County Water Agency & Benicia Grill & Crewboss & ABC 7 News Bay Area & Aquafornia & Alan Wuff & Disaster Warnings \\
\hline \multirow[t]{19}{*}{ U.S Department of Interior } & & Farallon Marketing & Fishery Update & Fairfield CA News & Center for Water & Anne Koeller & ESRI \\
\hline & & Joffe Emergency & & Vacaville CVB & Conservation Land Foundation & Audra & \\
\hline & & Lancer Specialties & & & Discover Solano County & Carolyn Higgins & \\
\hline & & Sacramento Daily Deals & & & Firewise Communities & Diana Beard & \\
\hline & & Solano County Business News & & & Quake Factor & Ethan Mobley & \\
\hline & & & & & Shaky & Jon Scott & \\
\hline & & & & & $\begin{array}{l}\text { Solano County Business } \\
\text { Innovation }\end{array}$ & Justin Aaron & \\
\hline & & & & & Solano County Business Jobs & Justin Aaron Morris & \\
\hline & & & & & Solano Library & Love Chappie & \\
\hline & & & & & Totally Unprepared & Mike Hudson & \\
\hline & & & & & & Nickole Cwik & \\
\hline & & & & & & Pam Nocella & \\
\hline & & & & & & Rachel Heller & \\
\hline & & & & & & Raj Hansra & \\
\hline & & & & & & $\begin{array}{l}\text { Rosemary } \\
\text { Southward }\end{array}$ & \\
\hline & & & & & & Shannon Karoglou & \\
\hline & & & & & & Steven Kays & \\
\hline & & & & & & Steven Kays & \\
\hline & & & & & & Wynne Kwan & \\
\hline
\end{tabular}


Appendix C. MHMP Public Outreach and Participation Survey 


\section{C.1 Survey Questions}

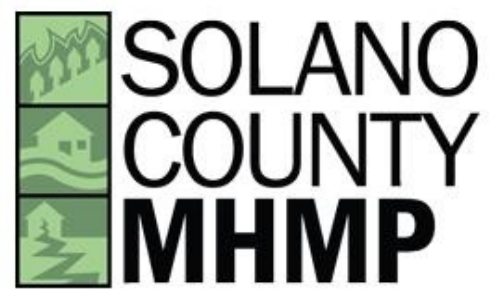

\section{Solano County MHMP Public Outreach and Participation Survey}

\section{Survey Information}

Thank you for participating in the Solano County Multi-Hazard Mitigation Plan (MHMP) Public Outreach and Participation Survey. This survey analyses the effectiveness of public engagement in the MHMP planning process though the Solano County MHMP online tools. These online tools include the MHMP project website, Facebook fan page, and Twitter page. The survey results will enable the MHMP Planning Team to improve its Public Outreach and Participation Strategies for Solano County and the surrounding Bay Area Counties.

The survey will take approximately 5 minutes to complete and is conducted anonymously. If you have any questions about the survey and/or on the MHMP planning process, please contact the MHMP Planning Team by email at info@SolanoCountyMHMP.org, calling 510-879-0969, or by mail to One Kaiser Plaza, Suite 1150, Oakland, CA 94612.

Your time and effort is greatly appreciated!

* 1. Are you a member of the Solano County MHMP Steering/Planning Committee?

Yes

No

Unsure

* 2. How old are you?

Under 18

$18-29$

$30-44$

$45-64$

65 and older

Do not wish to answer 
* 3. What is your primary language?

English

Spanish

Do not wish to answer

Other (please specify)

* 4. Where do you live?

Solano County (Incorporated Area)

Solano County (Unincorporated Area)

One of the eight surrounding Bay Area Counties - Alameda, Contra Costa, Marin, Napa, San Francisco, San Mateo, Santa Clara, and Sonoma County

Other (please specify)

* 5. Where do you source your information on Solano County's general planning projects? (Tick all that apply)

Public notices

- Solano County website (www.SolanoCounty.com)

- Social media tools (i.e. Facebook, Twitter, etc.)

— I do not source information on Solano County's planning projects

$\square$ Other (please specify)

* 6. Do you know about the Solano County MHMP project website? (www.SolanoCountyMHMP.org)

$\square$ Ves

W No

* 7. How did you learn about the Solano County MHMP project website?

$\square$ Public notice

- Solano County website (www.SolanoCounty.com)

— MHMP Facebook fan page

$\square$ MHMP Twitter page

Word of mouth

other (please specify) 
* 8. How many times did you visit the Solano County MHMP project website? (www.SolanoCountyMHMP.org)

$5+$ occasions

2 - 4 occasions

Once

Never

* 9. How did you access the Solano County MHMP project website? (Tick all that apply)

Computer (Work)

$\square$ Computer (Home)

T Smart phone

$\square$ ipad

Other (please specify)

* 10. What documents did you review on the Solano County MHMP project website? (Tick all that apply)

- MHMP related planning documents on the Resource Center webpage

MHMP mitigation action tables

MHMP hazard maps

MHMP Public Workshop information

- MHMP Planning Committee meeting documents

Other (please specify)

* 11. Did you find the Solano County MHMP project website a useful source of information on the MHMP planning project?

5 - very helpful

3 - neither helpful or unhelpful

1 - not helpful

12. How can the Solano County MHMP Planning Team improve the Solano County MHMP project website to be more helpful to the public?

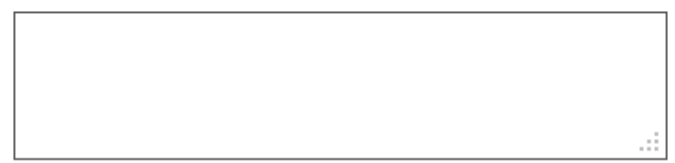

* 13. Do you use social media tools (i.e. Facebook, Flickr, Twitter, You Tube, etc)?

Ves

No 
* 14. Which social media tools do you frequently use [i.e. more than three times a week]? (Tick all that apply)

- Facebook

- Flickr

ए Twitter

ए You Tube

$\square$ Other (please specify)

* 15. Do you know about the Solano County MHMP Facebook fan page?

Yes

No

* 16. How did you learn about the Solano County MHMP Facebook fan page? (Tick all that apply)

$\square$ Public notice

[ Solano County website (www.SolanoCounty.com)

$\square$ MHMP project website (www.SolanoCountyMHMP.org)

$\square$ MHMP Twitter page

$\square$ Word of mouth

Other (please specify)

* 17. How many times have you visited the Solano County MHMP Facebook fan page?

$5+$ occasions

2 - 4 occasions

once

Never

* 18. How did you access the Solano County MHMP Facebook fan page? (Tick all that apply)

$\square$ Computer (Work)

Computer (Home)

$\square$ Smart phone

WiPad

Other (please specify)

19. Did you Like the Solano County MHMP Facebook fan page?

Yes

No

Unsure 
* 20. Did you find the Solano County MHMP Facebook fan page a useful source of information on the MHMP planning project?
5 - very helpful
3 - neither helpful or unhelpful
1 - not helpful

* 21. How did you find the frequency of the Solano County MHMP Facebook fan page updates?

Too many

Just right

Not enough

* 22. Do you know about the Solano County MHMP Twitter fan page

Yes

No

* 23. How did you learn about the Solano County MHMP Twitter page? (Tick all that apply)

- Public notice

$\square$ Solano County website (www.SolanoCounty.com)

$\square$ MHMP project website (www.SolanoCountyMHMP.org)

$\square$ MHMP Facebook fan page

Word of mouth

Other (please specify)

* 24. How many times have you visited the Solano County MHMP Twitter page?

$5+$ occasions

2 - 4 occasions

Once

Never

* 25. How did you access the Solano County MHMP Twitter fan page? (Tick all that apply)

$\square$ Computer (Work)

$\square$ Computer (Home)

- Smart phone

T ipad

Other (please specify)

* 26. Did you follow the Solano County MHMP Twitter page?

Y Yes

No

Unsure 
* 27. Did you find the Solano County MHMP Twitter page a useful source of information on the MHMP planning project?
5 - very helpful
3 - neither helpful or unhelpful
1 - not helpful

* 28. How did you find the frequency of the Solano County MHMP Twitter page tweets?

Too many

Just right

Not enough

* 29. Did you know about the Solano County MHMP Public Workshops?

Yes

No

* 30. How did you learn about the Solano County MHMP Public Workshops? (Tick all that apply)

- Public notice

Solano County website (www.SolanoCounty.com)

— MHMP project website (www.SolanoCountyMHMP.org)

- MHMP Facebook fan page

- MHMP Twitter page

Word of mouth

Other (please specify)

* 31. Did you attend the Solano County MHMP Public Workshops?

Yes

No

* 32. Did you find the Solano County MHMP Public Workshop a useful source of information on the MHMP planning project?

5 - very helpful

3 - neither helpful or unhelpful

1 - not helpful

* 32. Did you find the Solano County MHMP Public Workshop a useful source of information on the MHMP planning project?

5 - very helpful

3 - neither helpful or unhelpful

1 - not helpful 
* 33. If you did not attend the Solano County MHMP Public Workshop, why not? (Tick all that apply)

Forgot

[Too far to travel

— Too busy

- Not interested

Other (please specify)

* 34. Have you provided comments on the Solano County MHMP planning project?
Yes

No

* 35. How did you provide comments on the Solano County MHMP planning project? (Tick all that apply)

MHMP Planning Committee meeting

- MHMP Public Workshop

$\square$ MHMP Public Comment Form (found on the project website)

— MHMP email address (info@SolanoCountyMHMP.org)

$\square$ MHMP Facebook fan page

$\square$ MHMP Twitter page

$\square$ Phone call to the MHMP Planning Team

Other (please specify)

36. If you have any questions and/or comments on the Solano County MHMP Public Outreach and Participation Survey and/or the MHMP Planning Process, please use the provided comment box below.

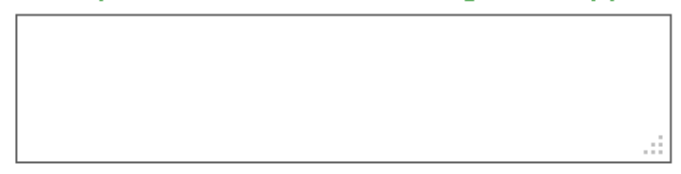

\section{Thank you!}

Thank you for participating in the Solano County MHMP Public Outreach and Participation Survey. Your time and effort is greatly appreciated! 
Intentional Blank Page 